\title{
Ryanodine receptors in experimental autoimmune encephalomyelitis, an animal model of multiple sclerosis
}

\author{
Dissertation \\ Presented to the Faculty of Biology and Psychology \\ of the Georg-August University of Göttingen in partial fulfillment \\ of the requirements for the degree \\ 'Doctor rerum naturalium (Dr. rer. nat.)' \\ in the basic program 'Biology' \\ of the Georg-August University School of Science (GAUSS)
}

submitted by

Manuel von Osten

born in Eberbach

Göttingen,

2015 


\section{Thesis committee members:}

$1^{\text {st }}$ reviewer: Prof. Dr. Dr. Hannelore Ehrenreich, Clinical Neurosciences, Max Planck Institute of Experimental Medicine, Göttingen

$2^{\text {nd }}$ reviewer: Prof. Dr. Wolfgang Brück, Dept. of Neuropathology, University Medical Center, Göttingen

Supervisor: Prof. Dr. Alexander Flügel, Dept. of Neuroimmunology, University Medical Center, Göttingen

Members of the examination board:

$1^{\text {st }}$ referee: $\quad$ Prof. Dr. Dr. Hannelore Ehrenreich, Clinical Neurosciences, Max Planck Institute of Experimental Medicine, Göttingen

$2^{\text {nd }}$ referee: Prof. Dr. Wolfgang Brück, Dept. of Neuropathology, University Medical Center, Göttingen

Additional members of the examination board

Prof. Dr. Alexander Flügel, Dept. of Neuroimmunology, University Medical Center, Göttingen

Prof. Dr. Mikael Simons, Cellular Neuroscience, Max Planck Institute of Experimental Medicine, Göttingen

Prof. Dr. Hauke Werner, Neurogenetics, Max Planck Institute of Experimental Medicine, Göttingen

Prof. Dr. Jürgen Wienands, Dept. of Cellular and Molecular Immunology, University Medical Center, Göttingen

Date of examination: $26^{\text {th }}$ June 2015 


\section{Affidavit}

Herewith I declare that my doctoral thesis entitled 'Ryanodine receptors in experimental autoimmune encephalomyelitis, an animal model of multiple sclerosis' has been written independently with no other sources and aids than quoted.

Manuel von Osten

Göttingen,

June 2015 


\section{Publications}

Wolf IMA, Diercks BP, Gattowski E, Czarniak F, Werner R, Schetelig D, von Osten $M$, Lodygin D, Flügel A, Fliegert R, and Guse AH. Frontrunners of $T$ cell activation: initial short-lived localized $\mathrm{Ca}^{2+}$ signals. 2015, manuscript in revision. 


\section{Table of Contents}

List of Figures __ vii

List of Tables__ ix

Abbreviations__ $\mathrm{x}$

Abstract__ xiii

1 Introduction

1.1 Multiple sclerosis__ 1

1.2 Experimental autoimmune encephalomyelitis___ 2

1.3 The CNS and the blood-brain barrier ___ 4

1.4 Leukocyte infiltration into the $\mathrm{CNS}$

1.5 Store-operated calcium entry _ 6

$1.6 \mathrm{Ca}^{2+}$ signaling in T lymphocytes__ 7

1.7 Intracellular $\mathrm{Ca}^{2+}$ release channels__ 8

1.8 Ryanodine receptors_ 10

1.8.1 Ryanodine receptor isoforms _ 10

1.8.2 Agonists and antagonists for ryanodine receptors _ 11

1.9 Objectives of this study__ 14

$2 \quad$ Materials and Methods___ 15

2.1 Buffers and Media___ 15

2.2 Molecular Procedures __ 17

2.2.1 Genotyping by polymerase chain reaction (PCR)__ 17

2.2.2 RNA extraction and cDNA synthesis__ 17

2.2.3 Quantitative real-time polymerase chain reaction__

2.3 Cell Culture Procedures___ 19

2.3.1 Preparation of cell suspensions from organs__ 19

2.3.2 Erythrolysis___ 19

2.3.3 Lymphocyte isolation from blood__ 19

2.3.4 Lymphocyte isolation from CNS 19

2.3.5 Isolation and enrichment of $\mathrm{T}$ and $\mathrm{B}$ cells__ 19

2.3.6 Isolation of astrocytes via $\mathrm{MACS}^{\circledR}$ purification_ 20

2.3.7 Generation of primary astrocytes and microglia__ 20

2.3.8 Cell counting__ 20

2.4 Animal Experiments__ 21

2.4.1 Mice__ 21 21

2.4.2 Generation of fetal liver and bone marrow chimeric mice___ 21

2.4.3 $\mathrm{MOG}_{35-55} \mathrm{EAE}$ induction by active immunization and disease evaluation___ 22

2.4.4 Dantrolene injections __ 22

2.4.5 Euthanasia___22

2.5 Experimental Procedures___ 23

2.5.1 Staining of cell surface markers___ 23 
2.5.2 Flow cytometry ___ 23

2.5.3 CFSE dilution assay _ _ 24

2.5.4 Transwell migration assay____ 24

2.5.5 Glutamate release detection assay___ 24

2.5.6 Thymidine incorporation assay___ 25

2.6 Immunocytochemistry__ 25

2.6.1 Cytospin and staining of suspension cells___ 25

2.6.2 Staining of adherent cells___ 25

2.6.3 Image acquisition___ 26

2.7 Histology and Immunohistochemistry__ 27

2.7.1 Perfusion__27

2.7.2 Dehydration and paraffin embedding of fixed tissues___ 27

2.7.3 Preparation of embedded samples for tissue stains___ 27

2.7.4 Hemalum \& eosine (HE) stain___ 27

2.7.5 Luxol fast blue-Periodic acid-Schiff stain___ 28

2.7.6 Bielschowsky's silver stain for axons___ 28

2.7.7 Antibody stains__ 28 28

2.7.8 Image acquisition__ 29

2.8 Imaging of Subcellular Calcium Signals___ 29

2.8.1 Preparation of cells for calcium signal measurements__ 29

2.8.2 Image acquisition and processing___ 29

2.8.3 Data evaluation__ 30

2.9 Statistics__ 30

$3 \quad$ Results__ 31

3.1 RyR1 and RyR3 in immune cells__ 31

3.1.1 Ryr1 and RyR3 mRNA is expressed in effector T cells__ 31

3.1.2 RyR1 and RyR3 are expressed in effector T cells in vitro___ 32

3.2 Generation and analysis of $R y r 1^{-/}, R y r 3^{--\alpha}$ and $R y r$ double knockout fetal liver chimeras

3.2.1 The immune system of Ryr-KO FLCs does not differ from that of control FLCs 35

3.2.2 Ryr1 deficient T cells show diminished TCR dependent intracellular $\mathrm{Ca}^{2+}$ response 40

3.2.3 Ryr1 deficient lymphocytes proliferate less in response to antiCD3 antibodies stimulation 40

3.2.4 EAE induction in Ryr $^{-1-} \rightarrow$ WT FLCs

3.2.5 EAE induction in $R y r$-DKO $\rightarrow$ WT FLCs__ 43

3.2.6 EAE induction in $\mathrm{Ryr}^{-/} \rightarrow$ WT FLCs

3.2.7 Characterization of $R y r$-KO T cells at the onset of EAE__ 45

3.3 The function of RyR3 in the CNS during EAE___ 47

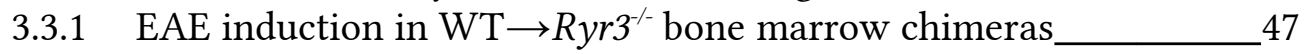

3.3.2 Active EAE in Ryr $3^{-/}$mice__ 49

3.3.3 Histology of Ryr $3^{-/}$EAE animals 50

3.3.4 Spontaneous EAE in $R y r 3^{-/} \times 2 \mathrm{D} 2 \times \mathrm{IgH}^{\mathrm{MOG}}$ mice___ 53

3.3.4.1 Histology of Ryr $3^{--} \times 2 \mathrm{D} 2 \times \operatorname{IgH}^{\mathrm{MOG}} \mathrm{EAE}$ animals__ 54

3.3.5 Analysis of the immune system of Ryr $3^{-/-}$mice__ 55 
3.3.5.1 Proliferation of $R y r 3^{-/}$lymphocytes 60

3.3.5.2 In vivo proliferation of $R y$ r $^{-/}$T cells

3.3.5.3 Encephalitogenic potential of Ryr3 deficient T cells

3.3.5.4 Antigen recall assay____ 63

3.4 The function of RyR3 in astrocytes during the course of EAE__ 64

3.4.1 Expression of RyR3 in primary murine astrocytes__ 64

3.4.2 Ryr3 ${ }^{-1-}$ astrocytes show laltered $\mathrm{Ca}^{2+}$ signaling responses__ 65

3.4.3 Ryr $3^{-/}$astrocytes secrete less glutamate upon stimulation__ 67

3.4.4 Ryr $3^{-/}$primary astrocytes produce lower amounts of CCL2, CCL5, CXCL10 and TNF- $\alpha$ in vitro 68

3.4.5 Astrocytes isolated from spinal cords of $\mathrm{Ryr}^{-/-}$mice produce lower amounts of CCL2, CCL5 and CXCL10 at the onset of EAE_ 71

3.4.6 Activation status and quantity of infiltrating $R y r 3^{-1-} \mathrm{T}$ cells _

3.4.7 T cell migration towards Ryr $3^{--}$astrocytes conditioned medium in vitro

3.4.8 MHCII expression is not altered in Ryr $3^{-/-}$astrocytes and microglia75

3.4.9 Dantrolene treated C57Bl/6 WT mice develop attenuated EAE 77

4 Discussion__ 80

4.1 Expression of RyRs in effector T cells

4.2 The role of RyR1 expression in T cells during EAE__ 80

4.3 The role of RyR3 in EAE___ 83

4.4 The importance of RyR3 in astrocytes__ 84

4.5 Pharmacological approaches to study RyRs__ 86

4.6 Conclusion__ 87

$5 \quad$ Summary__ 88

6 Acknowledgment

Bibliography__ 90

Curriculum vitae 


\section{List of Figures}

Fig. 1.1 | Calcium signaling in T lymphocytes

Fig. 1.2 3D structure of the mammalian RyR1 homotetramer 10

Fig. 1.3 | Skeletal formulas of selected RyR antagonists__ 12

Fig. 1.4 | Skeletal formulas of selected RyR agonists___ 13

Fig. 3.1 $\mid$ Ryr1 and Ryr3 mRNA expression in immune cells___ 32

Fig. 3.2 $\mid$ Ryr1 and Ryr3 mRNA expression in effector T cells____ 33

Fig. 3.3 | RyR1 and RyR3 protein expression in effector T cells____ 33

Fig. 3.4 | Scheme for the generation of fetal liver chimeras___ 34

Fig. 3.5 | Analysis of hematopoietic organs of fetal liver chimeric mice __ 35

Fig. 3.6 The frequency of $\mathrm{CD}^{+}$and $\mathrm{CD}^{+}$cells in the thymus of $R y r$-KO FLCs___ 36

Fig. 3.7 | Ryr-KO FLCs are similar to controls in the composition of the peripheral immune system 39

Fig. 3.8 $\mid$ Ryr1 deficient T cells show diminished intracellular $\mathrm{Ca}^{2+}$ response upon TCR stimulation 40

Fig. 3.9 | The knockout of Ryr1 attenuates the proliferative response of

T lymphocytes derived from Ryr $^{-/-} \rightarrow$ WT FLCs

Fig. 3.10 $\mid R y r 1^{-/-} \rightarrow$ WT FLCs develop attenuated EAE 42

Fig. 3.11 $\mid$ Ryr-DKO $\rightarrow$ WT FLCs develop attenuated EAE 43

Fig. 3.12 $\mid \mathrm{Ryr}^{-1} \rightarrow$ WT FLCs do not develop EAE different from that of control FLCs__ 45

Fig. 3.13 | T cells from Ryr1 $1^{-/}$and $R y r$-DKO FLCs express lower amount of the activation markers CD69 and CD25 46

Fig. 3.14 $\mid$ Ryr3 mRNA is highly expressed in the CNS 47

Fig. 3.15 | Ryr3 deficiency in non-hematopoietic cells attenuates EAE severity 48

Fig. 3.16 $\mid R y r 3^{-/}$mice develop attenuated EAE 49

Fig. 3.17 | Less immune cells infiltrate the SCs of Ryr $^{-/-}$mice at the peak of EAE 50

Fig. 3.18 | Less microglia co-localize at inflammatory sites in spinal cords of $R y r 3^{-/}$mice at the peak of EAE 51

Fig. 3.19 | Demyelination and axonal loss are significantly reduced in $R y r 3^{-/}$mice 52

Fig. 3.20 | Spontaneous EAE in Ryr3 deficient mice 54

Fig. 3.21 | Demyelination and axonal loss are reduced in $R y r 3^{-/-} \times 2 \mathrm{D} 2 \times \operatorname{IgH}^{\mathrm{MOG}}$ mice __ 55

Fig. 3.22 | Analysis of hematopoietic organs of Ryr $3^{-/}$mice 56 
Fig. 3.23 The frequency of $\mathrm{CD}^{+}$and $\mathrm{CD}^{+}$cells in the thymus of $R y r 3^{-/-}$mice is similar to that of controls

Fig. 3.24 $\mid$ The composition of the immune system in LNs of $R y r 3^{-/-}$mice is similar to that of control mice

Fig. 3.25 $\mid$ The composition of the immune system in spleens of $R y r 3^{-/}$mice is similar to that of control mice 59

Fig. 3.26 The knockout of Ryr3 does not severely alter the proliferative response of lymphocytes or splenocytes 60

Fig. 3.27 | Proliferation of MOG-specific T cells upon immunization is not affected by

Ryr3 deficiency

Fig. 3.28 | The encephalitogenic potential of MOG-specific T cells is not affected by Ryr3 deficiency

Fig. 3.29 $\mid$ Ryr $^{-/}$lymphocytes from the periphery are not impaired to antigen recall after immunization

Fig. 3.30 $\mid$ Ryr3 mRNA is highly expressed in activated astrocytes 64

Fig. 3.31 $\mid \mathrm{Ryr}^{-/-}$astrocytes show altered $\mathrm{Ca}^{2+}$ signals in response to ATP stimulation

Fig. 3.32 | Glutamate release is reduced in $R y r 3^{-/}$astrocytes 67

Fig. 3.33 | Chemokine and cytokine mRNA expression in response to LPS stimulation is reduced in Ryr $3^{-/-}$astrocytes

Fig. 3.34 | Chemokine and cytokine mRNA expression is reduced in Ryr $^{-/}$astrocytes after stimulation with IFN- $\gamma / \mathrm{TNF}-\alpha$ 70

Fig. 3.35 | Chemokine and cytokine mRNA expression is reduced in $R y$ r $^{-/-}$astrocytes during EAE 72

Fig. 3.36 | Activation status and quantity of infiltrating $R y r 3^{-/-} \mathrm{T}$ cells 73

Fig. 3.37 | The quantity and activation status of T cells in the periphery is not altered in $\mathrm{Ryr}^{-/}$animals before EAE onset 74

Fig. 3.38 | WT T cells transmigrate less towards Ryr $^{-/}$astrocytes derived supernatant containing medium 75

Fig. 3.39 $\mid$ MHCII expression in $R y$ r $^{-/-}$primary astrocytes and microglia is not altered compared to controls

Fig. 3.40 A-D | Dantrolene treated mice develop strongly attenuated and delayed EAE_78

Fig. 3.40 E, F | Demyelination and axonal loss are reduced in dantrolene treated mice__79

Fig. 4.1 | The functions of RyR1 and RyR3 during the development of autoimmune diseases of the CNS 87 


\section{List of Tables}

Table 1.1 | Expression of ryanodine receptor isoforms in immune cells_11

Table 2.1 | Primers for sequencing____ 17

Table 2.2 | Antibodies used for flow cytometry __ 23

Table 2.3 | Antibodies used for culture assays___ 25

Table 2.4 | Primary antibodies used in immunocytochemistry__ 26

Table 2.5 | Secondary antibodies used in immunocytochemistry___ 26

Table 2.6 | Primary antibodies used in immunohistochemistry__ 29

Table 2.7 | Secondary antibodies used in immunohistochemistry__ 29 


\section{Abbreviations}

$\begin{array}{ll}\text { Abs } & \text { Antibodies } \\ \text { AC } & \text { Astrocyte } \\ \text { APC } & \text { Antigen-presenting cell } \\ \text { ATP } & \text { Adenosine triphosphate } \\ \text { BBB } & \text { Blood-brain barrier } \\ \text { BCR } & \text { B cell receptor } \\ \text { BMC } & \text { Bone marrow chimera } \\ \text { Ca } & \text { Calcium (ions) } \\ \text { cADPR } & \text { Cyclic ADP-ribose } \\ \text { CD } & \text { Cluster of differentiation } \\ \text { cDNA } & \text { Complementary DNA } \\ \text { CICR } & \text { Calcium-induced calcium release } \\ \text { CNS } & \text { Central nervous system } \\ \text { CRAC } & \text { Calcium release activated calcium channel } \\ \text { CREB } & \text { cyclic-AMP-responsive-element-binding protein } \\ \text { CSF } & \text { Cerebrospinal fluid } \\ \text { Cntr, Ctrl } & \text { Control } \\ \text { cpm } & \text { counts per minute } \\ \text { DAG } & \text { Diacylglycerol } \\ \text { DC } & \text { Dendritic cell } \\ \text { DKO } & \text { Double knockout } \\ \text { DNA } & \text { Deoxyribonucleic acid } \\ \text { EAE } & \text { Experimental autoimmune encephaloymelitis } \\ \text { ER } & \text { Endoplasmic reticulum } \\ \text { FACS } & \text { Fluorescence-activated cell sorting } \\ \text { FLC } & \text { Getal liver chimera } \\ \text { GFP } & \text { Glu } \\ \end{array}$




\begin{tabular}{|c|c|}
\hline GM-CSF & Granulocyte macrophage colony-stimulating factor \\
\hline Iba1 & ionized calcium-binding adapter molecule 1 \\
\hline ICAM-1 & Intercellular adhesion molecule-1 \\
\hline ICC & Immunocytochemistry \\
\hline $\mathrm{ICH}$ & Immunohistochemistry \\
\hline $\operatorname{Ig}$ & Immunoglobulin \\
\hline i.p. & intraperitoneally \\
\hline $\mathrm{IP}_{3}$ & D-myo-inositol 1,4,5-trisphosphate \\
\hline $\mathrm{IP}_{3} \mathrm{R}$ & $\mathrm{IP}_{3}$ receptor \\
\hline i.v. & intravenously \\
\hline IFN- $\gamma$ & Interferon gamma \\
\hline IL-2 & Interleukin-2 \\
\hline IL-17 & Interleukin-17 \\
\hline $\mathrm{KO}$ & knockout \\
\hline LFA-1 & Lymphocyte function-associated antigen-1 \\
\hline LFB & Luxol fast blue \\
\hline $\mathrm{LN}$ & Lymph node \\
\hline LPS & Lipopolysaccharide \\
\hline MBP & Myelin basic protein \\
\hline Med & Medium \\
\hline MEF2 & myocyte enhancer factor 2 \\
\hline MG & Microglia \\
\hline $\mathrm{MH}$ & Malignant hyperthermia \\
\hline MHC & Major histocompatibility complex \\
\hline MOG & Myelin oligodendrocyte glycoprotein \\
\hline mRNA & Messenger RNA \\
\hline MS & Multiple sclerosis \\
\hline NAADP & nicotinic acid adenine dinucleotide phophate \\
\hline $\mathrm{NAD}^{+}$ & nicotinamide adenine dinucleotide \\
\hline nd & Not detectable \\
\hline $\mathrm{Neu}$ & Neuron \\
\hline $\mathrm{ns}$ & non-significant \\
\hline
\end{tabular}


NFAT

NF- $\kappa B$

ORAI1

OVA

PAS

PCR

p. i.

$\mathrm{PIP}_{2}$

PKC

PLC

PLP

PPMS

PRMS

PSGL-1

RFP

RNA

RRMS

RyR

SEM

SOC

SOCE

SPMS

SR

STIM1

TCR

Th

TNF- $\alpha$

TPC

VCAM-1

VLA-4

WT nuclear factor of activated $\mathrm{T}$ cells

nuclear factor kappa-light-chain-enhancer of activated B cells calcium release-activated calcium channel protein 1

Ovalbumin

Periodic acid-Schiff

Polymerase chain reaction

Post-immunization

Phospholipid phosphatidylinositol 4,5-bisphosphate

Protein kinase $\mathrm{C}$

Phospholipase C

Proteolipid protein

Primary progressive

Progressive-relapsing MS

P-selectin glycoprotein ligand-1

Red fluorescent protein

Ribonucleic acid

Relapsing-remitting MS

Ryanodine receptor

Standard error of the mean

store-operated channel

store-operated channel calcium entry

Secondary progressive MS

Sarcoplasmic reticulum

stromal interaction molecule-1

$\mathrm{T}$ cell receptor

helper $\mathrm{T}$ cell

Tumor necrosis factor alpha

Two-pore channel

Vascular cell adhesion protein-1

Very late antigen- 4

Wild type 


\section{Abstract}

The activation of auto-aggressive $\mathrm{T}$ cells is crucial for the development of autoimmune diseases, such as multiple sclerosis (MS) or its animal model experimental autoimmune encephalomyelitis (EAE). T cell activation relies on stimulation of the $\mathrm{T}$ cell receptor by antigen and results in rapid release of calcium $\left(\mathrm{Ca}^{2+}\right)$ from the endoplasmic reticulum (ER) into the cytosol. This process is mediated by $\mathrm{IP}_{3}$ receptors and, possibly by ryanodine receptors (RyRs). The release of $\mathrm{Ca}^{2+}$ from the ER into the cytosol follows a second influx of $\mathrm{Ca}^{2+}$ across the plasma membrane through $\mathrm{Ca}^{2+}$ release activated $\mathrm{Ca}^{2+}$ channels (CRAC). This store-operated calcium entry (SOCE) mediates further signal transduction by the activation of $\mathrm{Ca}^{2+}$ sensitive enzymes, such as calcineurin, which then leads to transcription and production of $\mathrm{T}$ cell characteristic cytokines.

Even though EAE in mice is in many aspects a well studied model, the role of RyRs has not yet been addressed in context of the disease. Previous studies using loss-of-function techniques unveiled the importance of RyR1 and RyR3 for NAADP mediated $\mathrm{Ca}^{2+}$ signaling in Jurkat cells, and in rat adoptive transfer EAE by pharmacological antagonism of NAADP, a putative ligand for RyR1.

In the present study we found that the gene encoding for the RyR1 isoform is expressed in antigen-experienced effector, but not in naïve mouse $\mathrm{T}$ cells. Genetic deletion of Ryr1 studied in fetal liver chimeric mice did not result in overt immune phenotype, however Ryr1 deficient Tlymphocytes show diminished $\mathrm{Ca}^{2+}$ signaling and reduced proliferation in response to TCR stimulation. This supported the observation that these animals developed less severe active EAE than control mice.

Although our data indicate that Ryr3 does not play a major role in $\mathrm{T}$ cells, yet we observed attenuated clinical EAE and CNS histopathology in mice with a whole-body knockout for the Ryr3 gene. There however, we have excluded that Ryr3 deficiency in $\mathrm{T}$ cells is responsible for mitigated neuroinflammation using chimeric mice and $\mathrm{T}$ cell transfer experiments. Instead we observed that Ryr3 deficient astrocytes display alteration in stimulated $\mathrm{Ca}^{2+}$ signaling in vitro, produce less chemokines in response to inflammatory stimuli in vitro but also in the inflamed CNS tissue, that limits infiltration of immune cells and associated tissue damage. We also demonstrate that pharmacological inhibition of RyR function has beneficial effects on the EAE disease. Thus, ryanodine receptors seem to play critical roles during autoimmune disease of the CNS (RyR1 in T cells whereas RyR3 in astrocytes) and can be considered as therapeutic targets. 


\section{Introduction}

\subsection{Multiple sclerosis}

Multiple sclerosis (MS) is a chronic autoimmune disorder affecting the central nervous system (CNS), where the immune system damages and destroys the protecting myelin sheaths of the neurons in brain and spinal cord, resulting in demyelination and axonal loss (CALABRESI, 2004, LOMA and HEYMAN, 2011). The disease then manifests in cortical lesions (plaques) in the brain's white matter. It is the most commonly diagnosed neurologic disease in young adults at ages between 20 and 40, occurring twice as frequently in women as in men. The total number of individuals with MS is estimated to around 2.5 million worldwide (COMPSTON AND COLES, 2008). The disease appears highly heterogenic in terms of clinical symptoms, disease course and pathology, as well as the response to therapies. MS symptoms are very variable and affect each patient differently. The first symptoms, used to identify MS, commonly present as blurred vision, and impairment of mobility and balance (due to muscle atrophy). Patients with established MS suffer from increasing gait abnormalities, loss of vision and impaired body coordination that may worsen over time to a severe paralysis. In addition, extreme fatigue, bladder dysfunction and pain can occur during MS (GOlDENBERG, 2012; CREE, 2014). The cause of MS is unknown, but a combination of genetic susceptibility and a non-genetic triggers are discussed (BARCELLOS et al., 2003, WILLER et al., 2003, HANDEL et al., 2010). First degree relatives and twins are 40-fold more susceptible to MS suggesting a genetic basis (BARCELLOS et al., 2003). Exposure to infectious agents like viruses, e.g. Epstein-Barr-Virus, or some mycoplasma strains, e.g. mycoplasma pneumoniae, but also smoking or sunlight exposure/vitamin D levels are discussed as environmental risk factors that can induce a selfsustaining autoimmune disorder and favoring MS (CREE, 2014).

According to its disease progress, MS is categorized into four major variants (HAUSER and GOODWIN, 2008):

1. Relapsing-remitting MS (RRMS): With a prevalence of $85 \%$, RRMS is the most occurring form of MS, characterized by abrupt disease phases (relapses) 1-2 times a year and disease-free phases, in that the patients show improved or no symptoms (remission).

2. Secondary progressive MS (SPMS): This variant may develop in patients with RRMS. In SPMS, patients suffer from continuous progression of disability occurring after a MS relapse.

3. Primary progressive MS (PPMS): PPMS affects about $10 \%$ of MS patients. It is characterized by continuous disease progression 


\section{Introduction}

without any relapse or remission periods.

4. Progressive-relapsing MS (PRMS): About $5 \%$ of MS patients develop this rare variant. It starts directly progressive, with intermediate relapses but no remissions and straight worsening along the course of disease.

There is no curative treatment for MS patients so far, partly due to the fact that many aspects of MS etiology remain elusive. Current treatments focus on modulation of the immune system but come along with significant side effects (LOMA and HEYMAN, 2011). Moreover, long-term studies on newer therapies are pending. Therefore, conceiving the complex etiology of MS is most important for an effective and safe treatment of MS patients.

\subsection{Experimental autoimmune encephalomyelitis}

The heterogeneity of MS complicates the research. To understand the molecular and cellular mechanisms that drive the disease and to identify new possible therapeutic targets require an experimental model that mimics certain aspects of neuroinflammation relevant for MS. In rodents, there are three clinically relevant and established disease models of MS. Demyelination evoked by viral infection-such as Theiler's Murine Encephalitis Virus or Semliki Forest Virus-is a helpful tool to model the viral motive of $\mathrm{MS}$ and leads to a progressive $\mathrm{CD}^{+}{ }^{+} \mathrm{T}$ cell mediated demyelinating disease (DONATI AND JACOBSON, 2002). Cuprizone treatment in mice is a model of toxic demyelination and is evoked by feeding young mice with the copper chelator cuprizone, that leads to oligodendrocyte death and reversible demyelination (TORKILDSEN et al., 2008). The most commonly used animal model of MS, however, is experimental autoimmune encephalomyelitis (EAE; ROBINSON et al., 2014). It requires active immunization against myelin antigens (active EAE) or the adoptive transfer of pathogenic effector T cells into naïve recipients (transfer EAE; MILLER et al., 2007). Active EAE is induced by the administration of myelin peptides, such as myelin basic protein (MBP), myelin oligodendrocyte glycoprotein (MOG) or proteolipid protein (PLP) in adjuvant in susceptible mouse strains. By contrast, transfer ('passive') EAE is induced by transferring encephalitogenic, myelin-specific $\mathrm{CD}^{+} \mathrm{T}$ cell blasts into donor mice (MILLER et al., 2007).

In active EAE, immunization against myelin antigens leads to the priming of myelin-specific $\mathrm{T}$ cells in the secondary lymphoid organs. Succeeding activation, $T$ cells rapidly proliferate and differentiate into effector cells and become licensed to exit the secondary lymphoid organs through the efferent 


\section{Introduction}

lymphatic vessels to enter the blood circulation. The expression of adhesion molecules and integrins allows $\mathrm{T}$ cells to overcome the blood-brain barrier (BBB), where they come in contact with CNS-resident antigen presenting cells (APCs), recognize endogenously expressed antigens and become reactivated. This leads to the expression and secretion of the proinflammatory cytokines IFN- $\gamma$, IL-17, GM-CSF and TNF- $\alpha$ by effector T cells (O'CONNOR et al., 2008; KROENKE et al., 2008). This leads to a disruption of the $\mathrm{BBB}$ and additional production of chemokines that in turn facilitate the recruitment of monocytes, macrophages, neutrophils and $\gamma \delta$ T cells into the CNS (GOVERMAN, 2009). These inflammatory cells cause and mediate damage to the myelin sheaths and axons, and are mainly responsible for the formation of lesions and the breakdown of the neuronal network within the CNS.

In transfer EAE, activated myelin-specific Th1, Th17 or mixed Th1/Th17 CD4 ${ }^{+}$ $\mathrm{T}$ cell blasts from immunized donor mice are injected into naïve recipient animals. By that, the effector phase of EAE can be modeled directly and it also allows the tracking of genetically labeled encephalitogenic $\mathrm{T}$ cells in vivo (JÄGER et al., 2009). The latter approach is a powerful tool to analyze $\mathrm{T}$ cell specific roles of a gene of interest.

Mice develop variable forms of EAE depending on the genetic background of the animals as well as the administered antigen. Active EAE induction with MOG protein or the $\mathrm{T}$ cell epitope $\mathrm{MOG}_{35-55}$ (MEVGWYRSPFSRVVHLY $\mathrm{RNGK}$ ) in $\mathrm{C} 57 \mathrm{Bl} / 6$ mice leads to a chronic form of the disease starting between days 9-12 post immunization with characteristic inflammatory foci appearing predominantly in the spinal cord rather than in brain (MENDEL et al., 1995). In contrast, immunization against the $\mathrm{T}$ cell epitope $\mathrm{PLP}_{139-151}$ (HCLGKWLGHPDKF) in SJL/J mice leads to a relapsing-remitting form of EAE (MCRAE et al., 1992). The generation of transgenic mice with deletion or over-expression of immunological relevant genes enlarged the experimental possibilities for studies on EAE. Examples of such genes are those encoding T cell receptors (TCRs) or major histocompatibility complex (MHC) molecules. Of particular interest is the model of spontaneous EAE. This specific variant of EAE occurs in mice that were generated by crossing MOGspecific TCR transgenic mice with MOG-specific Ig heavy-chain knock-in mice with an incidence of $59 \%$ (KRISHNAMOORTHY et al., 2006; BETTELLI et al., 2006). Disease induction in these mice proceeds completely spontaneously and overcomes the artificial component of immunization or transfer of preactivated T lymphocytes. That brings it closer to the human disease MS and is of great advantage when studying the triggers of CNS autoimmunity (Betelli et al., 2006), however it is difficult to study early $\mathrm{T}$ cell infiltration in the preclinical stage of disease in this model, as the onset time is unpredictable. 


\subsection{The CNS and the blood-brain barrier}

The CNS is a highly specialized and complex organ in aspects of physiology, neuroanatomy and immunology. It is considered as 'immune privileged', even though this term is under debate among neuroscientists (CARSON et al., 2006; HARRIS et al., 2014). The immune privilege was first described by Sir Peter Brian Medawar in 1948, when he demonstrated that allografts from mouse skin better persisted in eye and brain than in tissues from the periphery (MEDAWAR, 1948). For the CNS, immune privilege has been long characterized by the lack of lymphatic vessels and a surrounding endothelial barrier restricting immune cell contact (ILIFF AND NEDERGAARD, 2013). Furthermore, the low level expression of MHC molecules was considered as another evidence for the brain being an immunologically privileged site. Yet, as mentioned above, the term 'immune privilege' is under debate, because recent results suggest that the brain is capable of both immune and autoimmune reactions as well (RIVEST et al., 2009). This was supported by the discovery of MHC molecule expression on microglia and astrocytes (NEUMANN et al., 1996). While these cell populations usually express MHC molecules only at low levels, up-regulated expression can be found under inflammatory conditions that may be critical for antigen presentation. Reactive microglia and astrocytes with increased MHC-II expression have been reported in several neurological diseases (MARAGAKIS AND ROTHSTEIN, 2006; MCGEER et al, 1993).

The CNS is surrounded by the meninges, a set of membranes that consist of three layers termed the dura mater, the arachnoid mater and the pia mater. The dura mater is the membrane closest to the skull (brain) or the epidural space (spinal cord). The arachnoid and pia mater together are named the leptomeninges. They form the subarachnoid space in between, which is occupied by the cerebrospinal fluid (CSF). The CSF is produced in the choroid plexus and circulates within the ventricular system of the brain. It provides nutrients and acts as some kind of fluid dampening system additionally protective for the brain. The pia mater is the membrane that lies on the outer surface of the brain and spinal cord. Capillaries from blood vessels run through the pia mater, thereby sustaining the CNS.

The blood-brain barrier (BBB) is separating the CNS from the blood circulation and is composed of endothelial cells, an underlying basement membrane and the astrocytic endfeet. These astrocytic foot processes associate with a second basement membrane to create the glia limitans (glial limiting membrane) surrounding the endothelial cells of the BBB. These endothelial cells are connected by impermeable tight junctions that ensure that the brain is being shielded from soluble molecules (including antibodies) circulating through the blood vessels. Under neuroinflammatory conditions, the astrocytes of the glia limitans and the endothelial cells are also known as producers of chemokines and proinflammatory cytokines (CHOI et al., 2014). 


\subsection{Leukocyte infiltration into the CNS}

The migration of leukocytes from the blood circulation into infected or damaged tissue is called extravasation or diapedesis. In case of MS or EAE, leukocytes first have to overcome the BBB before entering the CNS. This makes it different from leukocyte extravasation in the periphery, where such barriers are missing. Several routes have been described for leukocyte extravasation into the CNS. The major one is from the blood into the parenchymal perivascular space through the BBB, while a second site of entry into the CNS is via the choroid plexus into the CSF (RANSOHOFF et al., 2003).

The interplay between leukocytes and the endothelium of the BBB that finally leads to diapedesis is described as a multistep process, in which different certain molecules on both leukocytes and endothelial cells are involved (ENGELHARDT AND RANSOHOFF, 2012). First, leukocytes come in contact with the endothelium. This step is termed 'tethering' or 'capture' and is mediated by P-selectin glycoprotein ligand-1 (PSGL-1) on leukocytes and its respective selectin counterparts on the vessel endothelium (AUSTRUP et al., 1997). Integrins-including very late antigen-4 (VLA-4, $\alpha 4 \beta 1$ ) and lymphocyte function-associated antigen 1 (LFA-1, $\alpha \mathrm{L} \beta 2$ )-as well as the adhesion molecules vascular cell adhesion protein-1 (VCAM-1) and intercellular adhesion molecule-1 (ICAM-1) support capturing of leukocytes and mediate the next step of leukocyte locomotion, which is the rolling of leukocytes on the vessel endothelium (LEY et al., 2007). Rolling of leukocytes comes to a stop once leukocytes recognize glycosaminoglycan bound chemokines on the endothelium that are produced locally or were translocated to the cellular surface (MIDDLETON et al., 2002). Chemokine binding induces conformational changes in integrins, leading to firm adhesion ('attachment') of leukocytes to the vessel endothelium. Next, leukocytes start to crawl-mainly against the blood flow-to locate a spot for extravasation. Thereby, leukocytes undergo a phenotypical change from spherical to a rather flattened shape. The firm adhesion is thereby necessary due to constant shear stress of the blood flow (LAWRENCE et al., 1987). VLA-4 seems to be a crucial factor for intraluminal crawling, since treatment with VLA-4 depleting antibodies prevented leukocytes from crawling and extravasation, in contrast to LFA-1, whose depletion did not critically alter leukocytes transmigration (BARTHOLOMÄUS et al., 2009). Finally, diapedesis can occur paracellular through endothelial junctions, or transcellular through the body of endothelial cells (LEY et al., 2007).

After successful diapedesis, leukocytes scan the leptomeningeal area for their respective antigen and come in contact with resident perivascular and meningeal phagocytes, which are potential APCs. After recognition of the antigen, leukocytes become reactivated. In case of $\mathrm{T}$ cells, they upregulate proinflammatory cytokines (IFN- $\gamma$, IL-17, TNF- $\alpha$, and IL-2) and surface 


\section{Introduction}

markers (OX40, IL-2R; BARTHOLOMÄUS et al., 2009), which allows them to penetrate deep into the spinal cord parenchyma and establish inflammation. However, the release of cytokines by infiltrating $\mathrm{T}$ cells may activate microglia and also astrocytes, that are beside endothelial cells involved in maintaining the integrity of the $\mathrm{BBB}$, to cause the release of certain immunomodulators such as chemokines at the pathological site. This further may compromise the $\mathrm{BBB}$, which is becoming permeable to peripheral immune cells, including lymphocytes and myeloid cells. As a result, the inflammation is further exacerbated and supports the generation of a chronic neuroinflammatory disease (TRAN et al., 2000; FLÜGEL et al., 2001; KAWAKAMI et al., 2004).

\subsection{Store-operated calcium entry}

As an important intracellular messenger, calcium $\left(\mathrm{Ca}^{2+}\right)$ exerts functions in almost every cell type (BOOTMAN et al., 2001). It is involved in muscle contraction, neurotransmitter signaling and synaptic plasticity. In addition to that, calcium regulates the activity of calcium sensitive enzymes and by that conducting a wide range of downstream signaling pathways (BERRIDGE et al., 2000). The calcium concentration within the cytoplasm is usually low, being in the range of $100 \mathrm{nM}$ ('resting state'), which is maintained by ion pumps that actively export $\mathrm{Ca}^{2+}$ into the extracellular space or sequester $\mathrm{Ca}^{2+}$ into store organelles first of all the endoplasmatic reticulum (ER). Upon specific stimuli $\mathrm{Ca}^{2+}$ is rapidly released from the ER and enters the cytoplasm through plasma membrane ion channels (ENDO, 2009). Calcium signaling is initiated in many cell types by activation of the phospholipase C (PLC) pathway (SCHMIDT et al., 2001). This particular enzyme can be activated by many cell surface receptors, including $G$ protein coupled receptors and tyrosine kinases. PLC catalyses the hydrolysis of the membrane phospholipid phosphatidylinositol 4,5-bisphosphate $\left(\mathrm{PIP}_{2}\right)$ into D-myo-inositol 1,4,5trisphosphate $\left(\mathrm{IP}_{3}\right)$ and diacylglycerol (DAG). $\mathrm{IP}_{3}$ and DAG exert their functions as second messengers. While DAG activates protein kinase $C$ (PKC) and by this several downstream signaling pathways, $\mathrm{IP}_{3}$ binds to ER membrane bound $\mathrm{IP}_{3}$ receptors $\left(\mathrm{IP}_{3} \mathrm{Rs}\right)$, which are $\mathrm{Ca}^{2+}$ channels itself, leading to the release of $\mathrm{Ca}^{2+}$ from the ER internal stores. In brief, this $\mathrm{Ca}^{2+}$ efflux activates 'store-operated channels' (SOCs) on the plasma membrane which provokes further $\mathrm{Ca}^{2+}$ entry from outside the cell. This results in a rapid increase in intracellular $\mathrm{Ca}^{2+}$ to a concentration of $1000 \mathrm{nM}$ ('activated state') (CLAPHAM, 2007). The $\mathrm{Ca}^{2+}$ regulated enzyme calmodulin ('calciummodulated protein') is one major downstream target of store-operated calcium entry (SOCE) and a potent mediator for the physiological effects of $\mathrm{Ca}^{2+}$ signaling. 


\section{6 $\mathrm{Ca}^{2+}$ signaling in $\mathrm{T}$ lymphocytes}

$\mathrm{Ca}^{2+}$ ions and their respective channels and transporters are essential for $\mathrm{T}$ lymphocytes in that they regulate cell differentiation, effector function and gene transcription (OH-HORA and RAO, 2008).

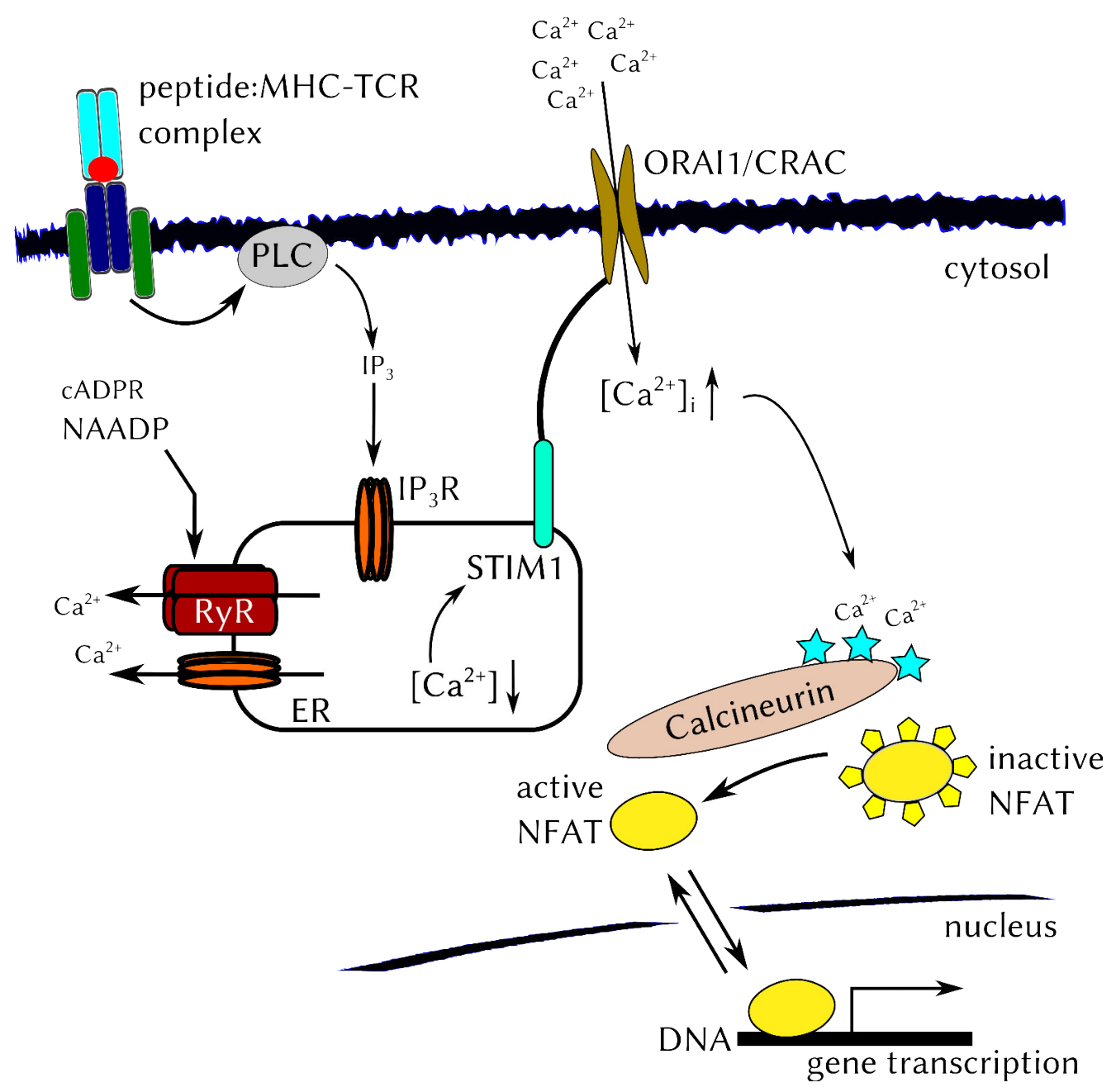

Fig. 1.1 Calcium signaling in T lymphocytes. Following formation of the peptide:MHCTCR complex, PLC activation mediates production of second messenger $\mathrm{IP}_{3}$ binds and activates to ER calcium channels, thereby depleting $\mathrm{Ca}^{2+}$ from the store. This depletion via STIM1 protein activates CRAC/ORAI channels on the cell membrane and triggers a massive influx of $\mathrm{Ca}^{2+}$ into the cytosol from extracellular space. As a result, calcineurin phosphatase becomes activated and induces NFAT translocation into the nucleus by dephosphorylation. In the nucleus NFAT mediates specific gene expression. $\mathrm{Ca}^{2+}$, calcium ion; $\left[\mathrm{Ca}^{2+}\right]_{\mathrm{i}}$, intracellular calcium concentration; cADPR, cyclic ADP-ribose; CRAC, calcium release activated channel; $E R$, endoplasmic reticulum; $I P_{3}$, inositol-3-phosphate; $I P_{3} R$, inositol-3phosphate receptor; MHC, major histocompatibility complex; NAADP, nicotinic acid adenine dinucleotide phophate, NFAT, nuclear factor of activated T cells; ORAI1, calcium release-activated calcium channel protein 1; RyR, ryanodine receptor; STIM1, stromal interaction molecule-1; TCR, T cell receptor. 


\section{Introduction}

Stimulation of the $\mathrm{T}$ cell receptor leads to the activation of phospholipase $\mathrm{C} \gamma 1$ (PLC $\gamma 1$ ) and the generation of $\mathrm{IP}_{3}$ (FESKE et al., 2012), which triggers the release of $\mathrm{Ca}^{2+}$ from the ER stores into the cytosol. This sudden release of $\mathrm{Ca}^{2+}$ is sensed by stromal interaction molecule 1 (STIM1) and STIM2 on the ER membrane, leading to activation of calcium releaseactivated calcium channel protein 1 (ORAI1), ORAI2 and ORAI3 that are located on the plasma membrane and build the pore of the calcium releaseactivated channel (CRAC; FESKE et al., 2006). The increase in $\mathrm{Ca}^{2+}$ concentration occurs within 30-60 seconds (WÜLFING et al., 1998) and induces the activation of a series of transcription factors, including cyclicAMP-responsive-element-binding protein (CREB), myocyte enhancer factor 2 (MEF2) and nuclear factor of activated T cells (NFAT). NFAT signaling is of great significance in T cells (MACIAN, 2005; LODYGIN et al., 2013). This particular transcription factor is activated by dephosphorylation, which is carried out by calcineurin, a serine/threonine phosphatase. Calcineurin activation is a two-step process. Increase of free cytosolic $\mathrm{Ca}^{2+}$ leads to the dissociation of the auto-inhibitory domain of calcineurin, which is mediated by a $\mathrm{Ca}^{2+}$ dependent conformational change of this subunit by that exposing the $\mathrm{Ca}^{2+} /$ calmodulin binding site of the protein. Binding of activated calmodulin to this site triggers another conformational change of calcineurin and full activation of the enzyme. The dephosphorylated NFAT then translocates into the nucleus and induces transcription of $T$ cell characteristic pro-inflammatory cytokines, e.g. IL-2 and IFN- $\gamma$ (HOGAN et al., 2003). In contrast to nuclear factor $-\kappa B(N F-\kappa B)$, that functions even at a transient increase of $\mathrm{Ca}^{2+}$ concentration, NFAT-dependent gene transcription requires strong and prolonged intracellular $\mathrm{Ca}^{2+}$ boosts, suggesting multiple regulatory mechanisms of $\mathrm{Ca}^{2+}$ signaling in $\mathrm{T}$ cells (KANNO AND SIEBENLIST, 1996; FESKE et al., 2001; FISCHER et al., 2001).

\subsection{Intracellular $\mathrm{Ca}^{2+}$ release channels}

The sarcoplasmatic reticulum (SR) and the ER are the main stores for intracellular $\mathrm{Ca}^{2+}$ in striated muscle cells or other cell types, respectively. Its release is performed by two major classes of receptors that have been identified on the SR/ER membrane, termed $\mathrm{IP}_{3}$ receptors $\left(\mathrm{IP}_{3} \mathrm{Rs}\right)$ and ryanodine receptors (RyRs). A third class of receptors is the target of the more recently identified second messenger NAADP (LEE and AARHUS, 1995; CHurchill AND Galione, 2000; GALIONE, 2011).

$\mathrm{IP}_{3} \mathrm{Rs}$ were the first purified calcium-induced $\mathrm{Ca}^{2+}$ release (CICR) channels (SUPATTAPONE et al., 1988) and hence studied intensively in their role of converting external signals into intracellular $\mathrm{Ca}^{2+}$ responses. They are diversely expressed and play a role in several cellular and physiological 


\section{Introduction}

processes including cell proliferation, behavior, memory and learning (BOSANAC et al, 2002). $\mathrm{IP}_{3}$ binding to $\mathrm{IP}_{3} \mathrm{Rs}$ is essential for $\mathrm{Ca}^{2+}$ release from the ER (BERRIDGE, 1997). However, $\mathrm{IP}_{3}$ Rs are highly regulated ion channels. They are modulated by phosphorylation, accessory proteins, adenosine triphosphate (ATP) and, most importantly, $\mathrm{Ca}^{2+}$ itself (GRAFTON and THWAITE, 2001). Three isoforms of $\mathrm{IP}_{3} \mathrm{Rs}$ are known, differing in their sensitivity to regulation by $\mathrm{Ca}^{2+}$. The possibility of the cell to modulate CICR in such a distinct manner emphasizes the significance of intracellular $\mathrm{Ca}^{2+}$ signaling via $\mathrm{IP}_{3} \mathrm{Rs}$ as a 'spatial-temporal' event (THOMAS et al., 1996, YULE, 2001). Ip3r1 - $^{-1}$ mice are rarely born alive, and adult mice lacking $I p 3 r 1$ were suffering from severe neurological symptoms (MATSUMOTO AND NAGATA, 1999). Experiments with bone marrow chimeras show that $\mathrm{IP}_{3} \mathrm{R} 1$ is dispensable for $\mathrm{T}$ cell activation and $\mathrm{Ca}^{2+}$ signaling (HIROTA et al., 1998). Studies on mice with deletion of the Ip3r2 and/or Ip3r3 gene showed the importance of these receptors for the generation of $\mathrm{Ca}^{2+}$ signals in astrocytes (SRINIVASAN et al., 2015). The importance of $\mathrm{IP}_{3} \mathrm{Rs}$ in the context of EAE has not yet been reported so far.

Besides $\mathrm{IP}_{3}$, nicotinic acid adenine dinucleotide phosphate (NAADP) and cyclic ADP-ribose (cADPR) are important second messengers for $\mathrm{Ca}^{2+}$ signaling within T cells (GUSE, 1999; BOOTMAN et al., 2002). Both NAADP and cADPR are metabolites of nicotinamide adenine dinucleotide $\left(\mathrm{NAD}^{+}\right.$; LEE et al., 1989). Discovered in 1999 by CANCELA et al. in pancreatic cells, NAADP was observed to trigger $\mathrm{Ca}^{2+}$ release from the ER after releasing $\mathrm{Ca}^{2+}$ from much smaller, lysosomal acidic stores (CHURCHILL et al., 2002). This is underlined by the characteristic of NAADP being a rather short-lived second messenger and it is assumed that it acts before $\mathrm{IP}_{3}$ and $\mathrm{cADPR}$ exert their messaging function (KINNEAR et al., 2004, KINNEAR et al., 2008, ERNST et al., 2013). It was demonstrated in Jurkat $T$ cells that NAADP emerges rapidly after stimulation of the TCR/CD3 complex (LEE, 2001; GASSER et al., 2006) and provides the very first local $\mathrm{Ca}^{2+}$ signals. These signals are thought to 'prime' $\mathrm{IP}_{3} \mathrm{Rs}$ and RyRs before $\mathrm{IP}_{3}$ and cADPR provide amplifying signals for $\mathrm{Ca}^{2+}$ release (GUSE et al., 1995, GALIONE, 2011). Yet, a distinct allocation of NAADP to a specific receptor is still under investigation (HOHENEGGER et al., 2002; GALIONE, 2011; OGUNBAYO et al., 2011). Even though evidences point out the family of two-pore channels (TPCs) to be a potential candidate as receptors for NAADP (ISHIBASHI et al., 2000; CALCRAFT et al., 2009), data of human $\mathrm{T}$ cells were presented in that RyRs are required for functional $\mathrm{Ca}^{2+}$ signaling (LANGHORST et al., 2004), and that in Jurkat T cells RyR1 worked out as the primary target of NAADP (DAMMERMANN et al., 2009).

cADPR and its non-cyclic form ADPR are produced from $\mathrm{NAD}^{+}$by $\mathrm{ADP}$ ribosyl cyclases (PETERSEN AND CANCELA, 1999). Equally to NAADP, it is generated after TCR/CD3 ligation (GUSE et al., 1995, GUSE, 1999) but acts directly on RyRs in Jurkat T cells (SCHWARZMANN et al., 2002). There, it induces $\mathrm{Ca}^{2+}$ entry and makes RyRs more sensitive to further $\mathrm{Ca} 2+$ and creates prolonged $\mathrm{Ca}^{2+}$ signals (LEE, 2001). 


\subsection{Ryanodine receptors}

Ryanodine receptors (RyRs) are named after the plant alkaloid ryanodine, which binds to RyRs with high affinity (IMAGAWA et al., 1987). To our current knowledge, RyRs are the largest known ion channels (TAKESHIMA et al., 1989). One receptor consists of four subunits, each approximately $565 \mathrm{kDa}$ in weight, together forming a homotetramer of about 2.3 MDa (Fig 1.1; ZALK et al., 2015).
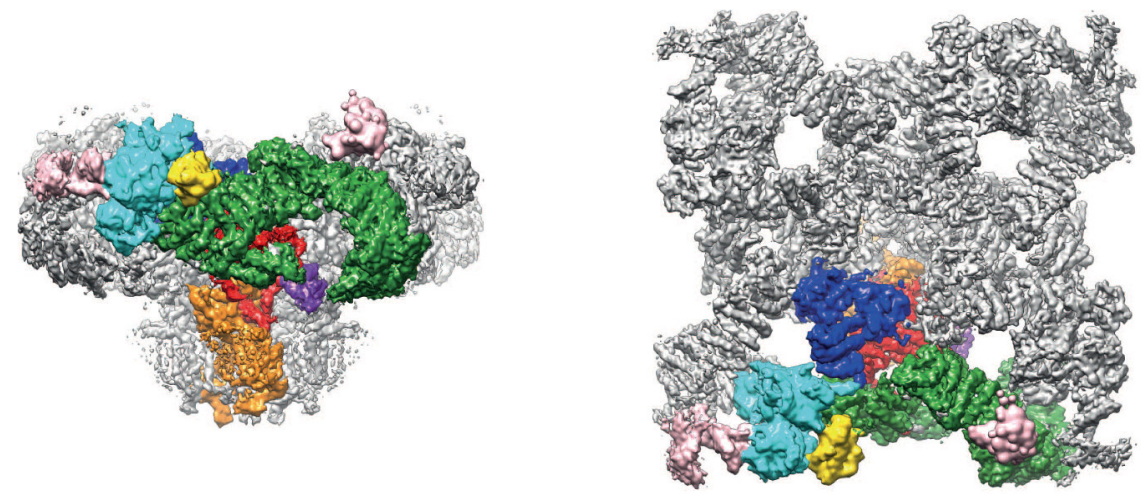

Fig. 1.2 | 3D structure of the mammalian RyR1 homotetramer determined by cryoelectronmicroscopy at a resolution of $4.8 \AA$. One protomer chain with its different domains is highlighted in color. Left panel: View in the plane of the SR membrane. Right panel: View from the cytosol. Figures from ZALK et al., 2015.

\subsubsection{Ryanodine receptor isoforms}

Three RyR isoforms have been identified, termed skeletal RyR (RyR1), cardiac RyR (RyR2) and brain RyR (RyR3) after their major compartment of expression. RyRs are located on the membranes of intracellular $\mathrm{Ca}^{2+}$ stores, either the SR or the ER and release $\mathrm{Ca}^{2+}$ from those stores upon stimulation. All isoforms of RyRs can be activated by cADPR and $\mathrm{Ca}^{2+}$ itself. While cADPR is the main agonist for RyRs (LEE, 2001), ERNST et al. (2013) suggest a possible role of NAADP as a ligand for RyRs in Jurkat T cells. Beside their major expression compartments, RyRs are also expressed in other cell types or tissues, repectively, including the immune system. The expression of RyRs has been identified in different lymphocyte subsets and some mononuclear cells (Table 1.1). Of special importance for this thesis was the discovery of RyR expression in Lewis rat effector T cells (DAMMERMANN et al., 2009). It was the first study on RyR expression in rodent $\mathrm{T}$ cells. There, expression of RyRs is restricted to effector, in contrast to naïve or memory $\mathrm{T}$ cells (CORDIGLIERI et al., 2010). Furthermore, it was demonstrated that certain 


\section{Introduction}

subtypes of RyRs, namely RyR1 and RyR3, but not RyR2 are expressed in rat effector T cells, even though RyR3 was expressed to a lesser extent than RyR1 (DAMMERMANN et al., 2009, CORDIGLIERI et al., 2010).

Table 1.1 | Expression of ryanodine receptor isoforms in immune cells

\begin{tabular}{|c|c|c|c|}
\hline Cell type & RyR1 & RyR2 & RyR3 \\
\hline Jurkat T cells & GUSE et al., 1999 & - & $\begin{array}{l}\text { HAKAMATA et al., } \\
\text { 1994, } \\
\text { GUSE } \text { et al., } 1999 \\
\end{array}$ \\
\hline $\begin{array}{l}\mathrm{CD}^{+} \mathrm{T} \text { cells } \\
\text { (Human) }\end{array}$ & THAKUR et al., 2012 & $\begin{array}{l}\text { HOSOI et al., 2001, } \\
\text { THAKUR et al., } 2012\end{array}$ & THAKUR et al., 2012 \\
\hline $\begin{array}{c}\text { CD19 } 9^{+} \text {B cells } \\
\text { (Human })\end{array}$ & $\begin{array}{l}\text { HOSOI et al., 2001, } \\
\text { SEI et al., } 2001\end{array}$ & - & - \\
\hline $\begin{array}{l}\mathrm{CD} 14^{+} \text {mono- } \\
\text { cytes (Human) }\end{array}$ & HosOI et al., 2001 & - & - \\
\hline $\begin{array}{l}\text { Dendritic cells } \\
(\mathrm{C} 57 \mathrm{Bl} / 6)\end{array}$ & $\begin{array}{l}\text { O'CONNELL et al., } \\
2002\end{array}$ & - & - \\
\hline $\begin{array}{l}\text { MBP-specific } \\
\text { effector T cells } \\
\text { (Lewis rat) }\end{array}$ & $\begin{array}{l}\text { CORDIGLIERI et al., } \\
2010\end{array}$ & - & $\begin{array}{c}\text { CORDIGLIERI } \text { et al., } \\
2010\end{array}$ \\
\hline
\end{tabular}

\subsubsection{Agonists and antagonists for ryanodine receptors}

To unravel the properties of RyRs as intracellular $\mathrm{Ca}^{2+}$ channels, a series of pharmacological studies has been performed, either with RyR agonists or antagonists, respectively. In this context, the pharmacological blocking of RyRs or the initiation of $\mathrm{Ca}^{2+}$ release from the SR/ER was the central aspect of the studies.

The alkaloid ryanodine is maybe the most notably and most intensively studied ligand for RyRs (Fig. 1.3, A). Ryanodine is found in the South American plant Ryania speciosa and shows high binding affinity to RyRs, which was used to designate this class of receptors (MEISSNER, 1986, LAI et al., 1988). It is a highly specific modulator of RyRs with bilateral properties. At nanomolar concentrations, ryanodine locks RyRs in their half-open state, causing $\mathrm{Ca}^{2+}$ release, while concentrations in the micromolar range irreversibly block RyRs and prevent channel opening (LINDSAY et al., 1994, TINKER et al., 1996, WELCH et al., 1997). Another RyR blocker is tetracaine (Fig. 1.3, B), which is used as a local anesthetic (ZUCCHI and RONCA-TESTONI, 1997). Similar to ryanodine, tetracaine blocks RyRs completely at high concentrations (>1.25 mM, GYÖRKE et al., 1997) but inhibits $\mathrm{Ca}^{2+}$ release reversibly at low concentrations (0.25-1.25 mM, OVEREND et al., 1998).

Dantrolene (Fig. 1.3, C) was first described in 1967 as a muscle relaxant and 


\section{Introduction}

was used to treat malignant hyperthermia $(\mathrm{MH})$, a rare but life-threatening form of muscle dysfunction (SNYDER et al., 1967) that is triggered during treatment with general anesthetics. In $\mathrm{MH}$, patients are suffering from drastic disorders in skeletal muscle oxidative metabolism, affecting its ability to regulate body temperature, to supply oxygen and to remove carbon dioxide, which may then lead to acidosis, organ failure and eventually, death (ROSENBERG et al., 2007). MH is an autosomal dominant inherited disease. In $50-70 \%$ of $\mathrm{MH}$ patients, mutations have been identified on the gene coding for RyR1, that affect its closing mechanism and thereby raising intracellular $\mathrm{Ca}^{2+}$ levels by excessive $\mathrm{Ca}^{2+}$ mobilization from the SR (GILLARD et al., 1992). The disorder is then therapeutically antagonized by dantrolene. Even though the mechanism of RyR1 inhibition by dantrolene is not yet completely understood, a direct effect on the RyR1 isoform has been implicated (ZHAO et al., 2001, KOBAYASHI et al., 2010). Furthermore, it was demonstrated that dantrolene may act on RyR3 as well, but not on RyR2 (ZHAO et al., 2001).

A

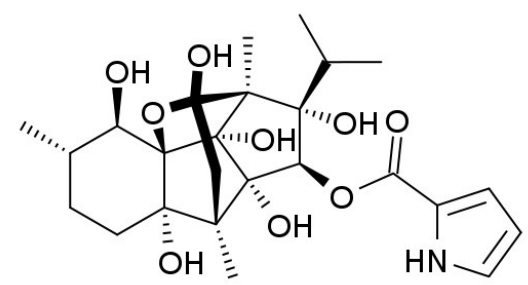

B<smiles>CCCCNc1ccc(C(=O)OCCN(C)C)cc1</smiles>

C<smiles>O=C1CN(/N=C/c2ccc(-c3ccc([N+](=O)[O-])cc3)o2)C(=O)N1</smiles>

Fig. 1.3 | Skeletal formulas of selected RyR antagonists that block RyR mediated $\mathrm{Ca}^{2+}$ release. (A) Ryanodine. (B) Tetracain. (C) Dantrolene.

Caffeine (Fig. 1.4, A) was the first discovered pharmacological substance to initiate $\mathrm{Ca}^{2+}$ release from intracellular stores via RyRs (ENDO, 1977, ROUSSEAU et al., 1988). It was shown that caffeine sensitizes RyRs to cytosolic $\mathrm{Ca}^{2+}$ at low concentrations $(<1 \mathrm{mM})$, while higher doses $(>2.5 \mathrm{mM})$ increase the sensitivity of RyRs to luminal $\mathrm{Ca}^{2+}$ (LEE, 1993, PORTA et al., 2011).

The ability of cyclic ADP-ribose (cADPR, Fig. 1.4, B), a metabolite of NAD ${ }^{+}$, to stimulate $\mathrm{Ca}^{2+}$ release via RyRs in sea urchin egg microsomes has been reported (GALIONE, 1993, GALIONE, 1994). These reports could be further extended to smooth muscle cells (MURTHY et al., 1995, PRAKASH et al., 1998) and finally, to Jurkat T cells (GUSE et al., 1997). It has been demonstrated that 


\section{Introduction}

cADPR can induce $\mathrm{Ca}^{2+}$ signaling independently from $\mathrm{IP}_{3}$ (DARGIE et al., 1990), and acting instead via the potentiation of CICR (GALIONE et al., 1991, LEE, 1993). The mechanism of cADPR is similar to that of caffeine, however, it shows higher potency in sensitization of RyRs to $\mathrm{Ca}^{2+}$. It has been suggested that interplay between cADPR and calmodulin as an accessory protein is essential for RyR activation in sea urchin eggs (LEE et al., 1994, LEE et al., 1995, TANAKA and TASHJIAN, 1995). There, cADPR induces a short, but rapid $\mathrm{Ca}^{2+}$ release, which is sustained by calmodulin. By means of single-particle electron cryomicroscopy, a calmodulin-like domain within the core of mammalian RyR1 was identified as a calcium sensor (ZALK et al., 2015), thereby confirming previous results suggesting calmodulin directly interacting with RyR1 (XIONG et al., 2006).

A<smiles>Cn1c(=O)c2c(ncn2C)n(C)c1=O</smiles>

B

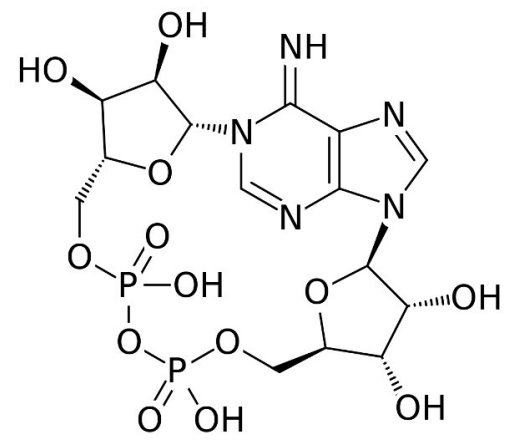

C

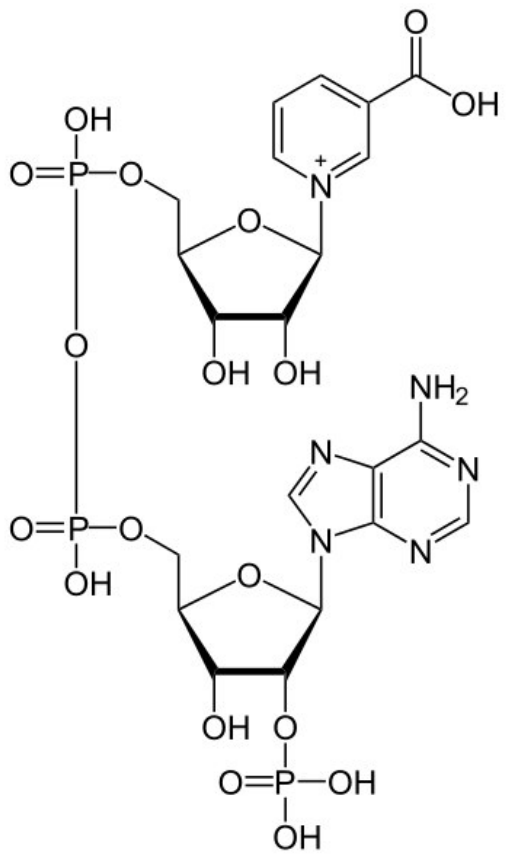

Fig. 1.4 Skeletal formulas of selected RyR agonists that initiate RyR mediated $\mathrm{Ca}^{2+}$ release. (A) Caffeine. (B) cADPR. (C) NAADP.

Such as cADPR, NAADP (Fig. 1.4, C) is a metabolite of $\mathrm{NAD}^{+}$. It was long assumed that NAADP-in contrast to cADPR and $\mathrm{IP}_{3}-$ mobilizes $\mathrm{Ca}^{2+}$ from separable stores (LEE and AARHUS, 1995), namely acidic lysosomes (CHURCHILl et al., 2002). However, it was demonstrated that NAADP is a potent mobilizer for $\mathrm{Ca}^{2+}$ in Jurkat T cells (BERG et al., 2000) and mediates T cell activation by high-affinity binding to RyRs (LANGHORST et al., 2004, DAMMERMANN and GUSE, 2005). Furthermore, it could be shown in bothJurkat $\mathrm{T}$ cells as well as in primary myelin basic protein (MBP)-reactive rat 


\section{Introduction}

T cells-that NAADP signaling to RyR1 could be successfully suppressed by BZ194, a synthetic NAADP antagonist (DAMMERMANN et al., 2009), showing that NAADP is an effective agonist for RyR1. Thereby the antagonizing effect of BZ194 was exclusively affecting the NAADP signaling pathway, but not cADPR or $\mathrm{IP}_{3}$ mediated $\mathrm{Ca}^{2+}$ signaling (DAMMERMANN et al., 2009). Preventive or therapeutic treatment of Lewis rats with BZ194 significantly ameliorated the course of EAE but did not affect primary immune responses (CORDIGLIERI et al., 2010). Accordingly, NAADP signaling is essential for the activation of auto-aggressive T cells.

\subsection{Objectives of this study}

RyRs are a family of $\mathrm{Ca}^{2+}$ channels that mediate $\mathrm{Ca}^{2+}$ release from intracellular stores upon activation by secondary messengers, such as NAADP or cADPR. In non-excitable cells, the depletion of $\mathrm{Ca}^{2+}$ stores in response to external stimuli evokes further $\mathrm{Ca}^{2+}$ entry across the plasma membrane, thereby activating $\mathrm{Ca}^{2+}$ sensitive signaling pathways. For example, the increase of intracellular $\mathrm{Ca}^{2+}$ in $\mathrm{T}$ cells represents an initial trigger for TCR dependent $\mathrm{T}$ cell activation.

T cells play a pivotal role in autoimmune diseases of the CNS like MS and its animal model EAE. The understanding of intrinsic factors that control the activation of (auto-aggressive) $\mathrm{T}$ cells is indispensable for the development of new therapies. In this context, the role of RyRs has been poorly investigated. However, recent studies suggested RyRs as a therapeutic target in T cell mediated autoimmune diseases.

Using Ryr1 and Ryr3 knockout mice, we aim to address following point:

1. Analysis of a steady state immune system in mice with ablation of the RyR1 and RyR3 genes.

2. Effect of RyR1 or RyR3 deletion on the clinical outcome and CNS pathology of active EAE.

3. Determination of mechanisms that mediate RyR1 and RyR3 contribution to the autoimmune neuroinflammatory disease. 


\section{Materials and Methods}

\subsection{Buffers and Media}

All solutions were prepared in Milli-Q purified water (MERCK MILLIPORE, Schwalbach, Germany) and sterilized by autoclaving and / or filtration before use. If not declared otherwise, all chemicals were purchased from CARL ROTH (Karlsruhe, Germany) or SIGMA-ALDRICH (Munich, Germany).

\section{Ammonium-Chloride-Potassium (ACK) erythrolysis buffer}

$0.15 \mathrm{M} \mathrm{NH}_{4} \mathrm{Cl}, 10 \mathrm{mM} \mathrm{KHCO}_{3}, 0.1 \mathrm{mM}$ EDTA.2Na in $\mathrm{H}_{2} \mathrm{O}, \mathrm{pH}$ 7.2-7.4.

\section{Dulbeccos's Modified Eagle Medium (DMEM)}

$133.8 \mathrm{~g}$ Gibco ${ }^{\circledast}$ DMEM powder (LIFE TEChNOLOGIES, Carlsbad, California, USA) in $10 \mathrm{~L} \mathrm{H}_{2} \mathrm{O}$, supplemented with $37 \mathrm{~g}$ acetic acid $\left(\mathrm{CH}_{3} \mathrm{COOH}\right)$.

\section{Eagle's HEPES (EH) medium}

133.8 g Gibco ${ }^{\circledR}$ DMEM powder (LIFE TeChNOLOGIES, Carlsbad, California, USA) in $10 \mathrm{~L} \mathrm{H}_{2} \mathrm{O}$, supplemented with $37 \mathrm{~g} \mathrm{CH}_{3} \mathrm{COOH}$ and $25 \mathrm{mM}$ HEPES (LIFE TECHNOLOGIES).

\section{FACS buffer}

$1 \times$ PBS supplemented with $0.5 \% \mathrm{BSA}$ and $0.05 \% \mathrm{NaN}_{3}$.

\section{Glial cell medium (GCM)}

GCM was prepared by supplementing DMEM with $15 \%$ FCS (BIOCHROM AG, Berlin, Germany), $1 \%$ Gibco $^{\circledast}$ minimum essential medium non-essential amino acids (MEM NEAA, 100x, LIFE TECHNOLOGIES), $1 \%$ Gibco $^{\circledR}$ penicillin/streptomycin (10,000 units/ml penicillin, $10,000 \mu \mathrm{g} / \mathrm{ml}$ streptomycin, LIFE TECHNOLOGIES), $1 \mathrm{mM}$ Gibco $^{\circledR}$ sodium pyruvate (LifE Technologies), $2 \mathrm{mM}$ L-glutamine (PAN-BIOTECH, Aidenbach, Germany), $1 \mathrm{mM}$ L-asparagine monohydrate and $0.4 \%$ 2-mercaptoethanol $(13.6 \mathrm{M})$. 


\section{L929 fibroblast-conditioned medium (LCCM)}

L929 cells were plated in a $10 \mathrm{~cm}$ petri dish (SARSTEDT, Nümbrecht, Germany) with DMEM supplemented with $10 \%$ FCS and $1 \%$ Gibco $^{\circledR}$ penicillin/streptomycin, $1 \mathrm{mM}$ Gibco $^{\circledR}$ sodium pyruvate and $2 \mathrm{mM}$ L-glutamine. Confluent cells were splitted into $175 \mathrm{~cm}^{2}$ flasks. After reaching confluence, the supernatant was collected and passed through a $0.22 \mu \mathrm{M}$ filter. The obtained medium was stored as $5 \times$ LCCM.

\section{Percoll, isotonic Percoll and underlay Percoll solutions}

Percoll $^{\circledast}$ (GE HealthCARE, Chalfont St. Giles, UK) density centrifugation medium was diluted 1:10 with $10 \times$ PBS to produce isotonic Percoll. Underlay Percoll was composed of $70 \%$ isotonic Percoll in $1 \times$ PBS.

\section{Phosphate buffered saline (PBS)}

$137 \mathrm{mM} \mathrm{NaCl}, 2.7 \mathrm{mM} \mathrm{KCl}, 10 \mathrm{mM} \mathrm{Na}_{2} \mathrm{HPO}_{4}$ and $1.8 \mathrm{mM} \mathrm{KH}_{2} \mathrm{PO}_{4}$ in $\mathrm{H}_{2} \mathrm{O}$, $\mathrm{pH}$ 7.4. Ten times the amount of $\mathrm{NaCl}, \mathrm{KCl}, \mathrm{Na}_{2} \mathrm{HPO}_{4}$ and $\mathrm{KH}_{2} \mathrm{PO}_{4}$ was used to produce $10 \times \mathrm{PBS}$.

\section{Proteinase K buffer}

$100 \mathrm{mM}$ Tris $\cdot \mathrm{HCl}, 200 \mathrm{mM} \mathrm{NaCl}, 0.2 \%$ SDS and $5 \mathrm{mM}$ EDTA in $\mathrm{H}_{2} \mathrm{O}, \mathrm{pH}$ 8.0. Fresh Proteinase K $(10 \mathrm{mg} / \mathrm{ml})$ was added directly before use to a final concentration of $1 \%$.

\section{Roswell Park Memorial Institute medium 1640 (RPMI 1640)}

$104.3 \mathrm{~g} \mathrm{Gibco}{ }^{\circledR}$ RPMI 1640 powder (LIFE TeChNOLOGIES) in $10 \mathrm{~L} \mathrm{H}_{2} \mathrm{O}$, supplemented with $22 \mathrm{~g} \mathrm{NaHCO}$.

\section{Restimulation medium (ReMed)}

ReMed was prepared by supplementing RPMI 1640 with $5 \%$ FCS, $1 \%$ Gibco $^{\circledR}$ minimum essential medium non-essential amino acids (MEM NEAA, 100×, LIFE TECHNOLOGIES), $1 \%$ Gibco $^{\circledast}$ penicillin/streptomycin $(10,000$ units $/ \mathrm{ml}$ penicillin, $10,000 \mu \mathrm{g} / \mathrm{ml}$ streptomycin, LIFE TECHNOLOGIES), $1 \mathrm{mM} \mathrm{Gibco}{ }^{\circledR}$ sodium pyruvate (LIFE TECHNOLOGIES), $2 \mathrm{mM}$ L-glutamine (PAN-BIOTECH, Aidenbach, Germany) and $0.4 \%$ 2-mercaptoethanol (13.6 M).

\section{Tris/Borate/EDTA (TBE) buffer, 10×}

$1 \mathrm{M}$ Tris, $0.9 \mathrm{M}$ boric acid and $0.01 \mathrm{M}$ EDTA in $1 \mathrm{~L} \mathrm{H}_{2} \mathrm{O}$. 


\subsection{Molecular Procedures}

\subsubsection{Genotyping by polymerase chain reaction (PCR)}

Genomic DNA (gDNA) was obtained by isopropyl alcohol precipitation after digestion of tissue or cells with Proteinase $\mathrm{K}\left(2-16 \mathrm{~h}, 56{ }^{\circ} \mathrm{C}\right.$, dry block thermostat TDB-100, BIOSAN). DNA fragments were amplified by PCR using the DreamTaq Polymerase Mix (THERMo FISCHER SCIENTIFIC INC., Waltham, Massachusetts, USA) and target specific primer pairs (BIOMERS, Ulm, Germany). Amplification programs were specific for each set of primers (Mastercycler ep gradient, EPPENDORF, Hamburg, Germany).

PCR products were loaded on $0.8-1.5 \%$ TBE agarose gels and electrophoresed at $100 \mathrm{~V}$ for 30-60 min before visualization with an E-BOX VX5 gel documentation system and the corresponding VisionCapt 15.0 software (VILBER LOURMAT, Eberhardzell, Germany).

Table 2.1 | Primers for sequencing

\begin{tabular}{|l|l|}
\hline Primer & Sequence \\
\hline Ryr1-KO fwd & TGG CCT GTC CCT TCT GGT TCC CAC C \\
\hline Ryr1-KO rev & CCC TTT CCC CTA TTA GCC GAT CAC T \\
\hline Ryr3-KO fwd & ATG AAG TTG TAC TCC AG TGC ATT GC \\
\hline Ryr3-KO rev & TCC AGG AAT CTC TGG TAT ACT AGG G \\
\hline NeoR fwd & GAA TAT CAT GGT GGA AAA TGG CCG CTT TTC \\
\hline
\end{tabular}

\subsubsection{RNA extraction and cDNA synthesis}

The RNeasy Kit (QIAGEN, Hilden, Germany) was used to isolate RNA from either organs, tissues or cells. Obtained RNA was transcribed into cDNA using random hexamer primers (FirstStrand cDNA Synthesis Kit, THERMO FISCHER SCIENTIFIC INC.) according to the manufacturer's instructions. cDNA was either stored at $-20{ }^{\circ} \mathrm{C}$ or subsequently used as template for quantitative real-time PCR.

\subsubsection{Quantitative real-time polymerase chain reaction}

Gene expression was assessed by (semi-) quantitative real-time PCR (qPCR) using the StepOnePlus ${ }^{\mathrm{TM}}$ Real-Time PCR System (APPLIED BIOSYSTEMS, Darmstadt, Germany) and the corresponding StepOne Software v2.0. The qPCR was performed with gene-specific TaqMan ${ }^{\circledR}$ probes labeled with $6-\mathrm{FAM}^{\mathrm{TM}}$ and quenched by TAMRA ${ }^{\mathrm{TM}}$. $\beta$-actin was used as the housekeeping gene. Individually designed primers and probes were ordered from SIGMA- 
ALDRICH. Before applied in qPCR, cDNA samples were diluted 1:50. Data from samples were obtained in duplicates.

Primer and probe sequences for qPCR: $\boldsymbol{A c t} \boldsymbol{b}$, sense, $5^{\prime}$-GTA CAA CCT CCT TGC AGC TCC T-3'; antisense, 5'-TTG TCG ACG ACG AGC GC-3'; probe, 5'-[6FAM]-CGC CAC CAG TTC GCC ATG GAT-[TAMRA]-3'. $\boldsymbol{C c l 2}$, sense, 5'-TGT CAT GCT TCT GGG CCT GC-3'; antisense, 5'-CCT GCT GCT GGT GAT CCT CT-3'; probe, 5'-[6FAM]-CTC ACC TGC TGG TAC TCA TTC ACC-[TAMRA]-3'. $\boldsymbol{C c l 5}$, sense, 5'-GGA GTA TTT CTA CAC CAG CAG CAA-3'; antisense, 5'-CAC ACA CTT GGC GGT TCC TT-3'; probe, 5'[6FAM]-TGC TCC AAT CTT GCA GTC GTG TTT GTC A-[TAMRA]-3'. c cr5, sense, 5'-GTT CTC CTG TGG ACC GGG TAT ACG-3'; antisense, 5' ATT GTC AAA CGC TTC TGC AAA C-3'; probe, $5^{\prime}$-[6FAM]-AGC TTA CAC GAT CAG GAT T-[TAMRA]-3'. Ccr6, sense, 5'-TCG TCC AGG CAA CCA AAT C-3'; antisense, 5'-CCA CAC TGC CAC ACA GAT GAC-3'; probe, [6FAM]-TTC CGG GTA CGC TCC AGA ACA CTG A-[TAMRA]-3'. c cr7, sense, 5'-GTG TAG TCC ACG GTG GTG TTC TC-3'; antisense, 5'-CTG GTC ATT TTC CAG GTG TGC T-3'; probe, 5' -[6FAM]-CCG ATG TAG TCG TCT GTG A-[TAMRA]-3'. Csf2, sense, 5'-GGG CGC CTT GAA CAT GAC-3'; antisense, 5'-CGC ATA GGT GGT AAC TTG TGT TTC-3'; probe, 5' [6FAM]-CCC CCC AAC TCC GGA AAC GGA-[TAMRA]-3’. $\boldsymbol{C x c l 1 0}$, sense, 5 '-CAT CCC TGC GAG CCT ATC C-3'; antisense, 5'-CAT CTC TGC TCA TCA TTC TTT TTC A-3'; probe, $5^{\prime}$-[6FAM]-CCC ACG TGT TGA GAT CAT

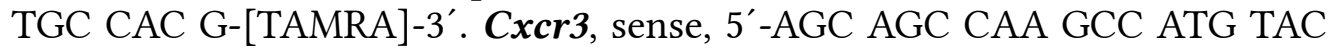
CTT-3'; antisense, 5' ${ }^{\prime}$-TAG GGA GAT GTG CTG TTT TCC A-3'; probe, 5' [6FAM]-AGG TCA GTG AAC GTC AAG GTC TAG ATG CCT C-[TAMRA]-3 '. Cxcr4, sense, 5'-GAG GTC ATC AAG CAA GGA ATG T-3'; antisense, 5'GGG TTC AGG CAA CAT TGG A-3'; probe, 5' -[6FAM]-TTC GAG AGC GTC GTG CAC AA-[TAMRA]-3'. Icam 1, sense, 5'-GCC AAG CCC ACG CTA

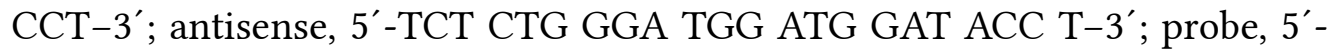
[6FAM]-TCA CCG TTG TGA TCC CTG GGC CT-[TAMRA]-3’. Vcam1, sense, 5'-CAG AGT GTA CAG CCT CTT TAT GTC AAC-3'; antisense, 5' GGA CTG CCC TCC TCT AGT ATA GGA-3'; probe, 5'-[6FAM]-TTG CCC CCA AGG AAA CCA CCA TC-[TAMRA]-3'. Ifng, sense, 5'-TCA AGT GGC ATA GAT GTG GAA GAA-3'; antisense, 5' ${ }^{\prime}$ TGG CTC TGC AGG ATT TTC ATG-3'; probe, 5'-[6FAM]-TCA CCA TCC TTT TGC CAG TTC CTC CAG[TAMRA]-3'. Ryr1, sense, 5'-CCG CCC TCA GGT TCC CCG CCA AGC C-3 '; antisense, 5' -GCG GTG CCG AAC CCC TCA GCG G-3'; probe, 5'-[6FAM]ATG GAG GAG GTG AAG GCG AG-[TAMRA]-3’. $\boldsymbol{R} y \boldsymbol{r} 3$, sense, 5’ATG AAG TTG TAC TCC AGT GCA TT-3'; antisense, 5' -CAC GAA ATT GCA GAC ACA GAG ATC-3'; probe, 5' -[6FAM]-GCA GCC GAG GGA CTT GGG AA[TAMRA]-3'. Tnfa, sense, 5'-TCG AGT GAC AAG CCC GTA GC-3'; antisense, 5'-CTC AGC CAC TCC AGC TCC TC-3'; probe, 5' -[6FAM]-CGT CGT AGC AAA CCA CCA AGC AGA-[TAMRA]-3'. 


\subsection{Cell Culture Procedures}

If not declared otherwise, cells were incubated at $37{ }^{\circ} \mathrm{C}$ in a humidified $5 \%$ $\mathrm{CO}_{2}$ atmosphere.

\subsubsection{Preparation of cell suspensions from organs}

Single cell suspensions of lymph nodes and spleen were prepared by smashing the organs through a metal mesh (UNIVERSITÄTSMEDIZIN GÖTTINGEN, in-house production) using a pistil (B. BRAUN MELSUNGEN AG, Melsungen, Germany). The obtained homogenizate was centrifuged $\left(4^{\circ} \mathrm{C}\right.$, $1200 \mathrm{rpm}, 5 \mathrm{~min}$ ) and resuspended in $\mathrm{EH}$ medium.

\subsubsection{Erythrolysis}

Erythrocytes residing in spleen or blood were depleted by resuspension of spleen homogenates or blood samples in ACK buffer and further incubation for $5 \mathrm{~min}$ on ice. Then, the cells were washed once in PBS and resuspended in EH medium.

\subsubsection{Lymphocyte isolation from blood}

Blood was either collected from the tail vein (living animals) or by cardiac puncture (dead animals) in $80 \mathrm{mM}$ EDTA/PBS. Lymphocytes were separated from whole blood by the use of lymphocyte separation medium 1077 (LSM 1077, GE HealthCARE, Chalfont St. Giles, UK) and centrifugation at $2000 \mathrm{rpm}$ for $20 \mathrm{~min}$ at $4{ }^{\circ} \mathrm{C}$ with minimal acceleration and brakes. Lymphocytes accumulated at the interphase and were collected in FACS buffer.

\subsubsection{Lymphocyte isolation from CNS}

Lymphocytes were isolated from spinal cord or brain by Percoll density gradient centrifugation. The CNS tissue was minced into a fine slurry, taken up in $25 \mathrm{ml} \mathrm{EH}$ medium and then mixed with $10 \mathrm{ml}$ of isotonic Percoll. $10 \mathrm{ml}$ of underlay Percoll medium was pipetted gently under the cell suspension prior to centrifugation $\left(20{ }^{\circ} \mathrm{C}, 30 \mathrm{~min}, 2780 \mathrm{rpm}\right)$ with minimal acceleration and brakes.

\subsubsection{Isolation and enrichment of $\mathrm{T}$ and $\mathrm{B}$ cells}

Single cell suspensions of lymph nodes or spleen were prepared as described. For the isolation, a concentration of $1 \times 10^{8}$ cells $/ \mathrm{ml}$ was achieved in 
recommended resuspension medium. $\mathrm{CD}^{+} \mathrm{T}$ cells, naïve $\mathrm{T}$ cells and $\mathrm{B}$ cells were isolated using the EasySep ${ }^{\mathrm{TM}}$ Enrichment Kits for murine $\mathrm{CD}^{+} \mathrm{T}$ cells, naïve $\mathrm{CD}^{+} \mathrm{T}$ cells and B cells (each STEMCELL TECHNOLOGIES, Vancouver, British Columbia, Canada) according to the manufacturer's instructions for "The Big Easy" EasySep ${ }^{\mathrm{TM}}$ Magnet. In brief, biotinylated antibodies directed against non-wanted cell populations and tetrameric antibody complexes against biotin conjugated with dextran-coated magnetic particles were applied to the single cell suspension to mark cells for magnetic forced removal. After enrichment, the cell purity was determined by flow cytometry and was usually $\geq 90 \%$.

\subsubsection{Isolation of astrocytes via MACS $^{\circledR}$ purification}

Astrocytes from spinal cord were isolated using the MACS $^{\circledR}$ anti-GLAST MicroBead Kit (MILTENYI BIOTECH GMBH, Bergisch Gladbach, Germany).

\subsubsection{Generation of primary astrocytes and microglia}

Cell cultures of primary astrocytes and microglia were generated as described (CHEN et al., 2012). In brief, neonatal mice (age 0-2 days) were killed by decapitation. The skin over the skull was flayed before opening the skull itself to access the brain. The brain was then placed on ice and the meninges were removed using a Stemi 2000 stereo microscope (CARL ZEISS, Jena, Germany). The cleaned brain was minced into a fine slurry and afterward digested with trypsin/EDTA for $15-30 \mathrm{~min}$ in a $37{ }^{\circ} \mathrm{C}$ incubator. The suspension was passed through a Falcon ${ }^{\circledR} 40 \mu \mathrm{m}$ cell strainer (CORNING, INC., Corning, New York, USA), centrifuged $\left(4{ }^{\circ} \mathrm{C}, 1200 \mathrm{rpm}, 5 \mathrm{~min}\right)$, resuspended in glial cell medium (GCM) and added to poly-D-lysine coated tissue culture flasks (TPP TECHNO PLASTIC PRODUCTS AG, Trasadingen, Switzerland). The cells were incubated at $37{ }^{\circ} \mathrm{C}$ in a humidified $5 \% \mathrm{CO}_{2}$ atmosphere for $24 \mathrm{~h}$ before adding LCCM. After 10-14 days the microglial cells were detached by using a heated orbital shaker (INKUTEC GMBH, Kiebitzhörn, Germany) at $240 \mathrm{rpm}$ for $2 \mathrm{~h}$. Both microglia and remaining plate-bound astrocytes could be further cultured in GCM at $37{ }^{\circ} \mathrm{C}$ in a humidified $5 \%$ incubator. Cell purity was assessed by immunocytochemistry.

\subsubsection{Cell counting}

To determine the cell number within a certain volume, $10 \mu \mathrm{l}$ of a given cell suspension were loaded on a Neubauer improved hemocytometer (LO LABOROPTIK LTD, Lancing, UK). Trypan blue (0.04\%) was added to the suspension to distinguish between viable and non-viable cells. The cell number was calculated with the use of the following equation:

$$
\frac{\text { Counted Cells }}{\text { Number of Quadrants }} \times \text { Dilution Factor } \times 10^{4}=\text { Cells } / \mathrm{ml}
$$




\subsection{Animal Experiments}

\subsubsection{Mice}

All animal experiments were carried out in the central animal facility of the University Clinical School Göttingen in accordance with the regulations for animal welfare of Lower Saxony, Germany. All mouse strains were kept in individually ventilated cages under specific-pathogen-free conditions in a normal $12 \mathrm{~h}$ day-night cycle and fed ad libitum. Experiments were performed with at least 10 weeks old mice. The following C57BL/6 strains were used: Wildtype (WT, CHARLES RIVER LABORATORIES, Wilmington, Massachusetts, USA), WT, CD45.1 congenic (CHARLES RIVER LABORATORIES), TCR ${ }^{\mathrm{MOG}}$ (2D2, BETELLI et al., 2003), IgH ${ }^{\mathrm{MOG}}$ (Th, LITZENBURGER et al., 1998), OT II (BARNDEN et al., 1998), Rosa26-tdRFP (LUCHE et al., 2007), Ryr1 ${ }^{+-}$(TAKESHIMA et al., 1994), Ryr3 ${ }^{-1}$ (TAKESHIMA et al., 1996). We crossed these strains to generate the following mutants that were used for this study: $R y r 1^{+/-} \times \mathrm{RFP}, R y r 3^{-1-} \times \mathrm{RFP}$, $\mathrm{Ryr}^{+/-} \times \mathrm{Ryr}^{-1-} \times \mathrm{RFP}, \quad \mathrm{Ryr}^{-/-} \times 2 \mathrm{D} 2 \times \mathrm{RFP}, \quad$ Ryr $3^{-1} \times 2 \mathrm{D} 2 \times \mathrm{IgH}^{\mathrm{MOG}} \times \mathrm{RFP}, \quad \mathrm{Ryr}^{3^{-1}}$ $\times \mathrm{OT}$ II $\times$ RFP.

\subsubsection{Generation of fetal liver and bone marrow chimeric mice}

In brief, pregnant female donor mice were euthanized at gestation day 14 . The individual embryos were removed aseptically and fetal livers were isolated. A single-cell suspension was made by passing the liver through a $1 \mathrm{ml}$ pipette tip. After centrifugation the cells were resuspended in StemSpan ${ }^{\mathrm{TM}}$ medium supplemented with $20 \mathrm{ng} / \mathrm{ml} \mathrm{SCF}, 20 \mathrm{ng} / \mathrm{ml} \mathrm{IL-3} \mathrm{and}$ $50 \mathrm{ng} / \mathrm{ml}$ IL-6 (STEMCELl TECHNOLOGIES SARL, Cologne, Germany) and cultivated for $3-4 \mathrm{~h}$. About $5 \times 10^{6}$ cells were intravenously injected into lethally irradiated mice $(\mathrm{C} 57 \mathrm{Bl} / 6: 12.5 \mathrm{~Gy})$. Recipient animals were maintained on neomycin trisulfate $(2 \mathrm{mg} / \mathrm{ml})$ containing drinking water for 4 weeks to prevent infections.

To generate bone marrow chimeric mice, donor mice were euthanized and the femur and tibia were collected. After removing excess flesh and the ends of the bone the bone marrow was flushed out using a 27-gauge needle. After erythrolysis, cells were counted and about $7 \times 10^{6}$ cells were injected into lethally irradiated mice $(\mathrm{C} 57 \mathrm{Bl} / 6: 12.5 \mathrm{~Gy})$. Recipient animals were maintained on neomycin trisulfate $(2 \mathrm{mg} / \mathrm{ml})$ containing drinking water for 4 weeks to prevent infections.

After 4 weeks, peripheral blood was collected to screen recipient mice for successful reconstitution by immunostaining (TCR- $\beta$ and B220 antibodies) and flow cytometry. 


\subsection{3 $\mathrm{MOG}_{35-55}$ EAE induction by active immunization and disease evaluation}

Mice were anesthetized by injection of ketamine $(80 \mathrm{mg} / \mathrm{kg}$, MEDISTAR, Ascheberg, Germany) and xylazine $(8 \mathrm{mg} / \mathrm{ml}$, ECUPHAR, Greifswald, Germany). EAE was then induced by immunization with the 2D2 TCR epitope $\mathrm{MOG}_{35-55}$ (MEVGWYRSPFSRVVHLYRNGK, purchased from the Institute for Medical Immunology, CHARITÉ UNIVERSITÄTSMEDIZIN BERLIN, Germany) in at least 10 weeks old mice. Antigen emulsion containing $50 \mu \mathrm{g}$ complete Freund's adjuvant (incomplete Freunds's adjuvant (Difco ${ }^{\mathrm{TM}}$, BECTON DICKINSON, Franklin Lakes, New York, USA, supplemented with Mycobacterium tuberculosis H37Ra (Difco ${ }^{\mathrm{TM}}$, BECTON DICKINSON)) and $50 \mu \mathrm{g}$ $\mathrm{MOG}_{35-55}$ was injected subcutaneously at the base of the tail. Pertussis toxin (LIST BIOLOGICAL LABORATORIES, Campbell, California, USA) was injected intraperitoneal on the day of immunization and $48 \mathrm{~h}$ later (except fetal liver and bone marrow chimeras). The mice were weighed and examined for clinical signs of EAE daily, starting on day 7 after immunization. EAE was assessed according to the following scoring system:

Score 0: healthy; no motor deficits and full tail tone;

Score 1: reduced tail tone;

Score 2: flaccid tail paralysis;

Score 3: absent body righting when walking;

Score 4: gait ataxia;

Score 5: mild paralysis of hind limbs;

Score 6: paralysis of one hind limb or moderate hind limb paraparesis;

Score 7: severe paraparesis or paraplegia;

Score 8: tetraparesis;

Score 9: moribund state;

Score 10: dead.

Mice with a score of $\geq 5$ were provided with easier access to food and water.

For ethical reasons, mice with a score $\geq 7$ were sacrificed.

\subsubsection{Dantrolene injections}

Dantrolene sodium salt was solved in $10 \%$ DMSO in PBS and was injected daily intraperitoneally at a concentration of $20 \mathrm{mg} / \mathrm{kg}$ body weight.

\subsubsection{Euthanasia}

Mice were asphyxiated with carbon dioxide $\left(\mathrm{CO}_{2}\right)$ gas. 


\subsection{Experimental Procedures}

\subsubsection{Staining of cell surface markers}

Surface proteins were stained with fluorescently labeled antibodies. $1 \times 10^{6}$ cells were resuspended in $200 \mu \mathrm{l}$ FACS buffer containing the respective antibodies and incubated in the dark at $4{ }^{\circ} \mathrm{C}$ for $30 \mathrm{~min}$. Cells were centrifuged at $4{ }^{\circ} \mathrm{C}$ at $1200 \mathrm{rpm}$ for $5 \mathrm{~min}$ before transfer into $5 \mathrm{ml}$ FACS tubes (BD BIOSCIENCES, Franklin Lakes, New Jersey, USA) in a volume of $200 \mu \mathrm{l}$ FACS buffer.

\subsubsection{Flow cytometry}

FACS analysis was performed using the flow cytometer FACSCalibur ${ }^{\mathrm{TM}}$ (BD Biosciences), that consists of an air-cooled argon laser $\left(\lambda_{\mathrm{ex}}=488 \mathrm{~nm}\right)$ and a red diode laser $\left(\lambda_{\mathrm{ex}}=640 \mathrm{~nm}\right)$, enabling the measurement of four different fluorescent parameters (channels).

With a flow cytometer the cell number in a given sample could be quantified using Calibrite APC beads (BD BIOSCIENCES). A certain number of beads was resuspended in PBS and $50 \mu \mathrm{l}$ of the suspension was added to $200 \mu \mathrm{l}$ cell suspension. The total cell number was calculated as follows:

$$
\left(\frac{\text { Beads } / 50 \mu l \times \text { Acquired Cells }}{\text { Acquired Beads }}\right) \times \text { Dilution Factor }=\text { Cell Count }
$$

Table 2.2 Antibodies used for flow cytometry

\begin{tabular}{|l|l|l|l|}
\hline Antigen & Label & Clone & Company \\
\hline CD4 & APC & RM4-5 & $\begin{array}{l}\text { BIOLEGEND } \\
\text { (San Diego, California, USA) }\end{array}$ \\
\cline { 2 - 4 } & PE-Cy5 & H129.19 & BIOLEGEND \\
\hline CD8a & biotin & $53-6.7$ & $\begin{array}{l}\text { BD PHARMINGEN } \\
\text { (Franklin Lakes, New Jersey, USA) }\end{array}$ \\
\cline { 2 - 4 } & FITC & $53-6.7$ & BD PHARMINGEN \\
\hline CD25 & APC & 3 C7 & BIOLEGEND \\
\cline { 2 - 4 } & FITC & 3 C7 & BIOLEGEND \\
\hline CD44 & APC & IM7 & BD PHARMINGEN ${ }^{\mathrm{TM}}$ \\
\cline { 2 - 4 } & FITC & HI44a & $\begin{array}{l}\text { IMMUNOTOOLS } \\
\text { (Friesoythe, Germany) }\end{array}$ \\
\hline CD45.1 & Biotin & A20 & BIOLEGEND \\
\hline
\end{tabular}




\begin{tabular}{|l|l|l|l|}
\hline CD45R/B220 & APC & RA3-6B2 & BIOLEGEND \\
\hline \multirow{2}{*}{ CD62L } & biotin & MEL-14 & BD PHARMINGEN ${ }^{\text {TM }}$ \\
\cline { 2 - 4 } & FITC & MEL-14 & BIOLEGEND \\
\hline CD69 & FITC & H1.2F3 & BIOLEGEND \\
\hline MHC-II $($ I-A $)$ & APC & AF6-120.1 & BIOLEGEND \\
\hline Streptavidin & FITC, PE-Cy5 & - & BIOLEGEND \\
\hline TCR $\beta$ chain & FITC & H57-597 & BIOLEGEND \\
\hline
\end{tabular}

\subsubsection{CFSE dilution assay}

Isolated, antigen-specific $\mathrm{T}$ cells were labeled with carboxyfluorescein diacetate succinimidyl ester (CFSE). In brief, $2 \times 10^{6} \mathrm{~T}$ cells were incubated in the presence of $0.25 \mu \mathrm{M}$ CFSE for $10 \mathrm{~min}$ at $37^{\circ} \mathrm{C}$. The CFSE labeled cells were then injected i.v. into host animals. $48 \mathrm{~h}$ hours after transfer the mice were immunized with $\mathrm{MOG}_{35-55}$. T cell proliferation in draining lymph nodes, nondraining lymph nodes and spleen was determined $48 \mathrm{~h}, 60 \mathrm{~h}, 72 \mathrm{~h}$ and $96 \mathrm{~h}$ after immunization by measuring the dilution of CFSE occurring with every cell division using flow cytometry.

\subsubsection{Transwell migration assay}

$\mathrm{T}$ cells were activated in vivo by immunization of mice against $\mathrm{MOG}_{35-55}$ peptide. On day 9 after immunization, lymph nodes, spleen and blood samples were taken and $\mathrm{T}$ cells were isolated by negative selection. The cells were then labeled with $0.25 \mu \mathrm{M}$ CFSE and placed on the upper layer of the cell permeable membrane (pore size $5.0 \mu \mathrm{m}$ ) of the migration chamber (Boyden multiwell chamber, CORNING INC., New York, USA), allowing them to migrate towards the lower chamber which contains the testing solution. The quantity of migrated cells was assessed by FACS after $5 \mathrm{~h}$ of incubation.

\subsubsection{Glutamate release detection assay}

The concentration of free glutamate in astrocyte culture supernatants was assessed by using the Glutamate Colorimetric Assay Kit (BIOVISION, INC., Milpitas, California, USA) according to the manufacturer's instructions. Confluent grown cultures of astrocytes were stimulated as indicated. Supernatants were collected $10 \mathrm{~min}, 2 \mathrm{~h}$ and $16 \mathrm{~h}$ after stimulation and were diluted 1:10 before use. 


\subsubsection{Thymidine incorporation assay}

Lymphocytes, splenocytes or enriched $\mathrm{T}$ cells $\left(3 \times 10^{5} /\right.$ well, in triplicates $)$ were stimulated with indicated concentrations of anti-CD3 and/or anti-CD28 antibodies, or $\mathrm{MOG}_{35-55}$ peptide in ReMed $\left(37^{\circ} \mathrm{C}, 5 \% \mathrm{CO}_{2}\right)$. After $24 \mathrm{~h}$ of stimulation, tritiated thymidine $\left(\left[{ }^{3} \mathrm{H}\right] \mathrm{dT}, 2 \mathrm{Ci} / \mathrm{mmol}\right.$, GE HEALTHCARE) was added to the culture. Radioactivity was measured $16 \mathrm{~h}$ later using a MicroBeta Trilux 1450LSC $\beta$ counter (PERKINELMER, Waltham, Massachusetts, USA).

Table 2.3 | Antibodies used for culture assays (for T cell stimulation)

\begin{tabular}{|l|l|l|l|}
\hline Antigen & Host & Clone & Company \\
\hline CD3 & Rat & $145-2 C 11$ & BIOLEGEND \\
\hline CD28 & Rat & 37.51 & BIOLEGEND \\
\hline
\end{tabular}

\subsection{Immunocytochemistry}

\subsubsection{Cytospin and staining of suspension cells}

For fluorescent stainings of non-adhering cells, 5-10 $\times 10^{4}$ cells were gently spun down (1000 rpm, $7 \mathrm{~min}$, medium acceleration and brakes, RT) on Superfrost ${ }^{\mathrm{TM}}$ Plus microscope slides using a Cytospin ${ }^{\circledR} 4$ cytocentrifuge (THERMO FISCHER SCIENTIFIC INC.). The cells were then first fixed with $4 \%$ PFA for 15 min before blocking in $10 \%$ FCS / $0.02 \%$ Triton X-100 in PBS for $30 \mathrm{~min}$ at RT in a humidified chamber to prevent drying of cells. Then, primary antibodies were applied $\mathrm{O} / \mathrm{N}$ at $4{ }^{\circ} \mathrm{C}$ in blocking buffer. After washing with PBS, secondary antibodies were applied for $60 \mathrm{~min}$ at RT. Afterward, nucleic acids were stained with DAPI (5 min, RT) to visualize cell nuclei. The samples were mounted with one drop of Fluoromount- $\mathrm{G}^{\mathrm{TM}}$ (SOUTHERNBIOTECH, Birmingham, Alabama, USA) and sealed with a coverslip. The slides were then directly used for microscopy or stored in the dark at $4{ }^{\circ} \mathrm{C}$.

\subsubsection{Staining of adherent cells}

To stain adherent cells like astrocytes and microglia, the cells were detached by trypsinization and seeded on cleaned coverslips in a 6-well or 12-well plate. After $24 \mathrm{~h}$, the cells were fixed with $4 \%$ PFA for $15 \mathrm{~min}$ before blocking in $10 \%$ FCS / $0.02 \%$ Triton X-100 in PBS for $30 \mathrm{~min}$ at RT. Then the coverslips were taken out and further processed upside down on Parafilm 
slices (BEMIS COMPANY, INC., Neenah, Wisconsin, USA) to allow lower incubation volumes for the antibody solutions. After incubation with primary and secondary antibodies and DAPI (as described in chapter 2.6.1), the coverslips were mounted with one drop of Fluoromount $-G^{\mathrm{TM}}$ and placed upside down on a microscope slide before microscopy or storage.

Table 2.4 | Primary antibodies used in immunocytochemistry

\begin{tabular}{|l|l|l|l|l|}
\hline Antigen & Dilution & Host & Clonality & Company \\
\hline RyR1 & $1: 1000$ & Rabbit & Polyclonal & MILLIPORE \\
\hline RyR3 & $1: 1000$ & Rabbit & Polyclonal & MILLIPORE \\
\hline GFAP & $1: 1000$ & Rabbit & Polyclonal & $\begin{array}{l}\text { DAKO } \\
\text { (Glostrup, Denmark) }\end{array}$ \\
\cline { 2 - 5 } & $1: 200$ & Mouse & Monoclonal & BIOLEGEND \\
\hline Iba1 & $1: 1000$ & Rabbit & Polyclonal & $\begin{array}{l}\text { WAKO PURE CHEMICALS } \\
\text { INDUSTIRES, LTD. (Neuss, Germany) }\end{array}$ \\
\hline
\end{tabular}

Table 2.5 | Secondary antibodies used in immunocytochemistry

\begin{tabular}{|l|l|l|l|l|}
\hline Antigen & Dilution & Host & Label & Company \\
\hline \multirow{2}{*}{ Rabbit IgG } & $1: 500$ & goat & Cy-2 & MILLIPORE \\
\cline { 2 - 5 } & $1: 500$ & goat & AF-594 & ABCAM \\
\hline Mouse IgG & $1: 500$ & rat & FITC & BD PHARMINGEN ${ }^{\mathrm{TM}}$ \\
\hline
\end{tabular}

\subsubsection{Image acquisition}

Fluorescent images were acquired using the Zeiss Axio Observer.Z1 microscope equipped with a Zeiss Plan Apochromat $20 \times$ or $40 \times$ lens (both CARL ZEISS, Jena, Germany) and a HXP 120C metal halide lamp (LEISTUNGSELEKTRONIK JENA GMBH, Jena, Germany) as a light source. Fluorescent emission was detected using a Zeiss AxioCam HSm (CARL ZEISS). Excitation $\left(\lambda_{\mathrm{ex}}\right)$ and emission $\left(\lambda_{\mathrm{em}}\right)$ wavelengths were as followed: GFP, FITC, $\lambda_{\mathrm{ex}}=470 \mathrm{~nm}, \lambda_{\mathrm{em}}=509 \mathrm{~nm} ; \mathrm{RFP}$, AF594, $\lambda_{\mathrm{ex}}=558 \mathrm{~nm} ; \lambda_{\mathrm{em}}=583 \mathrm{~nm} ;$ DAPI, $\lambda_{\mathrm{ex}}=350 \mathrm{~nm} ; \lambda_{\mathrm{em}}=470 \mathrm{~nm}$. Images were processed by using the Zeiss AxioVision v4.8 software (CARL ZEISS). 


\subsection{Histology and Immunohistochemistry}

\subsubsection{Perfusion}

After euthanasia, the thorax was opened to access the heart. The mice were first perfused with PBS through the left ventricle for 10 min and a small incision was made into the right atrium to allow efflux of the blood. The mice were then perfused for another 10 min with $4 \%$ PFA to allow fixation of tissues. After perfusion, organs of interest were stored in $4 \%$ PFA for at least another $48 \mathrm{~h}$ at $4{ }^{\circ} \mathrm{C}$ before further processing.

\subsubsection{Dehydration and paraffin embedding of fixed tissues}

PFA-fixed organs were washed with PBS and sliced into appropriate pieces before inserting them into tissue cassettes (TESPA, Gießen, Germany). The samples were then dehydrated $(70 \% \mathrm{EtOH}, 1$ change, $60 \mathrm{~min} ; 80 \% \mathrm{EtOH}, 1$ change, $60 \mathrm{~min}$; $90 \% \mathrm{EtOH}, 2$ changes, $60 \mathrm{~min}$ each; $95 \% \mathrm{EtOH}, 2$ changes, 90 min each; $100 \% \mathrm{EtOH}, 2$ changes, 90 min each; xylene, 2 changes, 60 min each; paraffin wax, $56-58{ }^{\circ} \mathrm{C}, 120 \mathrm{~min}$ each) with an automatic tissue processor TP1020 (LEICA BIOSYSTEMS, Wetzlar, Germany). Following dehydration, tissues were embedded into paraffin blocks with a Leica EG1160 embedding machine.

\subsubsection{Preparation of embedded samples for tissue stains}

The tissue containing paraffin blocks were cut into $3 \mu \mathrm{m}$ thick slices with a Leica SM2000R microtom, taken up on microscope slides and dried at $37{ }^{\circ} \mathrm{C}$ $\mathrm{O} / \mathrm{N}$. Prior to further processing, samples were rehydrated (xylene, 2 changes, 15 min each; $100 \% \mathrm{EtOH}, 2$ changes, 2 min each; $96 \% \mathrm{EtOH}, 2$ changes, 2 min each; $70 \% \mathrm{EtOH}, 2$ changes, 2 min each; distilled water, 2 changes, $2 \mathrm{~min}$ ).

\subsubsection{Hemalum \& eosine (HE) stain}

Rehydrated samples were stained with filtered Mayer's hemalum solution (MERCK, Darmstadt, Germany) for 10 min to visualize nuclei, followed by 10 min extensive washing with non-distilled water. To stain the cytoplasm, the samples were exposed to $0.1 \%$ eosine Y solution (MERCK, diluted with acetic acid) for $2 \mathrm{~min}$. After washing, the samples were again dehydrated (70\% EtOH, 2 changes, 2 min each; $96 \%$ EtOH, 2 changes, 2 min each; $100 \%$ EtOH, 2 changes, 2 min each; xylene, 2 changes, 15 min each), mounted with Entellan $^{\mathrm{TM}}$ and sealed with a coverslip. 


\subsubsection{Luxol fast blue-Periodic acid-Schiff stain}

The samples were rehydrated incompletely (stop after $96 \% \mathrm{EtOH}$ ) and incubated $\mathrm{O} / \mathrm{N}$ at $56{ }^{\circ} \mathrm{C}$ in $0.1 \%$ LFB solution (ABCR GMBH \& $\mathrm{CO}$. KG, Karlsruhe, Germany, diluted with $96 \% \mathrm{EtOH} / 0.05 \%$ acetic acid). Then they were washed in $96 \% \mathrm{EtOH}$ and incubated in $0.1 \%$ lithium carbonate $\left(\mathrm{Li}_{2} \mathrm{CO}_{3}\right)$ for $30 \mathrm{sec}$. The samples were washed very briefly in $70 \% \mathrm{EtOH}$ and distilled water before incubation for $10 \mathrm{~min}$ in $0.8 \%$ periodic acid $\left(\mathrm{H}_{5} \mathrm{IO}_{6}\right)$ to wash off excess $\mathrm{Li}_{2} \mathrm{CO}_{3}$. After washing with distilled water, the specimens were incubated in Schiff reagent for $20 \mathrm{~min}$. Excess reagent was washed off with sulfite washing solution $(0.1 \%$ of concentrated $(37 \%) \mathrm{HCl}, 4 \%$ potassium metabisulfite $\left(\mathrm{K}_{2} \mathrm{~S}_{2} \mathrm{O}_{5}\right)$ in $\left.\mathrm{H}_{2} \mathrm{O}\right)$. Prior final dehydration and embedding, the samples were washed extensively in non-distilled water for $10 \mathrm{~min}$.

\subsubsection{Bielschowsky's silver stain for axons}

Prior to further processing, samples were completely rehydrated. Next, the samples were incubated for $15 \mathrm{~min}$ at $37{ }^{\circ} \mathrm{C}$ in preheated silver nitrate $\left(\mathrm{AgNO}_{3}\right)$ and were washed afterward in distilled water. During this washing step, ammonia $\left(\mathrm{NH}_{3}\right)$ is given to the previously used $\mathrm{AgNO}_{3}$ solution to prepare silver hydroxide $(\mathrm{AgOH})$. The specimens were then incubated in this solution for $10 \mathrm{~min}$ at $37{ }^{\circ} \mathrm{C}$ in the dark. Afterward, samples were washed twice in $0.1 \% \mathrm{NH}_{3}$. To the used $\mathrm{AgOH}, 11-15$ drops of developer solution (5.4 $\mathrm{ml} 37 \%$ formaldehyde in $114.6 \mathrm{ml} \mathrm{H}_{2} \mathrm{O}+1$ drop of $65 \%$ nitric acid $\left(\mathrm{HNO}_{3}\right)+0.5 \mathrm{~g}$ citric acid) were added. In this solution, the samples were incubated for 4-10 min under gentle shaking. The specimens were washed briefly in $0.1 \% \mathrm{NH}_{3}$ and distilled water before final dehydration and embedding. The slides were stored at $4{ }^{\circ} \mathrm{C}$ in the dark.

\subsubsection{Antibody stains}

Specimens were completely rehydrated as described before boiling in $0.1 \mathrm{M}$ citric acid ( $\mathrm{pH}$ 6.0) for $20 \mathrm{~min}$ in a microwave oven at $600 \mathrm{~W}$. After cooling down to RT, the samples were washed in distilled water and PBS ( 2 min, 4 changes each) followed by incubation in $3 \%$ hydrogen peroxide $\left(\mathrm{H}_{2} \mathrm{O}_{2}\right)$ in PBS for $10 \mathrm{~min}$. The binding sites were then blocked by incubation in $10 \%$ FCS / $0.02 \%$ Triton X-100 in PBS for 10 min. Primary antibodies were applied in blocking buffer $\mathrm{O} / \mathrm{N}$ at $4{ }^{\circ} \mathrm{C}$. After washing with $\mathrm{PBS}$, secondary, biotinylated antibodies were applied at RT for $60 \mathrm{~min}$. After additional washing, a streptavidin-peroxidase complex (ExtrAvidin ${ }^{\circledR}$-Peroxidase, SIGMAALDRICH) was applied to the specimens (incubation at RT, $60 \mathrm{~min}$ ). Diaminobenzidine (DAB, $2 \mathrm{~g}$ dissolved in $80 \mathrm{ml} \mathrm{PBS}$ ) was used as a substrate for oxidation which results in a dark-brown color (10 min incubation, RT). By that, the antibody labeled proteins could be visualized. The specimens were counterstained with Mayer's hemalum solution to visualize cell nuclei. Afterward, the samples were dehydrated, embedded and stored at RT. 
Table 2.6 | Primary antibodies used in immunohistochemistry

\begin{tabular}{|l|l|l|l|l|}
\hline Antigen & Dilution & Host & Clonality & Company \\
\hline CD3 & $1: 1000$ & Rat & Polyclonal & BD PHARMINGEN $^{\mathrm{TM}}$ \\
\hline MAC3 & $1: 1000$ & Rat & Polyclonal & BD PHARMINGEN $^{\mathrm{TM}}$ \\
\hline Iba1 & $1: 1000$ & Rabbit & Polyclonal & WAKO \\
\hline
\end{tabular}

Table 2.7 | Secondary antibodies used in immunohistochemistry

\begin{tabular}{|l|l|l|l|l|}
\hline Antigen & Dilution & Host & Clonality & Company \\
\hline Rat IgG & $1: 200$ & Rabbit & Polyclonal & $\begin{array}{l}\text { VECTOR LABORATORIES } \\
\text { (Burlingame, California, USA) }\end{array}$ \\
\hline Rabbit IgG & $1: 200$ & Rat & Polyclonal & VECTOR LABORATORIES \\
\hline
\end{tabular}

\subsubsection{Image acquisition}

Pictures were taken with an Olympus BX51 microscope equipped with an UPlan FL N $10 \times$ or $20 \times$ lens and processed with analySIS ${ }^{\mathrm{B}}$ imaging software (each OlYMPUS, Shinjuku, Tokyo, Japan).

\subsection{Imaging of Subcellular Calcium Signals}

\subsubsection{Preparation of cells for calcium signal measurements}

Astrocytes were seeded on a chambered microscope slide ( $\mu$-Slide 8 Well, IBIDI GMBH, Planegg / Martinsried, Germany) in a concentration of 5$10 \times 10^{4}$ cells per well. The cells were incubated with membrane permeable AM esters of $\mathrm{Ca}^{2+}$ dyes Fluo-4 and Fura-2 $(10 \mu \mathrm{M}$ each) in $0.04 \%$ Pluronic F-127 (SigmA-ALDRICH) for $30 \mathrm{~min}$ at $37^{\circ} \mathrm{C}$ in the dark. Next, the cells were washed once with $\mathrm{Ca}^{2+}$ buffer $\left(140 \mathrm{mM} \mathrm{NaCl}, 5 \mathrm{mM} \mathrm{KCl}, 1 \mathrm{mM} \mathrm{MgSO}_{4}, 1 \mathrm{mM}\right.$ $\mathrm{CaCl}_{2}, 20 \mathrm{mM}$ HEPES, $1 \mathrm{mM} \mathrm{NaH} \mathrm{PO}_{4}, 5 \mathrm{mM}$ glucose, $\mathrm{pH}$ 7,4) before further incubation in $\mathrm{Ca}^{2+}$ buffer for $20 \mathrm{~min}$ at $\mathrm{RT}$ in the dark for de-esterification. All substances for stimulation were applied in $\mathrm{Ca}^{2+}$ buffer.

\subsubsection{Image acquisition and processing}

An DM IRBE microscope (LEICA MiCROSYSTEMS, Wetzlar, Germany) with $100 \times$ magnification was used in combination with a DG-4 light source 
(SUTTER InSTRUMENTS, Novato, California, USA). Images were acquired every $5 \mathrm{sec}$ over a total time of $20 \mathrm{~min}$ using an EM-CCD C9100 camera (HAMAMATSU PHOTONICS, Hamamatsu, Japan) with a resolution of $512 \times 512$ pixels (14-bit color depth; $2 \times$ binning) and a DualView module (PERKINELMER, INC.). The following filter set (AHF ANALYSENTECHNIK, Tübingen, Germany) was used for acquisition: Exitation $\lambda=480 / 40 \mathrm{~nm}$; beamsplitter $\lambda=495 \mathrm{~nm}$; emission $1 \lambda=542 / 50 \mathrm{~nm}$; emission $\lambda=650 / 57 \mathrm{~nm})$. Acquisition was performed using the Volocity v6.6.2 software (PERKINELMER, INC.).

\subsubsection{Data evaluation}

Image processing using the Fiji v1.47 software (GPL v2) allowed splitting of frames acquired with the DualView module into the two wavelength channels for post-measurements and calculation of the Fura-2/Fluo-4 emission wavelength ratio (using Openlab software v5.5.2, PERKINELMER, INC.) as described (KUNERTH et al., 2003; WOLF et al., 2015, manuscript in revision).

\subsection{Statistics}

If not declared otherwise, data are always depicted as mean + standard error of the mean (SEM). Methods for statistical evaluation were indicated in each figure and annotated with the following p-values: ns $P \geq 0.05,{ }^{*} P \leq 0.05,{ }^{* *} P \leq$ 0.01 and ${ }^{* * *} P \leq 0.001$. 


\section{Results}

\subsection{RyR1 and RyR3 in immune cells}

The elevation of intracellular free $\mathrm{Ca}^{2+}\left(\left[\mathrm{Ca}^{2+}\right]_{\mathrm{i}}\right)$ provides a major signal for $T$ cell activation upon antigen recognition. Within the cell, the endoplasmic reticulum (ER) is the main storage compartment for free calcium, whose release into the cytosol is mediated by two types of calcium channels- $\mathrm{IP}_{3}$ receptors and ryanodine receptors (RyRs)-upon activation by second messengers. It has been suggested recently that RyRs constitute a potential target for the second messenger NAADP in Jurkat and Lewis rat T cells (DAMMERMANN et al., 2009). It was demonstrated that pharmacological antagonism of NAADP strongly reduced RyR mediated intracellular $\mathrm{Ca}^{2+}$ signals in Jurkat $\mathrm{T}$ cells and rat $\mathrm{T}_{\mathrm{MBP}}$ cells. Furthermore, effector $\mathrm{T}_{\mathrm{MBP}}$ cells were more susceptible to NAADP antagonism than naïve or memory T cells, and expression of the RyR isoforms RyR1 and RyR3 was up-regulated in effector T cells. The impact of NAADP antagonism on $\mathrm{Ca}^{2+}$ signaling was supported by the finding that antagonizing NAADP during Lewis rat EAE significantly ameliorated the course of the disease (DAMMERMANN et al., 2009).

For this study, Ryr knockout mice were used to investigate the role of RyRs in the murine immune system and to evaluate the NAADP-RyR signaling pathway as a potential target for treatment of autoimmune diseases of the CNS.

\subsubsection{Ryr1 and RyR3 mRNA is expressed in effector $T$ cells}

Multiple sclerosis (MS) and its animal model experimental autoimmune encephalomyelitis (EAE) are described as T cell mediated inflammatory diseases (MILLER et al., 2007). As part of EAE pathology, T cells recruit other leukocyte populations like B cells and macrophages into the CNS, thereby sustaining the disease and damaging the CNS (PIERSON et al., 2013). In order to investigate the function of RyRs in T cells and EAE, the expression of Ryr 1 and Ryr3 mRNA in immune cells of WT C57BL/6 mice was determined by means of qRT-PCR. Therefore, naïve $\mathrm{T}$ cells $\left(\mathrm{CD} 4^{+} \mathrm{CD} 62 \mathrm{~L}^{\text {high }} \mathrm{CD} 44^{\text {low }}\right)$, effector $\mathrm{T}$ cells $\left(\mathrm{CD} 4^{+} \mathrm{CD} 62 \mathrm{~L}^{\text {low }} \mathrm{CD} 44^{\text {high }}\right)$, naïve B cells $\left(\mathrm{B} 220^{+} \mathrm{CD} 19^{+}\right)$, activated $\mathrm{B}$ cells, and dendritic cells (DCs; CD11 ${ }^{+}$) were analyzed (Fig. 3.1). Consistent with previous studies, Ryr 1 and Ryr3 mRNA was not detectable in naïve T cells, but present in effector T cells. No expression of Ryr1 and Ryr3 mRNA were found either in naïve or activated B cells. In DCs, only minimal amounts of Ryr1 and Ryr3 mRNA were detected (Fig. 3.1). 


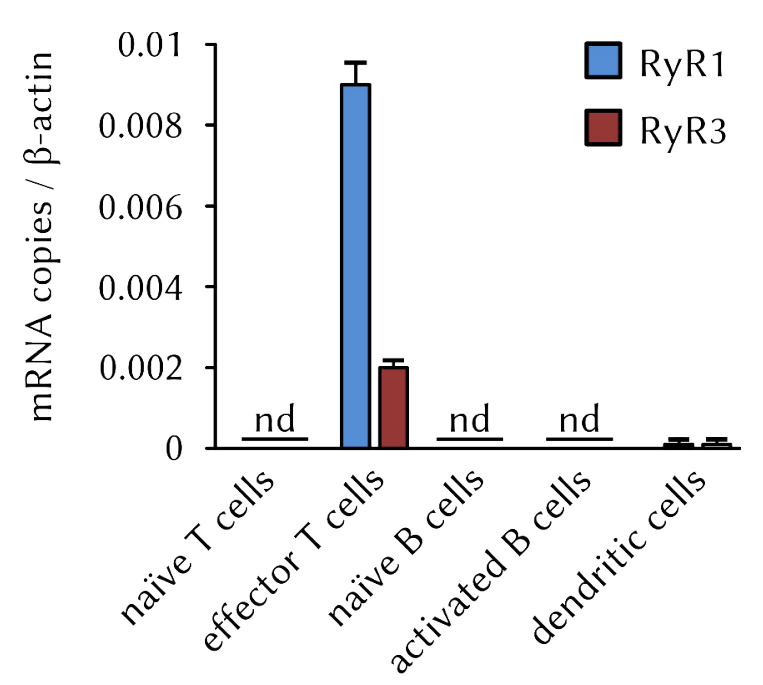

Fig. 3.1 Ryr1 and Ryr3 mRNA expression in immune cells. Naïve T cells $\left(\mathrm{CD} 4^{+} \mathrm{CD} 62 \mathrm{~L}^{\text {high }} \mathrm{CD} 44^{\text {low }}\right)$ and MOG-specific B cells $\left(\mathrm{B} 220^{+} \mathrm{CD} 19^{+}\right)$were isolated from mixed populations of lymph node cells and splenocytes. Effector T cells were enriched from draining lymph nodes of mice immunized against $\mathrm{MOG}_{35-55}$ peptide. B cells were activated in vitro with $100 \mathrm{ng} / \mathrm{ml}$ LPS and $10 \mu \mathrm{g} / \mathrm{ml} \mathrm{MOG}_{35-55}$. Dendritic cells (CD11c ${ }^{+}$) were a kind gift from my colleague Tanja Litke. Bars represent the mean (+SEM) from three independent experiments normalized to the expression of beta-actin.

\subsubsection{RyR1 and RyR3 are expressed in effector $T$ cells in vitro}

Having demonstrated that expression of Ryr 1 and Ryr3 mRNA was found in effector T cells, we analyzed the kinetic of RyR expression in $\mathrm{T}$ cells upon unspecific stimulation with monoclonal antibodies or antigen-specific $\left(\mathrm{MOG}_{35-55}\right.$ peptide) stimulation in vitro (Fig. 3.2). We cultured total splenocytes of $\mathrm{C} 57 \mathrm{Bl} / 6 \mathrm{WT}$ and $\mathrm{TCR}^{\mathrm{MOG}}$ (2D2, MOG-specific TCR transgenic) mice in the presence of anti-CD3/anti-CD28 antibodies and $\mathrm{MOG}_{35-55}$ peptide, respectively, and analyzed $\mathrm{CD}^{+}$T cells $24 \mathrm{~h}, 48 \mathrm{~h}, 72 \mathrm{~h}$, and $96 \mathrm{~h}$ after stimulation. Ryr 1 and Ryr3 mRNA expression was determined by qRT-PCR. Increased levels of Ryr1 mRNA were detected in T cells $48 \mathrm{~h}$ to $96 \mathrm{~h}$ after antibody stimulation, while Ryr 3 mRNA was not detected. After stimulation with $\mathrm{MOG}_{35-55}$ peptide, Ryr1 mRNA levels were increased in $\mathrm{CD}^{+} \mathrm{T}$ cells $72 \mathrm{~h}$ and $96 \mathrm{~h}$ after stimulation, and low levels of Ryr 3 mRNA were detected $96 \mathrm{~h}$ after stimulation.

Cells from the samples that were used for mRNA expression analysis were also used for immunocytochemistry for RyR1 and RyR3 expression (Fig. 3.3). According to the corresponding mRNA data, T cells expressed RyR1 $72 \mathrm{~h}$ to $96 \mathrm{~h}$ after anti-CD3/anti-CD28 antibody treatment and both RyR1 and RyR3 $72 \mathrm{~h}$ to $96 \mathrm{~h}$ after stimulation with $\mathrm{MOG}_{35-55}$ peptide. By that, we could confirm expression of RyR1 and RyR3 in activated T lymphocytes. 


\section{Results}
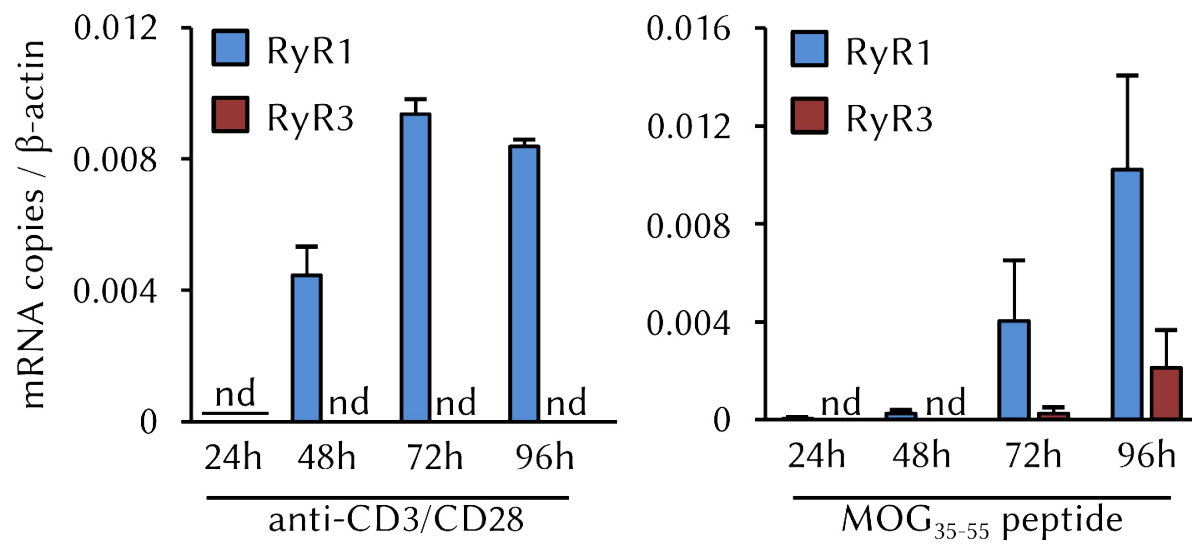

Fig. 3.2 | Ryr1 and Ryr3 mRNA expression in effector T cells. Left panel: Lymph node cells and splenocyte cultures from WT C57Bl/ 6 mice were stimulated with $1 \mu \mathrm{g} / \mathrm{ml}$ anti-CD3 and $5 \mu \mathrm{g} / \mathrm{ml}$ anti-CD28 antibodies. Right panel: Lymph node cells and splenocyte cultures from 2D2 mice were stimulated with $10 \mu \mathrm{g} / \mathrm{ml} \mathrm{MOG}_{35-55}$ peptide. At indicated time points, T cells were purified via negative selection and used for mRNA isolation and real-time PCR analysis for Ryr1 and Ryr3. Bars represent the mean (+SEM) from three independent experiments.

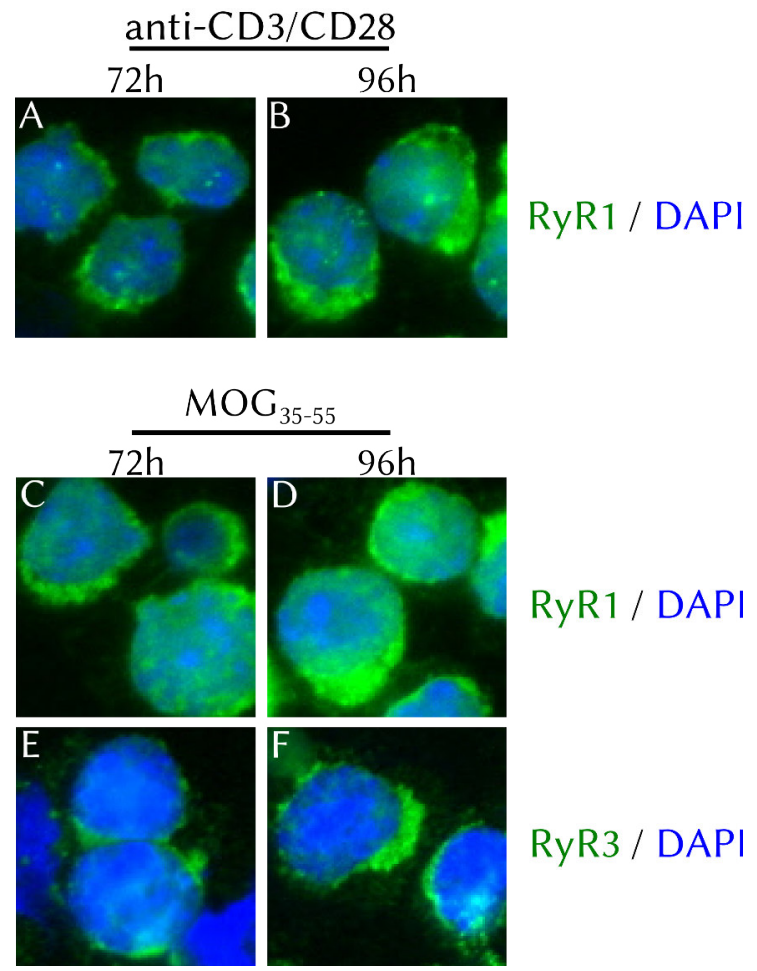

Fig. 3.3 | RyR1 and RyR3 protein expression in effector T cells. The expression of RyR1 and RyR3 was assessed by ICC at indicated time points. (A), (B): Lymph node cells and splenocyte cultures from WT mice were stimulated with $1 \mu \mathrm{g} / \mathrm{ml}$ anti-CD3 and $5 \mu \mathrm{g} / \mathrm{ml}$ antiCD28 antibodies. (C) - (F): Lymph node cells and splenocyte cultures from TCR ${ }^{\text {MOG }}$ mice were stimulated with $10 \mu \mathrm{g} / \mathrm{ml} \mathrm{MOG}_{35-55}$ peptide. T cells were purified via negative selection before fixation and antibody staining against RyR1 or RyR3. Nuclei were visualized with DAPI. Scale bar represents $25 \mu \mathrm{m}$. 


\subsection{Generation and analysis of $R y \mathrm{rI}^{-/}, \mathrm{Ryr}^{-{ }^{--}}$and Ryr double knockout fetal liver chimeras}

The Ryr1 gene knockout results in early postnatal lethality in mice (TAKESHIMA et al., 1994). Yet to investigate the effect of Ryr1 deletion in immune cells, $R y r^{-} \rightarrow$ WT fetal liver chimeras (FLCs) were generated (Fig. 3.4, A). For this purpose, hematopoietic progenitor cells derived from livers of $\mathrm{Ryr}^{-1-}$ fetuses were isolated at 14.5 days post conception and injected into lethally irradiated WT C57Bl/6 animals. Expression of the RFP reporter gene thereby allowed further identification of the newly generated donor cells. Blood analysis by FACS showed that reconstitution levels of hematopoietic cells was about $75-80 \%$ for $\mathrm{T}$ cells $\left(\mathrm{TCR} \beta^{+} \mathrm{RFP}^{+}\right)$and about $80-85 \%$ for B cells $\left(\mathrm{B} 220^{+} \mathrm{RFP}^{+}\right)$four weeks after transfer (Fig. 3.4, B).

A
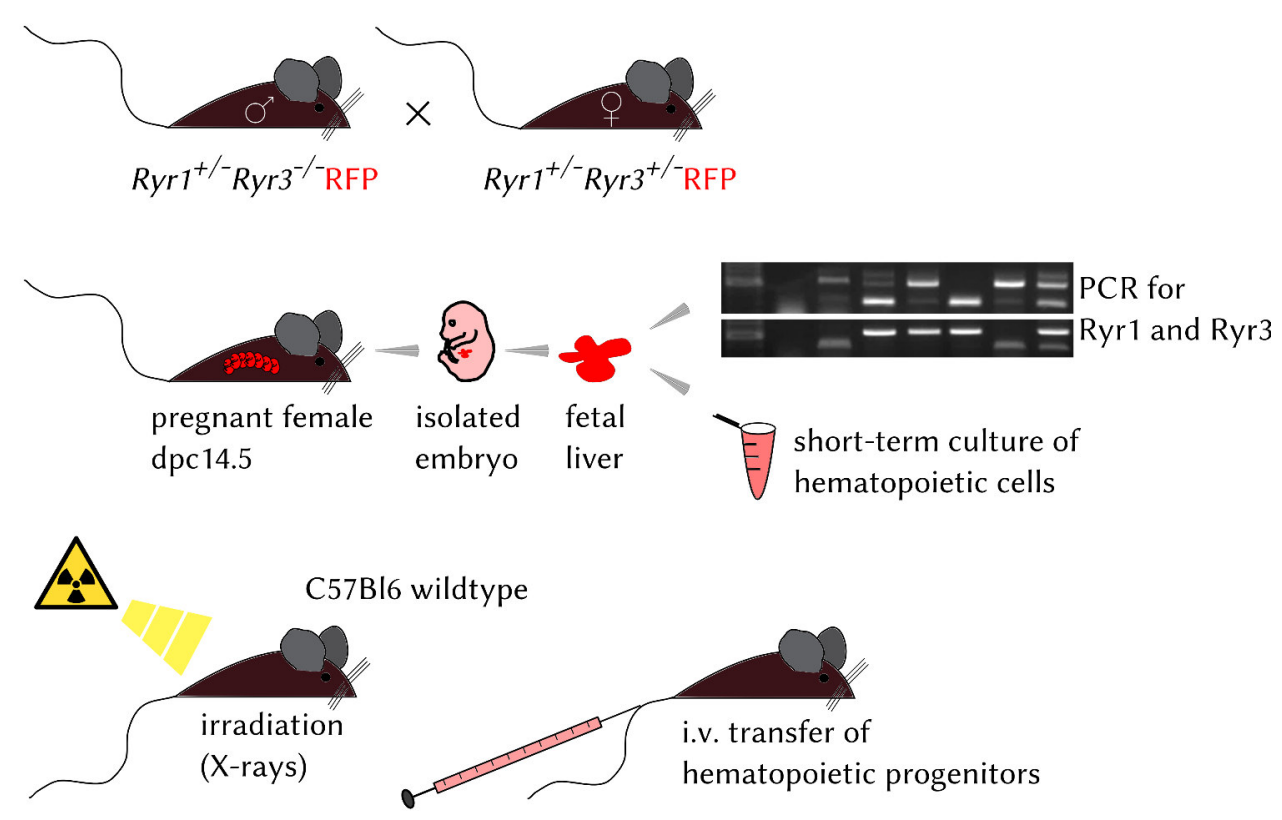

B

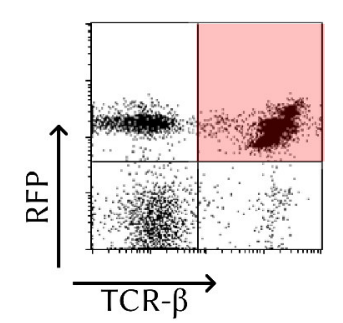

test for sufficient reconstitution by blood analysis 4 weeks after transfer

Fig. 3.4 | Scheme for the generation of fetal liver chimeras. See text and methods chapter 2.4.2 for detailed description. 
Afterward, the mice were either used for phenotyping analyses or EAE induction. In parallel to generating $R y r 1^{-/} \rightarrow$ WT FLCs, Ryr $3^{-/} \rightarrow$ WT FLCs, Ryr1 and Ryr3 double knockout FLCs, respective heterozygous controls $(\mathrm{Ctrl} \rightarrow \mathrm{WT}$; Ctrl) were generated and analyzed as well.

\subsubsection{The immune system of Ryr-KO FLCs does not differ from that of control FLCs}

Chimeric mice presented healthy and showed no obvious abnormalities. The status and composition of the immune system in chimeras was examined in its naïve state. Thymi and spleens had normal appearance (not shown) and were similar in weight and cellularity (Fig. 3.5).

A

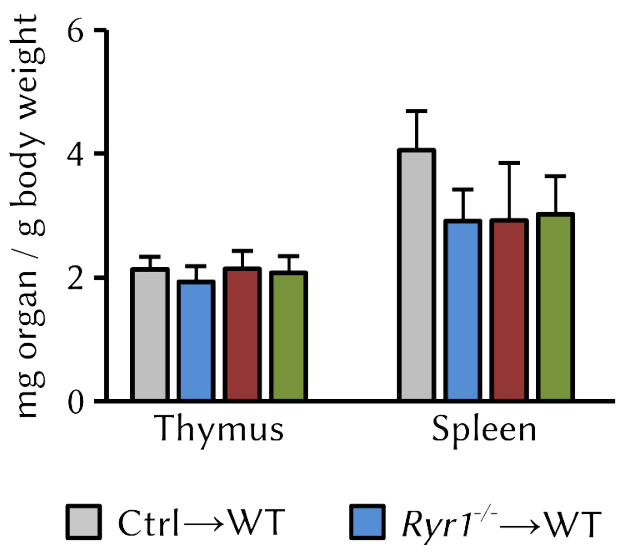

B

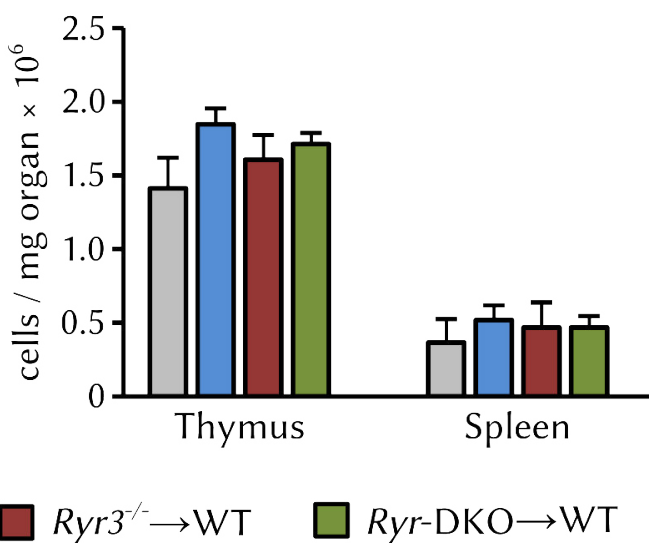

Fig. 3.5 | Analysis of hematopoietic organs of fetal liver chimeric mice. In comparison with control mice, thymus and spleen of $R y r 3^{-/}$mice were not altered in weight $(\mathbf{A})$ and cellularity (B). Bars represent the mean (+SEM) from three independent experiments.

Lymphoid progenitors generated in the bone marrow home to the thymus where they develop into mature T cells. During this process several checkpoints operate in a manner dependent on the TCR engagement and $\mathrm{Ca}^{2+}$ signaling. Thymocytes differentiate from $\mathrm{CD}^{-} \mathrm{CD} 88^{-}$(double negative) cells into $\mathrm{CD}^{+} \mathrm{CD}^{+}$(double positive) cells and further into mature $\mathrm{CD} 4^{+}$or $\mathrm{CD}^{+}$single positive cells. These transition is severely disturbed when key signaling molecules, such as Zap70, are deleted. Therefore, the frequency of transgenic RFP $\mathrm{CD}^{+}$and $\mathrm{CD}^{+}$thymocytes in $R y r$ knockout FLCs was assessed by FACS staining (Fig. 3.6). Neither Ryr1 nor Ryr3 deletion changed the frequency of $\mathrm{CD} 4^{+}$or $\mathrm{CD} 8^{+}$cells or the rate of $\mathrm{CD} 4^{+} \mathrm{CD} 8^{+}$double positive thymocytes. 

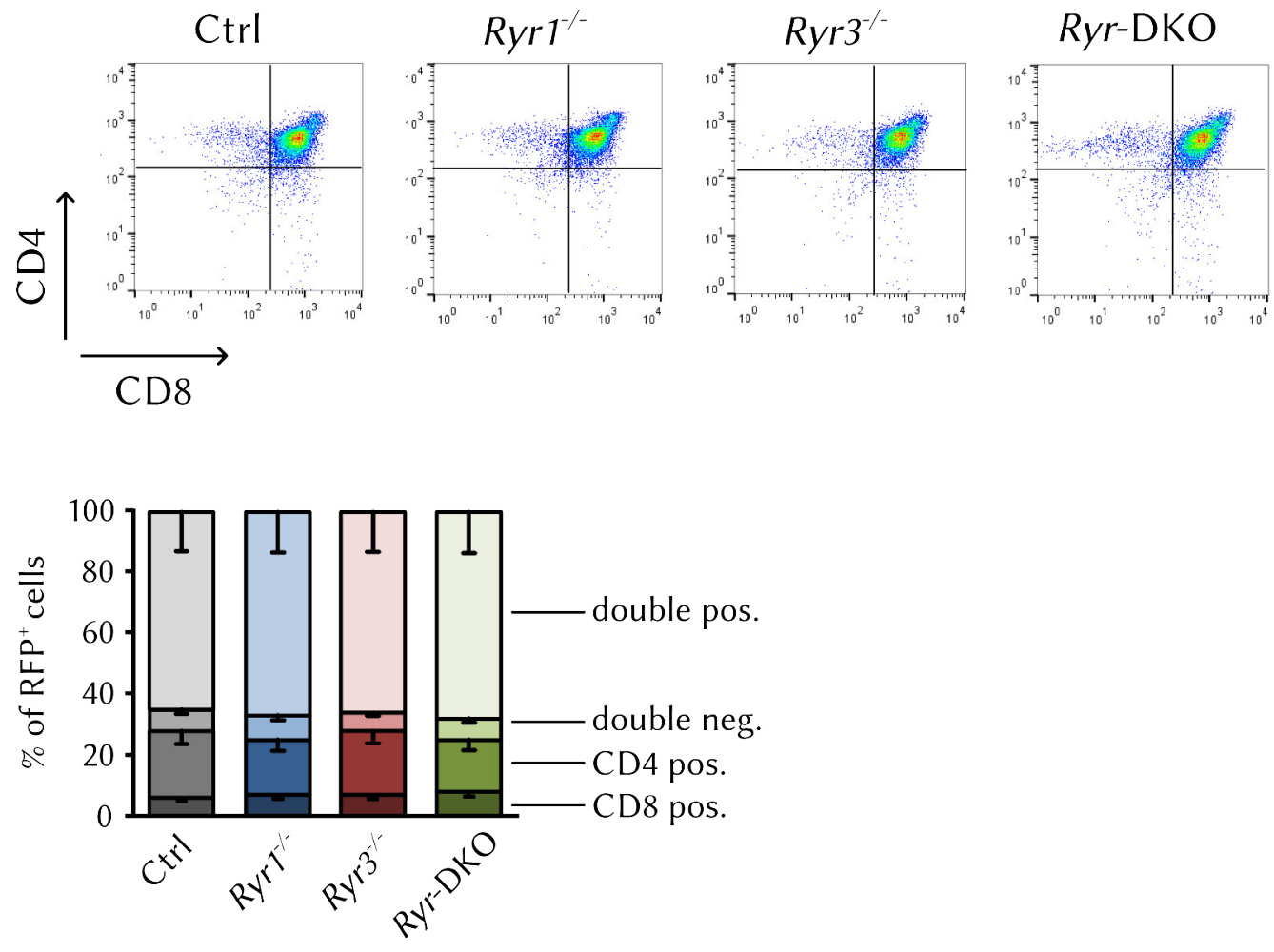

Fig. 3.6 The frequency of $\mathrm{CD} 4^{+}$and $\mathrm{CD} 8^{+}$cells in the thymus of $R y r-K O$ FLCs is similar to that of control FLCs. Single cell suspensions of thymocytes were stained and analyzed via flow cytometry for the expression of surface markers CD4 and CD8. To exclude host cells we gated on the $\mathrm{RFP}^{+}$population. Depicted are representative flow cytometry data (upper panel) and the quantification from three individually performed experiments (lower panel; bars represent mean+SEM).

Furthermore, the composition of the peripheral immune system of $R y r$-KO FLCs was investigated in spleen, lymph nodes and blood. Cells of these organs did not differ from each other in the ratio of expression of the surface markers CD4 and CD8 (helper vs. cytotoxic T cells), TCR- $\beta$ and B220 (T cells vs. B cells) or CD44 and CD62L (effector vs. naïve T cells; Fig. 3.7). 


\section{Results}

A

\section{Spleen}
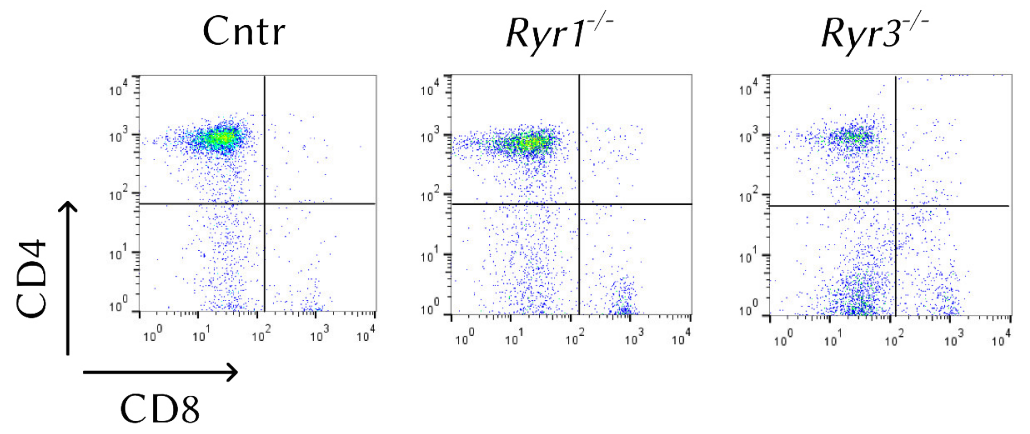

Ryr-DKO
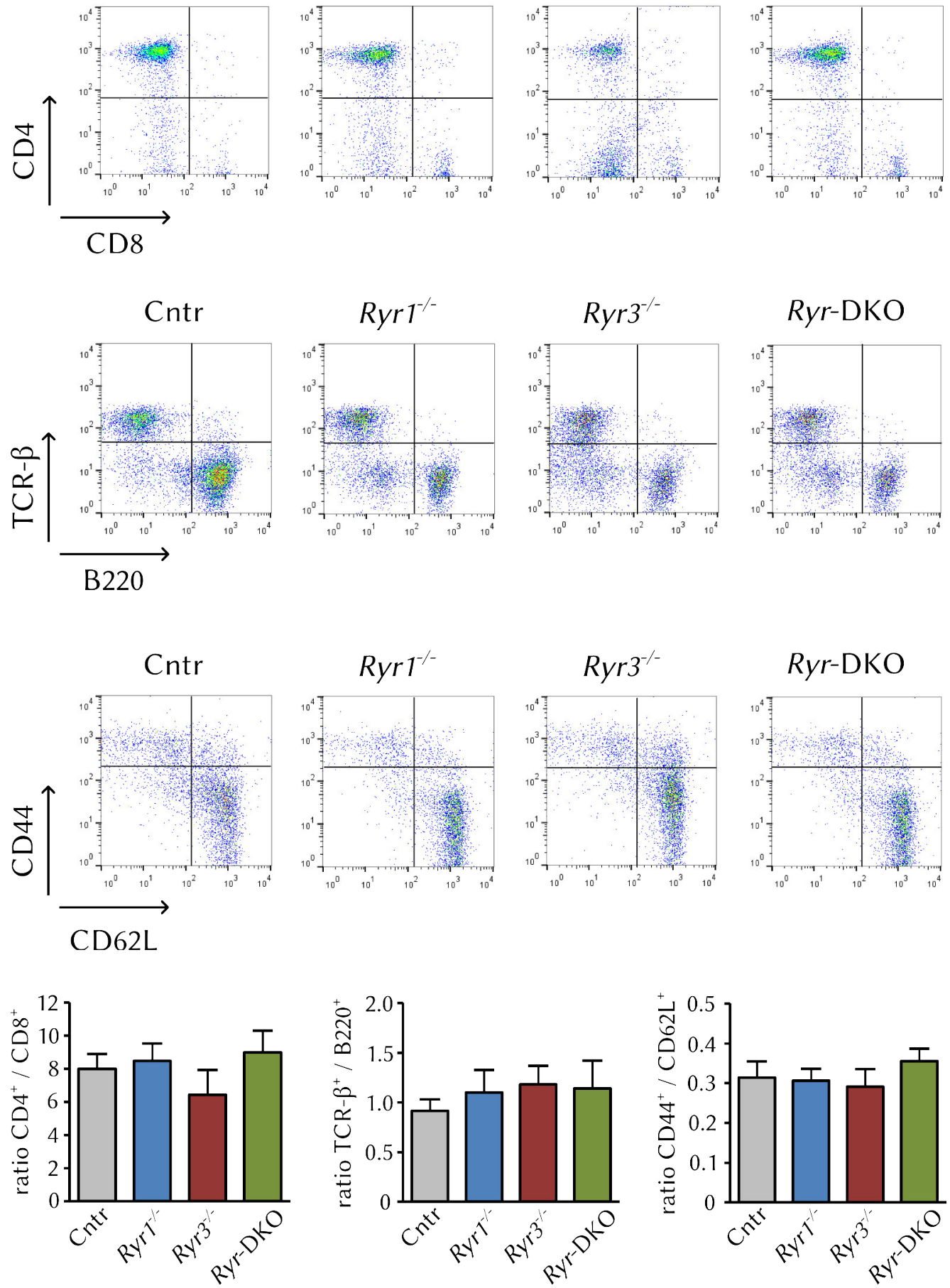


\section{Results}

\section{B}

Lymph nodes
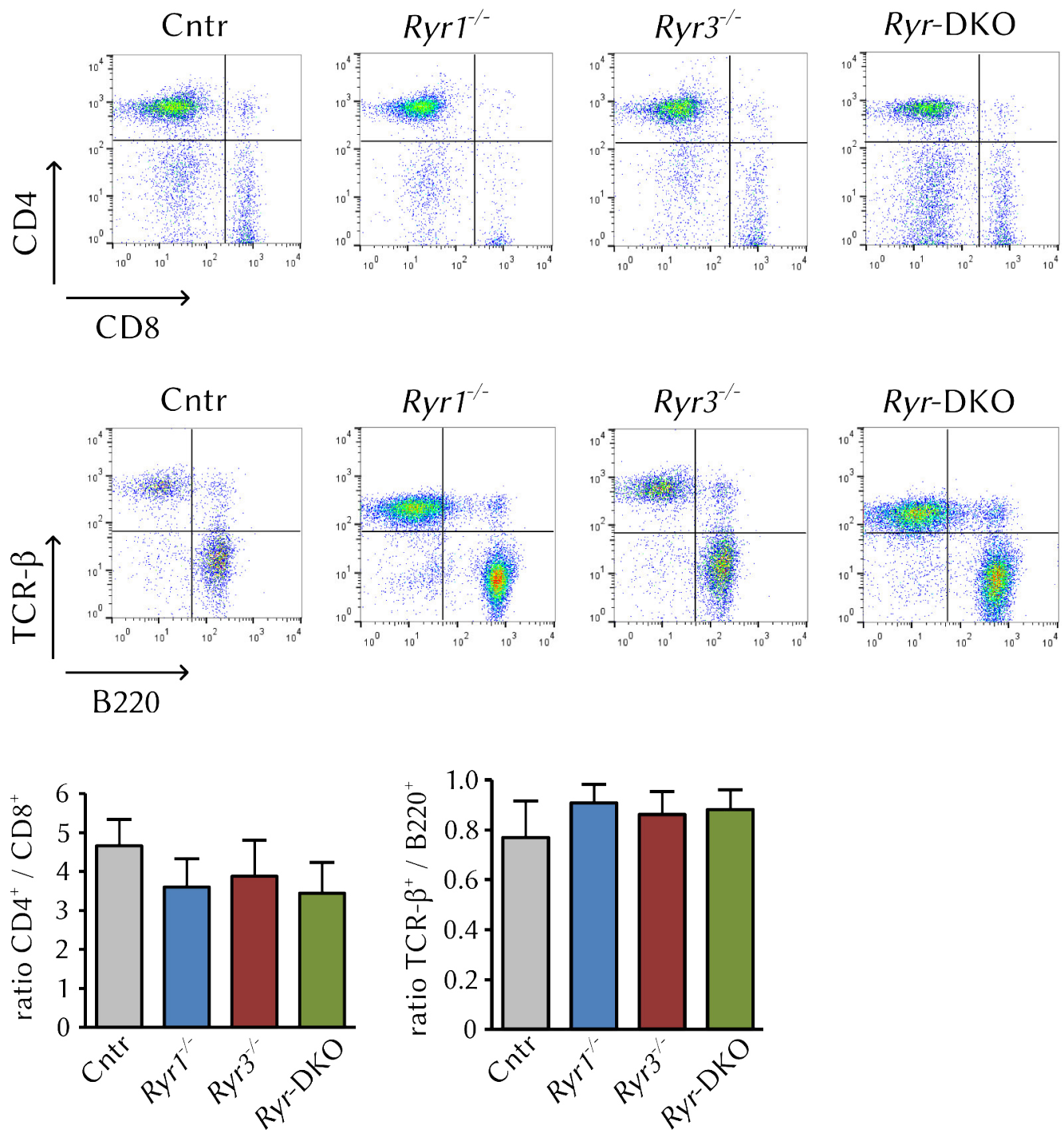


\section{Results}

C

Blood
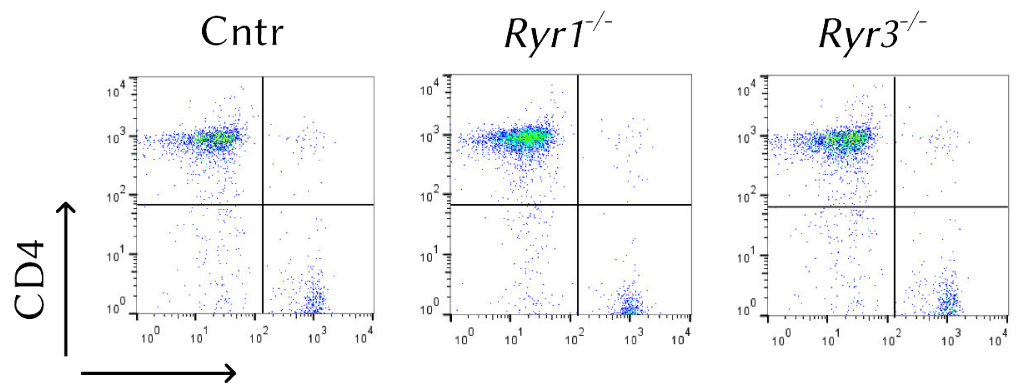

Ryr-DKO

CD8
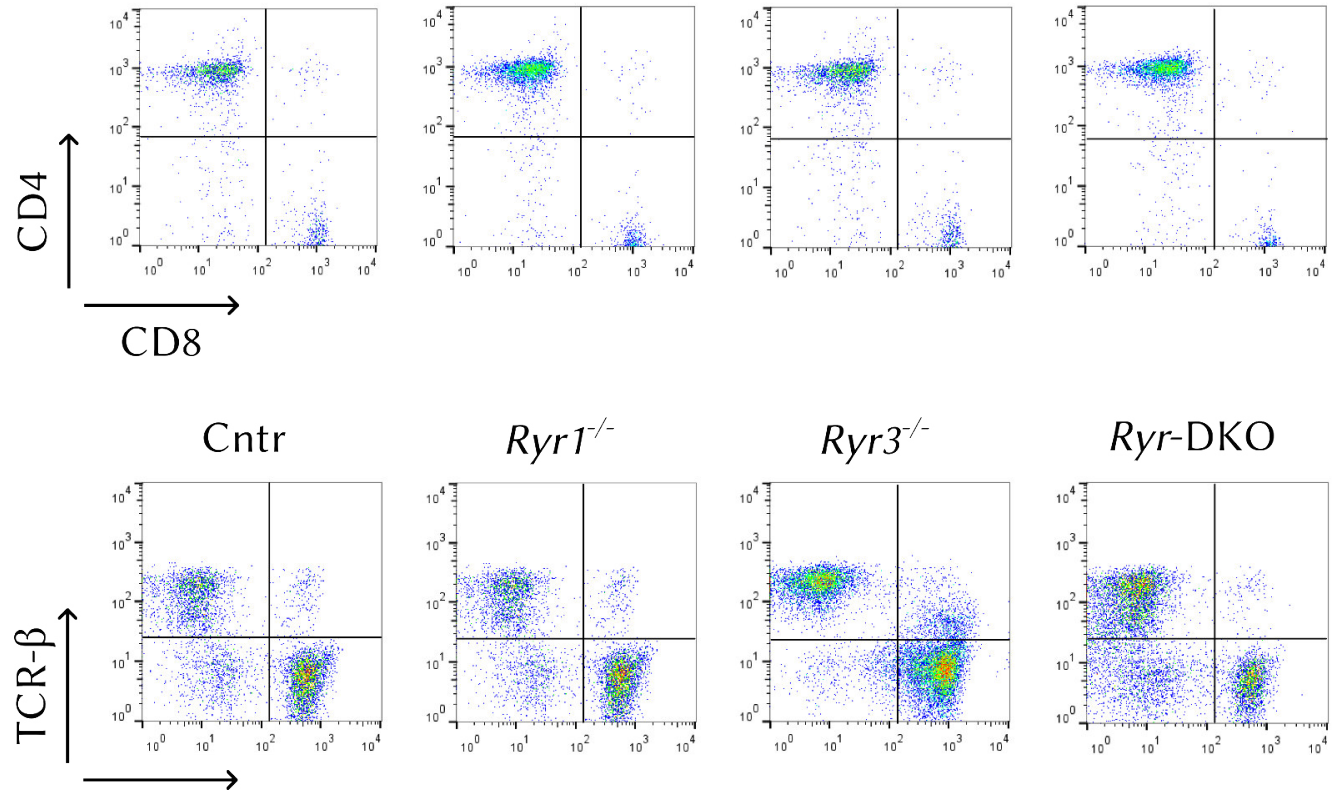

B220
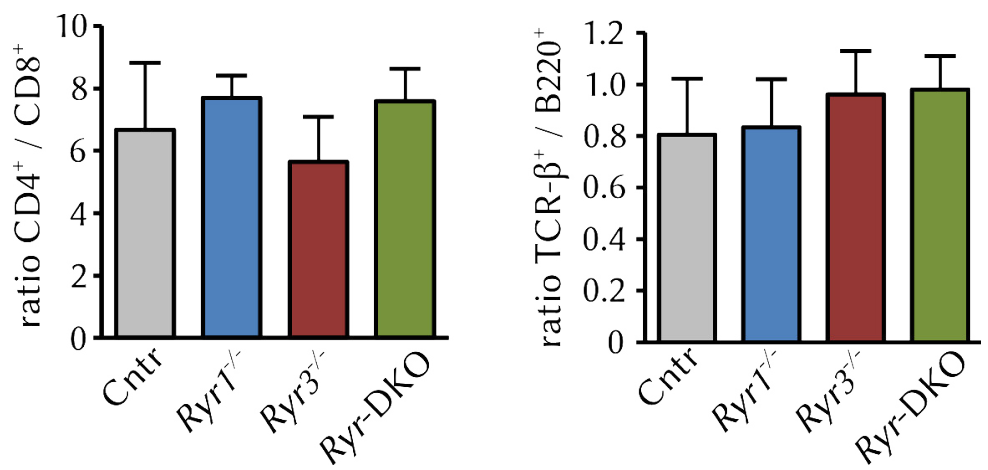

Fig. 3.7 | Ryr-KO FLCs are similar to control FLCs in the composition of the peripheral immune system. Analyzed were (A) spleen, (B) lymph nodes and (C) blood for the ratio of $\mathrm{CD} 4^{+}$to $\mathrm{CD} 8^{+}$cells, $\mathrm{T}$ to $\mathrm{B}$ cells (TCR- $\left.\beta / \mathrm{B} 220\right)$ and the ratio of effector to naïve $\mathrm{T}$ cells (CD44 / CD62L; only data for spleen). Single cell suspensions of the indicated organs were prepared if necessary, depleted for erythrocytes and stained for the respective surface markers for analysis in flow cytometry. To analyze transgenic cells only, cells were gated on the $\mathrm{RFP}^{+}$population. Depicted are representative flow cytometry data (upper panels) and the quantification from three individually performed experiments (lower panel; bars represent mean+SEM). 


\subsubsection{Ryr1 deficient T cells show diminished TCR dependent intracellular $\mathrm{Ca}^{2+}$ response}

T cells lacking Ryr1 were less responsive to NAADP stimulation, and showed diminished intracellular $\mathrm{Ca}^{2+}$ signals upon stimulation with anti-CD3 antibody conjugated beads (WOLF et al., 2015, manuscript in revision, and Fig. 3.8; Data kindly provided by Insa Wolf and Bjoern-Philip Diercks from the lab of Dr. A. Guse, UKE, Hamburg).

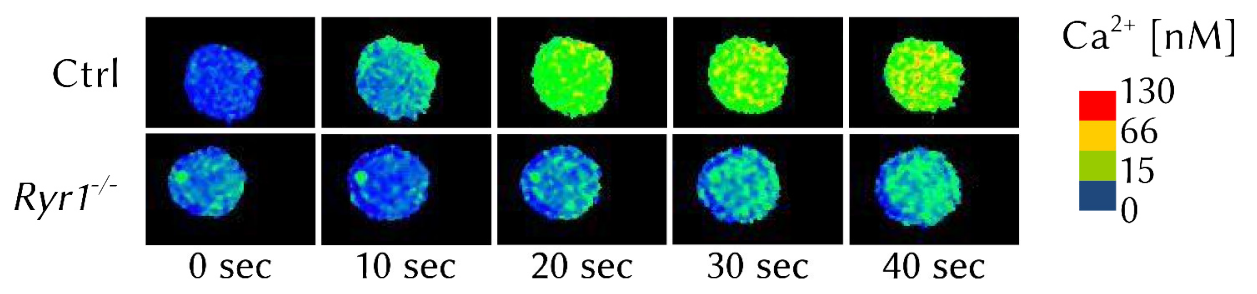

Fig. 3.8 | Ryr1 deficient T cells show diminished intracellular $\mathrm{Ca}^{2+}$ response upon TCR stimulation. $\mathrm{Ryr}^{-/-}$and control T cells were loaded with the membrane permeable $\mathrm{Ca}^{2+}$ dyes Fluo-4 and Fura-2 as described (chapter 2.8.1) and stimulated with anti-CD3 antibody conjugated beads.

\subsubsection{Ryr1 deficient lymphocytes proliferate less in response to anti- CD3 antibodies stimulation}

$\mathrm{Ca}^{2+}$ signals are an essential mechanism for $\mathrm{T}$ cell activation and prompt the proliferative $\mathrm{T}$ cell response. However, inhibition of $\mathrm{Ca}^{2+}$ signals, for example with BZ194, a NAADP antagonist, results in diminished $\mathrm{T}$ cell activation and proliferation (DAMMERMANN et al., 2009). We investigated if the proliferation of Ryr knockout lymphocytes in response to anti-CD3 stimulation was reduced compared to heterozygous control cells (Fig. 3.9). T lymphocytes from $\mathrm{Ryr}^{-1-} \rightarrow$ WT FLCs proliferated in a dose-dependent manner to antiCD3 stimulation, but significantly less in comparison to $R y r^{1^{+-}} \rightarrow$ WT FLC control cells (Fig. 3.9, A). The same was observed when cells were strongly stimulated with anti-CD3/anti-CD28 antibodies. In $R y r$-DKO $\rightarrow$ WT lymphocytes, the proliferative response was similarly reduced, but not more than in Ryr1 single KO cells. Obviously an additional knockout of Ryr3 had no further effect on proliferation (Fig. 3.9, B). This became clearer when the proliferation of lymphocytes from Ryr $^{-/} \rightarrow$ WT FLCs was analyzed (Fig. 3.9, C). Lymphocytes from Ryr $^{-} \rightarrow$ WT FLCs proliferated in a dose dependent manner to anti-CD3 antibody stimulation, but with no significant reduction to the control group. Cells from either control or chimeric mice proliferated substantially to stimulation with anti-CD3/anti-CD-28 antibodies and did not proliferate when left unstimulated. 
A

B
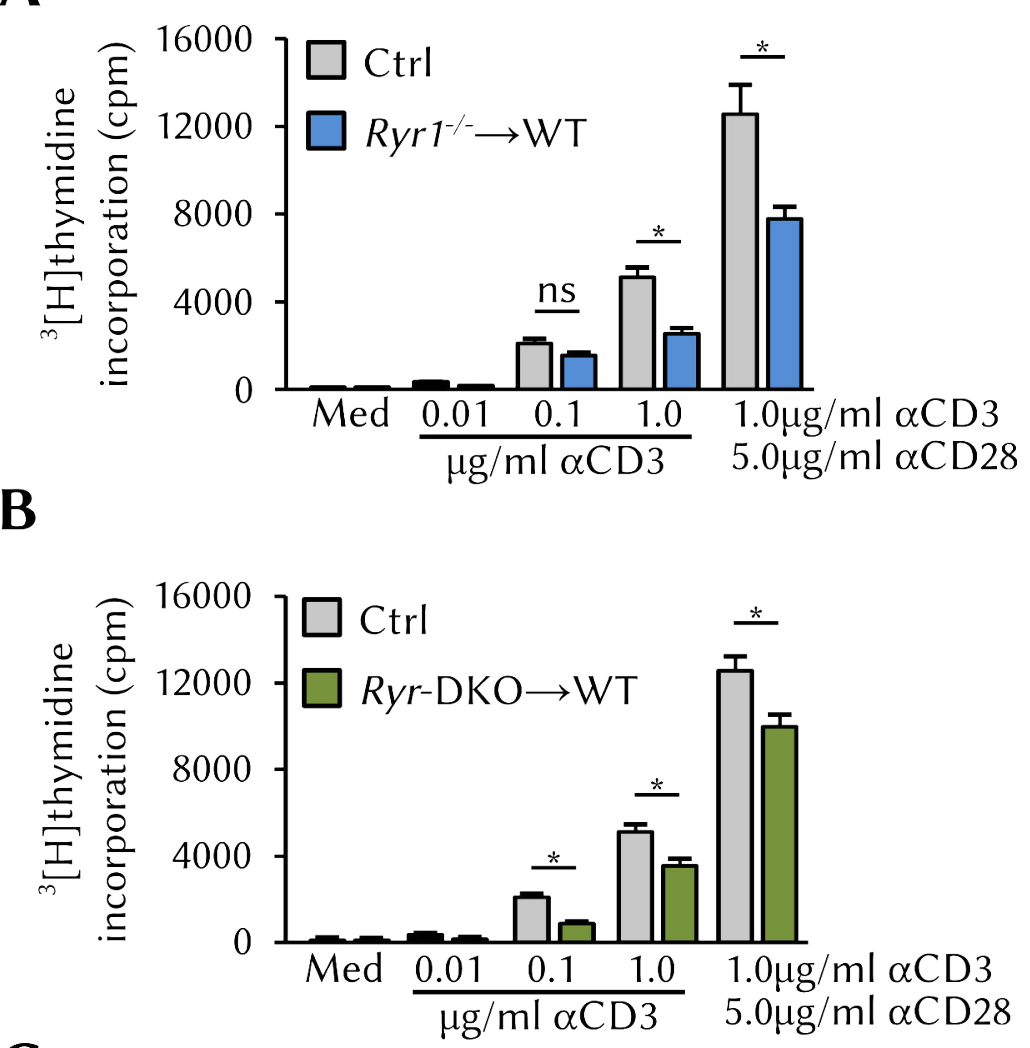

$\mathbf{C}$

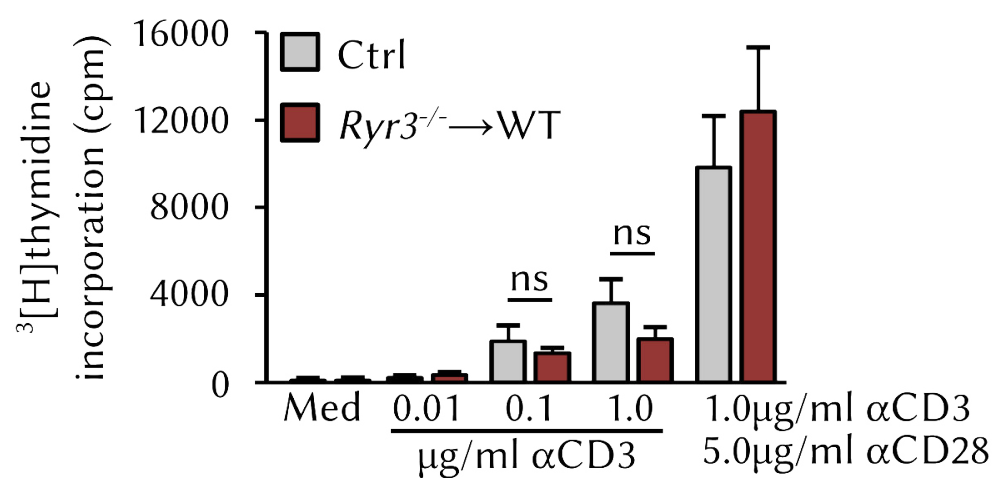

Fig. 3.9 | The knockout of Ryr1, but not of Ryr3 attenuates the proliferative response of T lymphocytes derived from $R y r T^{-/} \rightarrow \mathrm{WT}$ and $R y r-\mathrm{DKO} \rightarrow \mathrm{WT}$ FLCs in comparison to

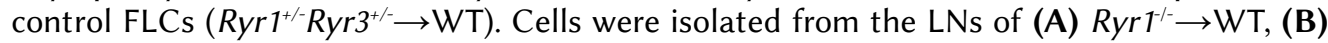
$R y r-\mathrm{DKO} \rightarrow \mathrm{WT}$, and $(\mathbf{C}) \mathrm{Ryr}^{-/} \rightarrow \mathrm{WT}$ FLCs. From single cell suspensions of LN cells, $3 \times 10^{5}$ cells per well were stimulated for $48 \mathrm{~h}$ with anti-CD3 and/or anti-CD28 antibodies in indicated concentrations before chasing with ${ }^{3}[\mathrm{H}]$ thymidine for another $16 \mathrm{~h}$ and measurement of ${ }^{3}[\mathrm{H}]$ thymidine incorporation. Medium (Med) served as negative control. Each condition was analyzed in triplicates. Bars represent the mean (+SEM) of three independent experiments. Statistical analysis was performed using a two-tailed Student's $t$ test $\left({ }^{*} P \leq 0.05\right)$. 


\subsubsection{EAE induction in $\mathrm{Ryr}^{-1-} \rightarrow$ WT FLCs}

To assess the role of RyR1 in EAE, Ryr $1^{-/} \rightarrow$ WT FLCs and respective control FLCs were immunized against $\mathrm{MOG}_{35-55}$ peptide (Fig. 3.10).

$\begin{aligned} \mathrm{A} & \rightarrow \mathrm{Ctrl} \rightarrow \mathrm{WT} \\ & +\mathrm{Ryrl}^{-} \rightarrow \mathrm{WT}\end{aligned}$

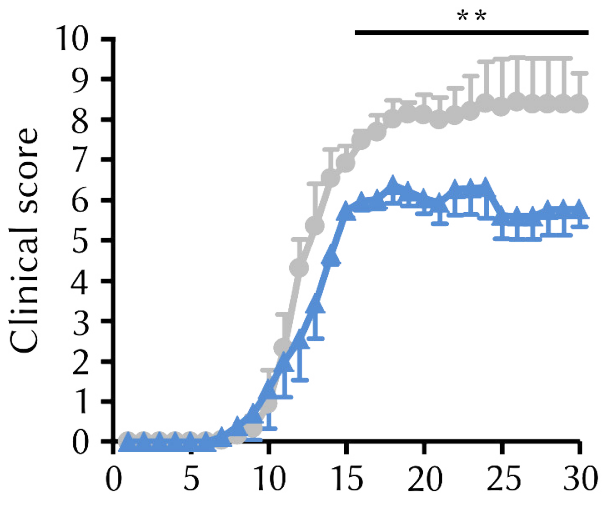

C

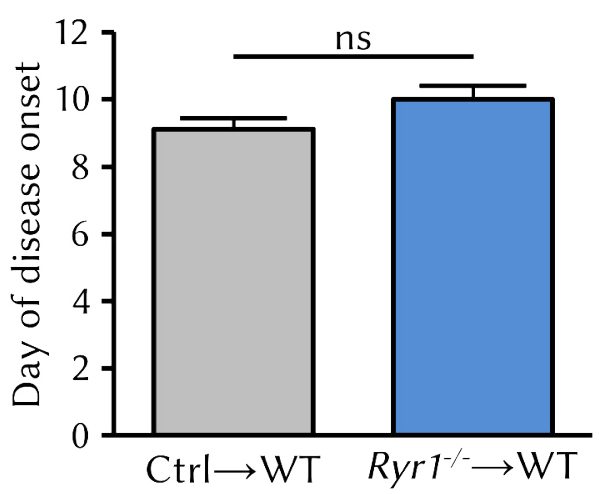

B
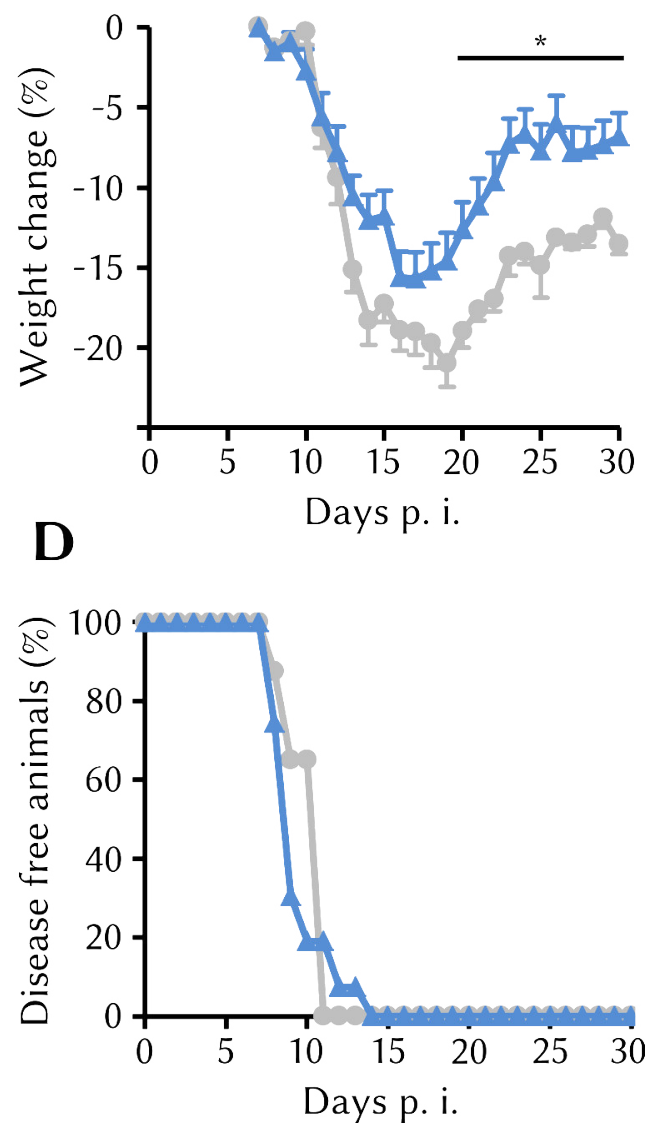

Fig. 3.10 $\mid R y r T^{1-} \rightarrow$ WT FLCs develop attenuated EAE. Control $(n=20)$ and $R y r T^{-1} \rightarrow$ WT $(n=20)$ FLCs were immunized against $M O_{35-55}$ peptide. (A) EAE disease course and (B) weight change course of $R y r 1^{-/} \rightarrow$ WT FLCs (blue line) and control FLCs $\left(R y r 1^{1^{+-}} R y r 3^{+/} \rightarrow\right.$ WT; grey line). In (C) the day of disease onset and in (D) the percentage of disease free animals are shown for each group. In all panels the mean (+SEM) of three independent experiments is shown. Data were tested for statistical significance using the Mann-Whitney $U$ test for clinical courses $\left(\mathbf{A}, \mathbf{B} ;{ }^{* *} P \leq 0.01 ;{ }^{*} P \leq 0.05\right)$ and a two-tailed Student's $t$-test $(\mathbf{C} ;$ ns $P \geq 0.05)$.

$\mathrm{Ryr}^{-1-} \rightarrow$ WT FLCs developed first clinical symptoms about one day later than control animals (Fig. 3.10, A, C and D). Also, the progress of the disease during the acute phase was slightly delayed in $R y r 1^{1-} \rightarrow$ WT FLCs and resulted in a milder disease at the peak than that of control FLCs. The chronic phase was characterized in both groups by persisting EAE symptoms that were, however, significantly less pronounced in Ryr $^{-1} \rightarrow$ WT FLCs (Fig. 
3.10, A). In concordance with the clinical scores, $R y r 1^{-/-} \rightarrow$ WT mice lost less weight during the course of EAE compared to control FLCs (Fig. 3.10, B). Therefore ablation of Ryr 1 in hematopoietic cells reduces the clinical severity of EAE.

\subsubsection{EAE induction in $R y r-D K O \rightarrow W T$ FLCs}

$R y r$-DKO $\rightarrow$ WT FLCs developed a disease onset and an acute phase that was similar to that of control animals (Fig. 3.11, A, C and D). This was in contrast to the EAE observed in $R y r 1^{-} \rightarrow$ WT FLCs. However, the peak and the EAE progress was attenuated in $R y r$-DKO $\rightarrow$ WT FLCs. Furthermore, some of the mice partially recovered from EAE symptoms, which was not observed in control animals or $R y r 1^{-1-} \rightarrow$ WT FLCs. Likewise in EAE of $R y r 1^{1-1}$ $\rightarrow$ WT FLCs, $R y r$-DKO $\rightarrow$ WT FLCs lost less weight than control FLCs (Fig. 3.11, B).

A $\quad-\mathrm{Ctrl} \rightarrow \mathrm{WT}$ $\mp R y r-\mathrm{DKO} \rightarrow \mathrm{WT}$
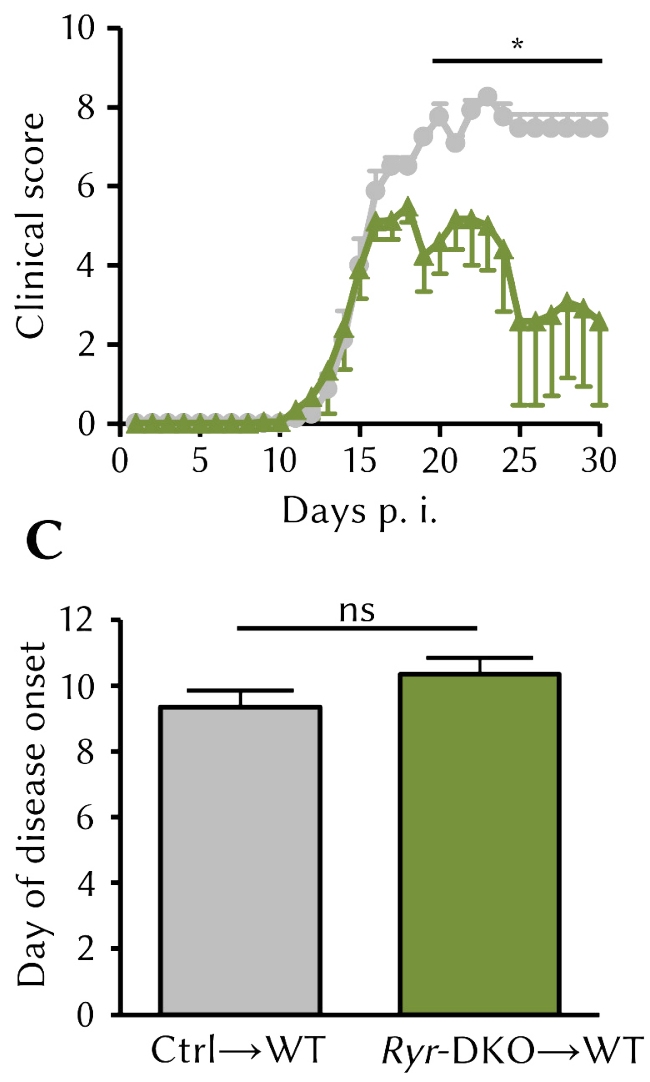

B
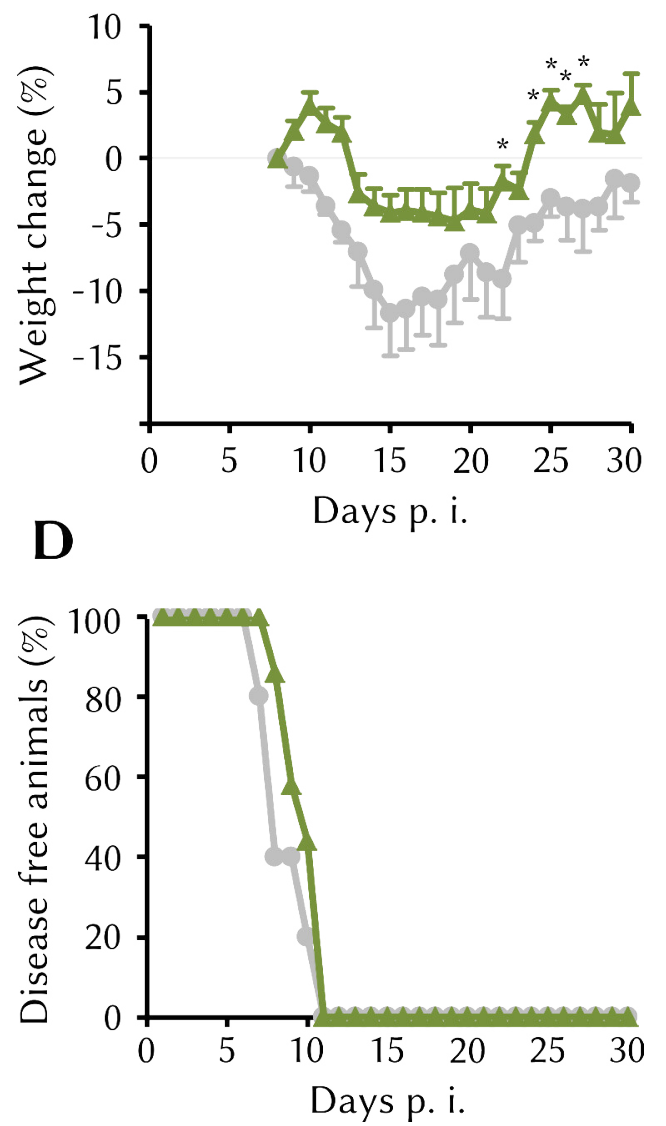

Fig. 3.11 $\mid$ Ryr-DKO $\rightarrow$ WT FLCs develop attenuated EAE. Control $(n=6)$ and $R y r$-DKO $\rightarrow$ WT $(n=7)$ FLCs were immunized against $M_{30 G}$ peptide. (A) EAE disease course, and (B) weight change course of $R y r-\mathrm{DKO} \rightarrow \mathrm{WT}$ FLCs (green line) and control FLCs $\left(R y \mathrm{r}^{+/-} \mathrm{Ryr}^{+{ }^{+-}}\right.$ 
$\rightarrow$ WT; grey line). (C) Day of disease onset and (D) percentage of disease free animals for each group. In all panels the mean (+SEM) of two independent experiments is shown. Statistics were carried out using the Mann-Whitney $U$ test for clinical courses $\left(A ;{ }^{*} P \leq 0.05\right)$ and a two-tailed Student's $t$-test $\left(\mathbf{B}, \mathbf{C} ;{ }^{*} P \leq 0.05\right)$.

We concluded that mice developed an attenuated course of EAE as far as Ryr1 was deleted in hematopoietic cells as a single knockout or as a double $\mathrm{KO}$ in combination with Ryr3.

\subsubsection{EAE induction in $R y r 3^{-1-} \rightarrow$ WT FLCs}

Our data on the expression of Ryr3 in T cells and proliferative response of Ryr3 deficient $\mathrm{T}$ cells are in agreement with previously published results (TAKESHIMA et al., 1996). Consistently, Ryr $3^{--} \rightarrow$ WT FLCs developed EAE on about the same day after immunization such as the control FLCs (Fig. 3.12, A, C and D). The onset and the acute phase of EAE proceeded similar in Ryr $^{-} \rightarrow$ WT and control FLCs and EAE symptoms peaked about that same day post immunization. In contrast to the amelioration noticed in $R y r^{-1}$ $\rightarrow$ WT FLCs in the chronic phase, the disease progress was rather similar between Ryr $^{-} \rightarrow$ WT FLCs and control FLCs. Even though EAE progressed by tendency slightly milder in $R y r 3^{-/} \rightarrow$ WT FLCs, the difference did not reach statistically significance levels, whereas weight loss of $R y r 3^{-/} \rightarrow$ WT FLCs was significantly less severe compared to control mice (Fig. 3.12, B). However, these results showed that deletion of Ryr3 in hematopoietic cells had only minor influence on the clinical course of EAE. 
A $\quad-\mathrm{Ctrl} \rightarrow \mathrm{WT}$

$\pm \mathrm{Ryr3}^{-/-} \rightarrow \mathrm{WT}$

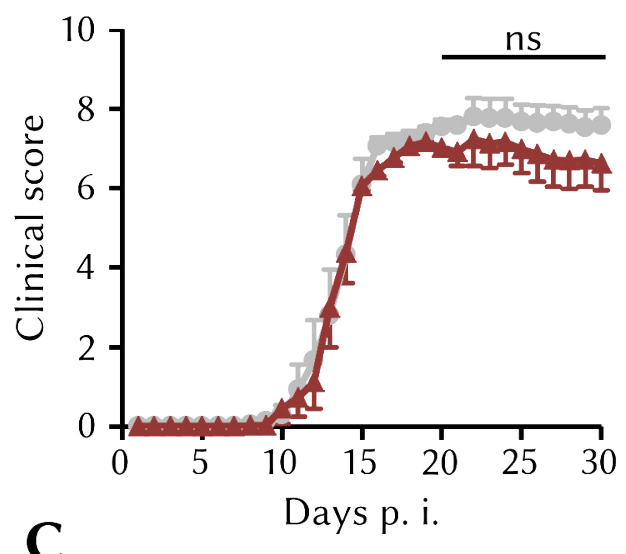

C

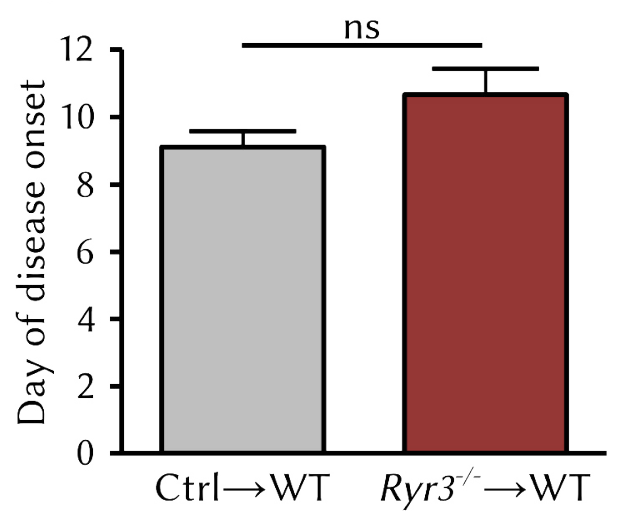

B
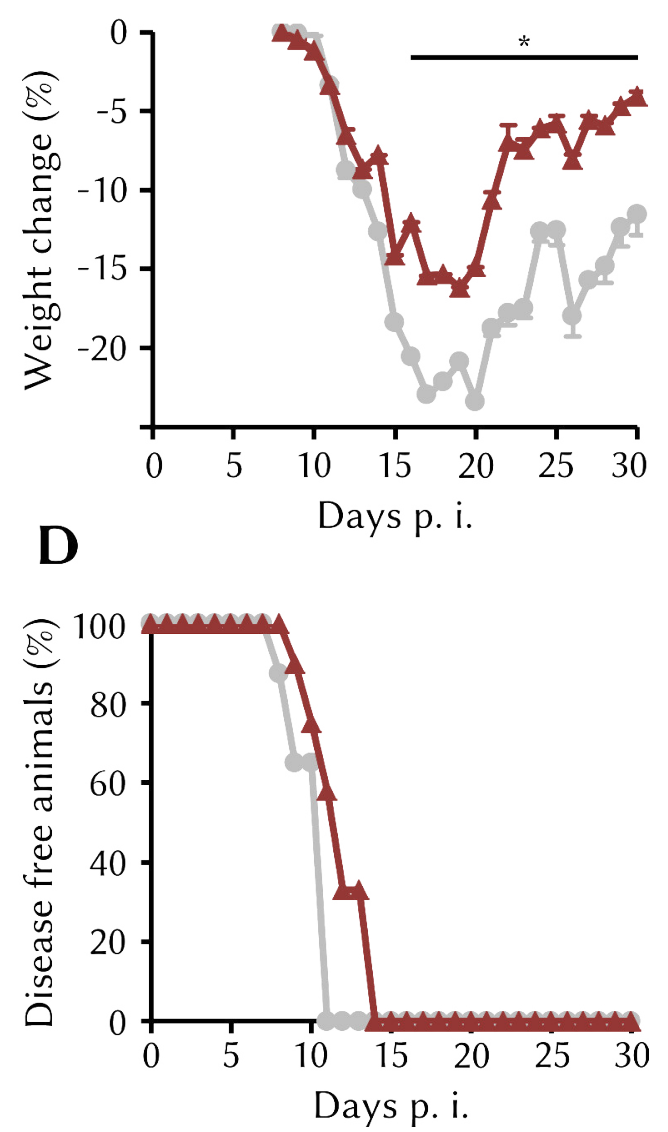

Fig. 3.12 $\mid R y r^{3 /-} \rightarrow$ WT FLCs do not develop EAE different from that of control FLCs. Control ( $n=15)$ and $\mathrm{Ryr}^{-1-} \rightarrow \mathrm{WT}(n=18)$ FLCs were immunized against $\mathrm{MOG}_{35-55}$ peptide. (A) EAE disease course, and (B) weight change course of $R y r 3^{-1-} \rightarrow$ WT FLCs (red line) and control FLCs $\left(R y r 1^{+-} R y r 3^{+/} \rightarrow \mathrm{WT}\right.$; grey line). In (C) the day of disease onset and (D) the percentage of disease free animals are shown for each group. In all panels the mean (+SEM) from three independent experiments is shown. Groups were statistically tested using the Mann-Whitney $U$ test for clinical courses $\left(\mathbf{A}, \mathbf{B} ;{ }^{*} P \leq 0.05\right.$, ns $\left.P \geq 0.05\right)$ and a two-tailed Student's $t$-test $(\mathbf{C}$; ns $P \geq 0.05)$.

\subsubsection{Characterization of Ryr-KO T cells at the onset of EAE}

In order to further investigate the impact of Ryr deletion on EAE pathogenesis, the status of infiltrating $\mathrm{T}$ cells in the CNS was analyzed in Ryr $1^{-1} \rightarrow$ WT FLCs, Ryr-DKO $\rightarrow$ WT FLCs and control FLCs at d14 p. i. (Fig. 3.13). To characterize their activation status, $T$ cells were stained for the surface markers CD25 and CD69. It was found that T cells in the CNS from Ryr $^{-} \longrightarrow$ WT FLCs were less activated than those from control FLCs. 


\section{Results}
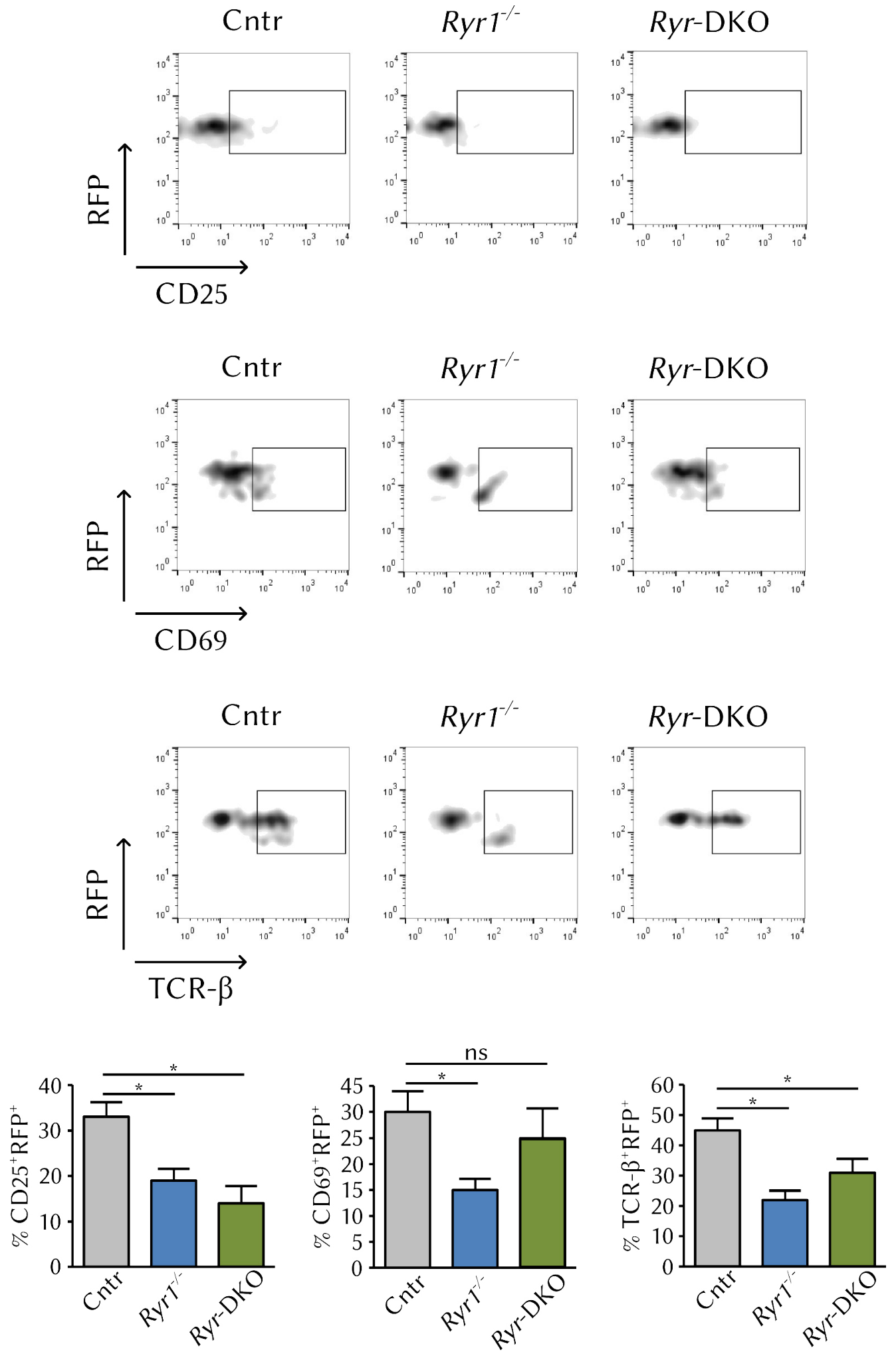

Fig. 3.13 Encephalitogenic T cells from $R y r 1^{-1-}$ and $R y r$-DKO FLCs express lower amount of the activation markers CD69 and CD25 and infiltrate less frequently into the CNS than T cells from control FLCs $\left(R y r 1^{+/} R y r 3^{+/} \rightarrow \mathrm{WT}\right)$. Animals were sacrificed on d14 p. i. to recover T cells during the acute phase of EAE. Lymphocytes were isolated from the CNS 
using Percoll density centrifugation. Single cell suspensions were then stained for flow cytometry. To analyze only transgenic T cells, cells were gated on the CD4 ${ }^{+} \mathrm{RFP}^{+}$population. Depicted are representative flow cytometry data (upper panels) and the quantification from three individually performed experiments (lower panel; bars represent mean+SEM). Statistical analysis was performed using a two-tailed Student's $t$-test ( ${ }^{*} P \leq 0.05$, ns $P \geq 0.05$ ).

\subsection{The function of RyR3 in the CNS during EAE}

The previous results indicated that a knockout of Ryr3 in hematopoietic cells has no major effect on the clinical progression of EAE thus far as it was observed for $R y r^{-/}$. Accordingly, the $\mathrm{T}$ cell function was not severely affected by Ryr3 deletion. However, in contrast to the rather low expression levels in T cells, Ryr3 mRNA was found highly expressed in the brain and in the spinal cord of WT C57Bl/6 mice (Fig. 3.14).

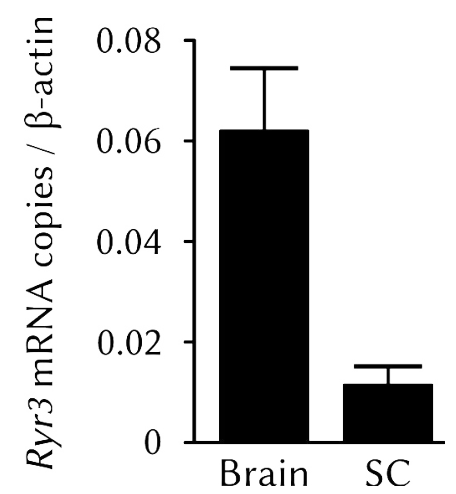

Fig. 3.14 $\mid$ Ryr3 mRNA is highly expressed in the CNS. Homogenates from total brain $(n=3)$ and spinal cord (SC; $n=3$ ) were used for mRNA isolation and real-time PCR analysis.

\subsubsection{EAE induction in $\mathrm{WT} \rightarrow R y r 3^{-/-}$bone marrow chimeras}

In order to further investigate the role of RyR3 in the CNS during EAE in $R y r 3^{-/}$mice, bone marrow chimeras (BMCs) were generated by transferring bone marrow cells from CD45.1 WT mice into lethally irradiated Ryr $3^{-1-}$ animals, which were congenic CD45.2. CD45.1 $\rightarrow$ Ryr $3^{+/-}$BMCs served as control animals. In contrast to $R y r 3^{--} \rightarrow$ WT FLCs, these mice now exhibit the knockout of Ryr3 in the CNS (and other tissues), while hematopoietic cells remain WT for RyR3. After successful reconstitution, EAE was induced by immunization against $\mathrm{MOG}_{35-55}$ peptide (Fig. 3.15). No obvious differences between CD45.1 $\rightarrow$ Ryr $3^{-/}$and control animals were observed during the onset and early clinical phase of EAE (Fig. 3.15 A, C and D). However 14-15 days 
after immunization in the EAE continued to progress in control $\mathrm{CD} 45.1 \rightarrow$ Ryr3 $^{+-}$BMCs but not in Ryr3 KO recipients. (Fig. 3.15 A). In concordance with the clinical scores, CD45.1 $\rightarrow$ Ryr $3^{-/}$BMCs lost less weight during the course of EAE compared to control BMCs (Fig. 3.15, B). Therefore, deficiency of RyR3 in the CNS-contrary to T cells or other hematopoietic cells-was determining EAE severity.
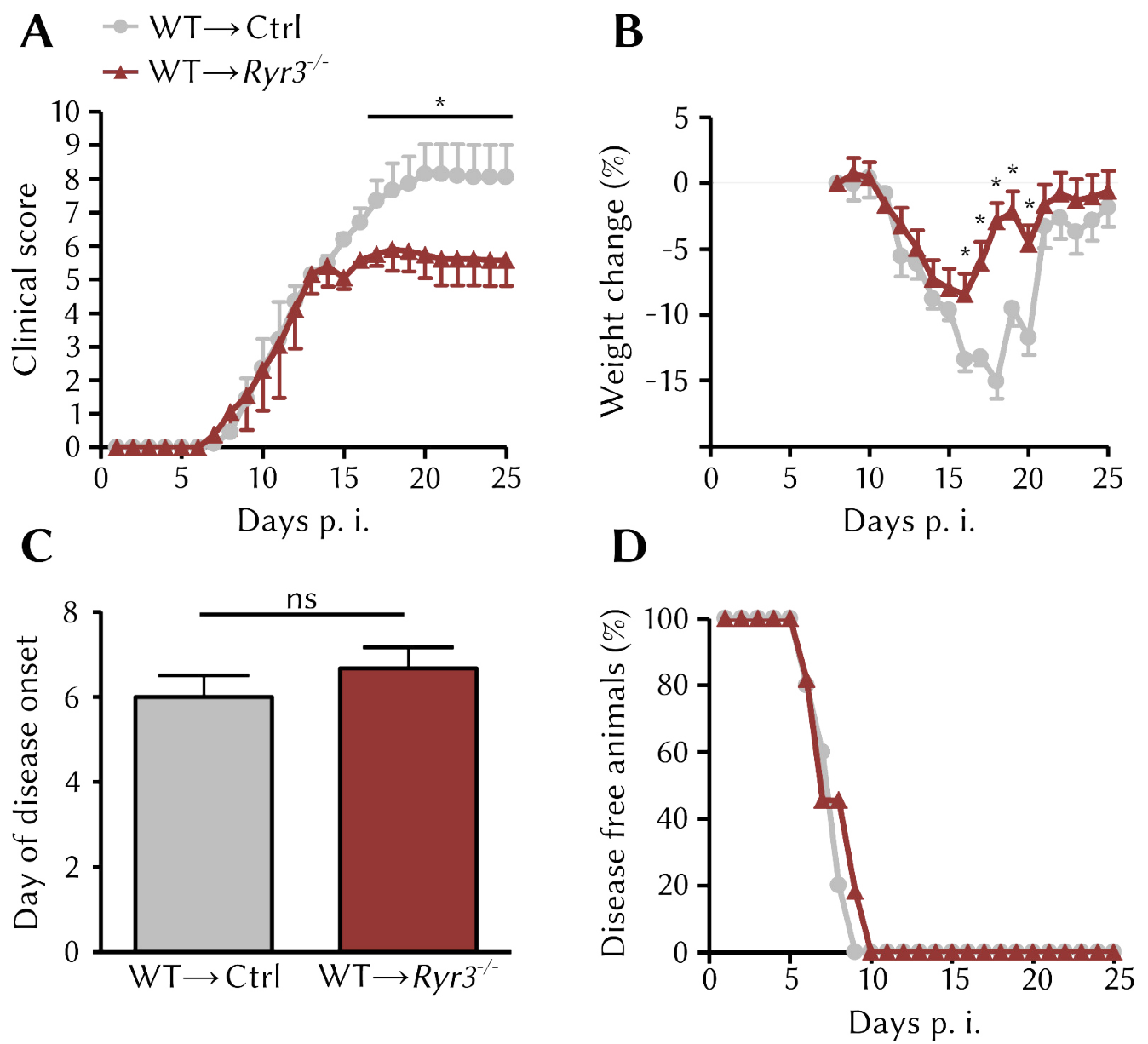

Fig. 3.15 Ryr3 deficiency in non-hematopoietic cells attenuates EAE severity. Control $(n=15)$ and $\mathrm{WT} \rightarrow R y r 3^{-/}(n=15)$ BMCs were immunized against $\mathrm{MOG}_{35-55}$ peptide. (A) EAE disease course, and (B) weight change course of WT $\rightarrow$ Ryr $3^{--}$BMCs (red line) and control FLCs (grey line). (C) Day of disease onset. (D) Percentage of disease free animals. In all panels the mean (+SEM) of three independent experiments is shown. Statistics were carried out using the Mann-Whitney $U$ test for clinical courses $\left(A,{ }^{*} P \leq 0.05\right)$ and a two-tailed Student's $t$-test $\left(\mathbf{B}, \mathbf{C} ;{ }^{*} P \leq 0.05\right.$, ns $\left.P \geq 0.05\right)$. 


\subsubsection{Active EAE in $\mathrm{Ryr}^{-/-}$mice}

For the further experiments, mice with a germline knockout of Ryr3 were used. In contrast to Ryr1 knockout animals, mice homozygous for Ryr3 deletion were healthy and fertile-though hyperlocomotion and impaired learning and memory were reported (TAKESHIMA et al., 1996, KOUZO et al., 1999). In these mice, EAE could be effectively induced by immunization against $\mathrm{MOG}_{35-55}$ peptide (Fig. 3.16). No difference in disease incidence was found between control $\left(R y r 3^{+-}\right)$and $R y r 3^{--}$mice (Fig. 3.16 A, C and D). Both groups developed EAE at day 9-10 after immunization and shared a similar early clinical phase of EAE (Fig. 3.16 A and C). However, the peak of EAE was reached 3-4 days earlier in Ryr3 ${ }^{-/}$animals and presented significantly lower clinical scores (Fig. 3.16 A). While control animals developed EAE as expected (MENDEL et al., 1995), clinical symptoms of $R y r^{-/-}$mice significantly improved during the chronic phase of EAE.

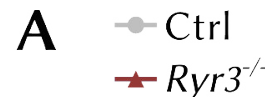
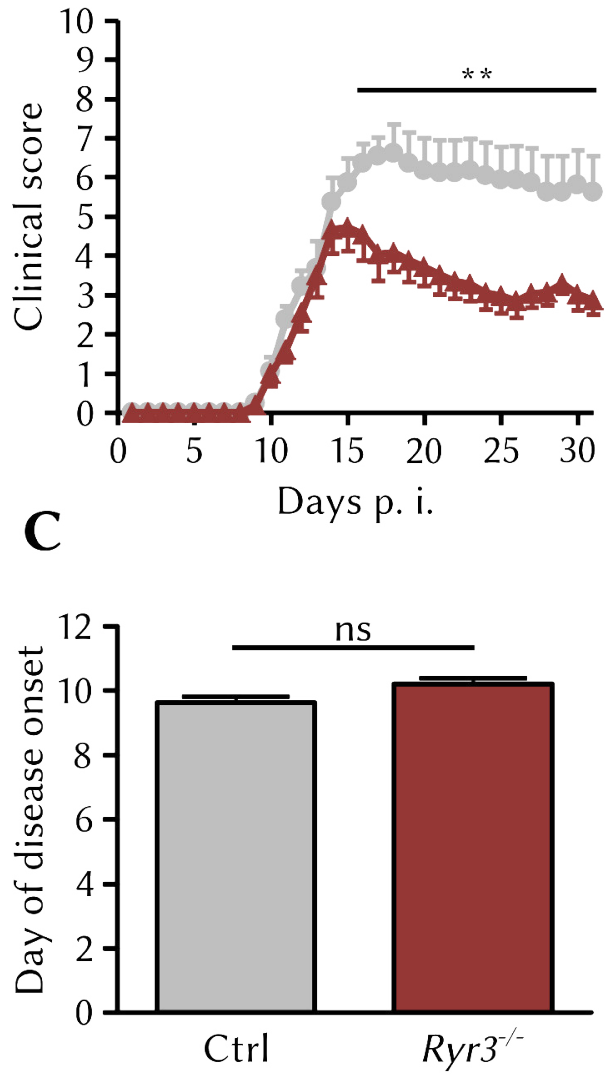

B
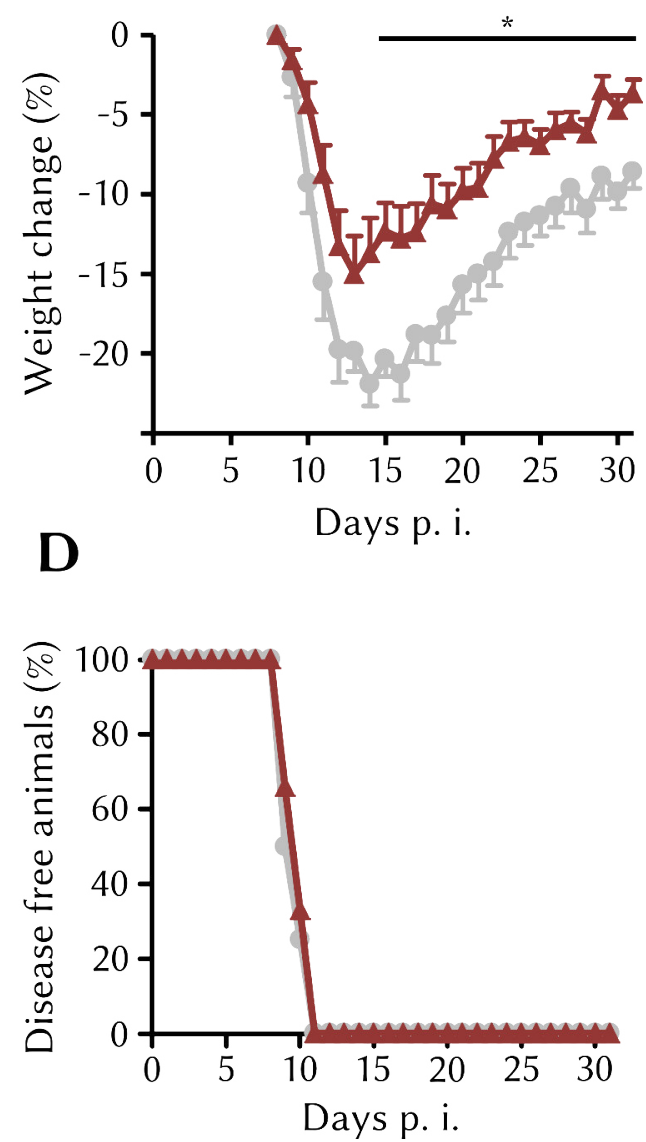

Fig. 3.16 $\mid$ Ryr3 $^{-/-}$mice develop attenuated EAE. Control $(n=20)$ and $R y r 3^{-/-}$mice $(n=20)$ were immunized against $\mathrm{MOG}_{35-55}$ peptide. (A) EAE disease course, and (B) weight change course of $R y r 3^{---}$(red line) and control mice (grey line). (C) Day of EAE onset. (D) Percentage of disease free animals. In all panels the mean (+SEM) of three independent experiments is shown. Statistics were carried out using the Mann-Whitney $U$ test for clinical courses (A, $\left.\mathbf{B} ;{ }^{* *} P \leq 0.01 ;{ }^{*} P \leq 0.05\right)$ and a two-tailed Student's $t$-test $(\mathbf{C} ;$ ns $P \geq 0.05)$. 


\section{Results}

\subsubsection{Histology of Ryr $3^{-/}$EAE animals}

Demyelination and axonal degeneration in the spinal cord are the main histopathological features of EAE that result from infiltration of encephalitogenic $\mathrm{T}$ cells and recruited macrophages. In order to characterize the pathology of EAE in $R y r 3^{-/}$mice, animals were analyzed at day 17 post immunization, when mice of the control group were at the peak of the disease. Fixed spinal cord tissue was used for preparation of paraffin sections and further analyzed by IHC for the frequency of infiltrating T cells, macrophages and activated microglia.

To determine the quantity of infiltrating $\mathrm{T}$ cells, tissue sections were stained for $\mathrm{CD}^{+} \mathrm{T}$ cells (Fig. 3.17, A). It was found that the number of $\mathrm{T}$ cells in spinal cord sections of $R y r 3^{-/}$mice was significantly reduced compared to controls. A highly significant reduction in cell infiltrates was found when spinal cord sections were stained for the number of recruited MAC3+ macrophages (Fig. 3.17, B).

A
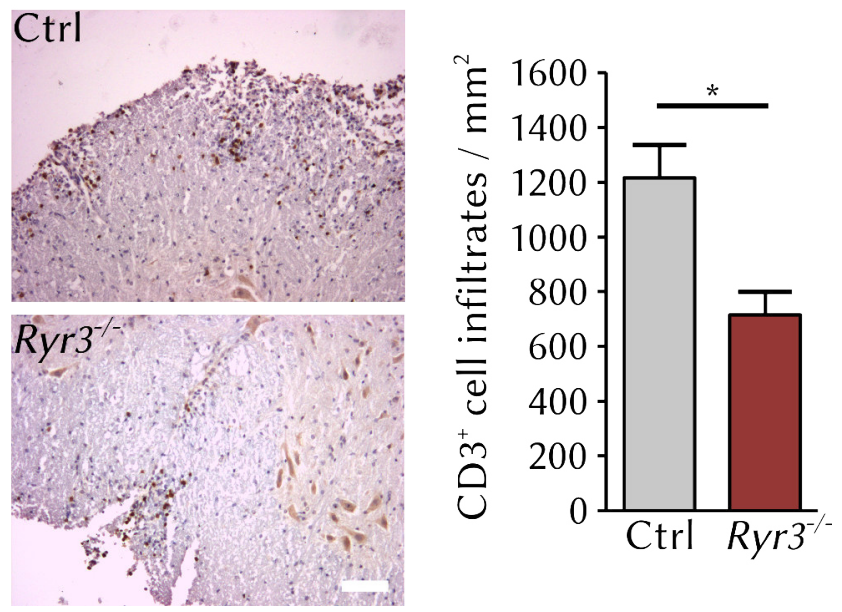

B
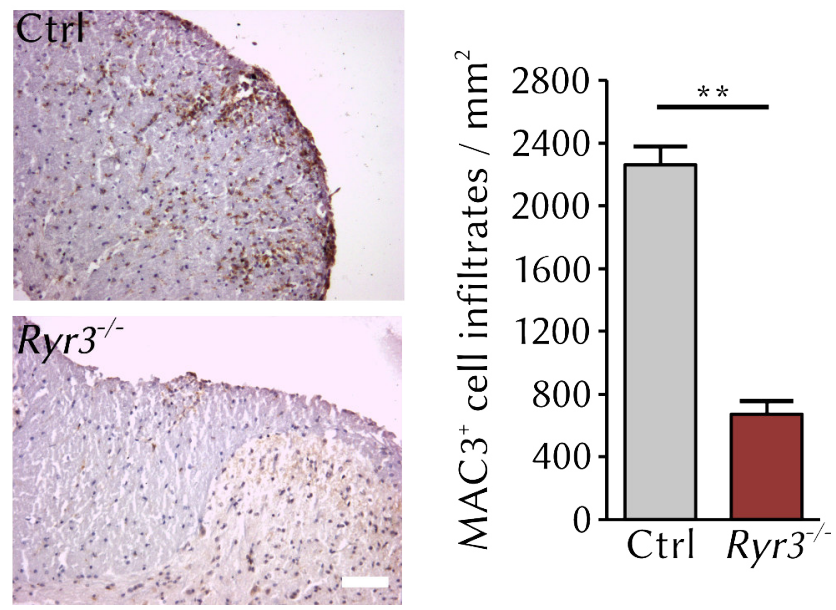
Fig. 3.17 | Less immune cells infiltrate the spinal cords of $R y r 3^{-/-}$mice at the peak of EAE. Control $(n=4)$ and $\operatorname{Ryr}^{-/}(n=4)$ mice were immunized against $\mathrm{MOG}_{35-55}$. Spinal cords were isolated at the peak of EAE (d17 p. i.) and used for paraffin sections. Antibody stainings were performed for (A) CD3 (T cells) and (B) MAC3 (macrophages) and counterstained with Mayer's hemalum solution to visualize cell nuclei. For the statistical analysis, at least five sections from the cervical, thoraic and lumbar segment were investigated for each spinal cord. Bars represent mean $(+S E M)$. Data were statistically tested using a two-tailed Student's $t$-test $\left({ }^{* *} P \leq 0.01,{ }^{*} P \leq 0.05\right)$. Representative images are shown from animals with a clinical score of 6.0 (control) and $3.5\left(\right.$ Ryr $\left.^{-/}\right)$.

Microglia are CNS resident immune cells of hematopoietic origin that permanently scan tissue for damage or infections. During inflammation microglia cells accumulate at the pathological site and can act as antigenpresenting cells for $\mathrm{T}$ helper cells. As they are potent producers of proinflammatory cytokines, they highly contribute to neuroinflammation. Upon activation, microglia change their morphology from a ramified to a roundish shape and strongly up-regulate Iba1 expression, Significantly less Iba1 ${ }^{+}$ microglia/activated macrophages were counted in spinal cord sections of Ryr $3^{--}$mice compared to controls (Fig. 3.18). It was also observed that microglia were distributed more even in spinal cords from $R y r 3^{-/}$mice but accumulated dense at inflammatory sites in control animals.
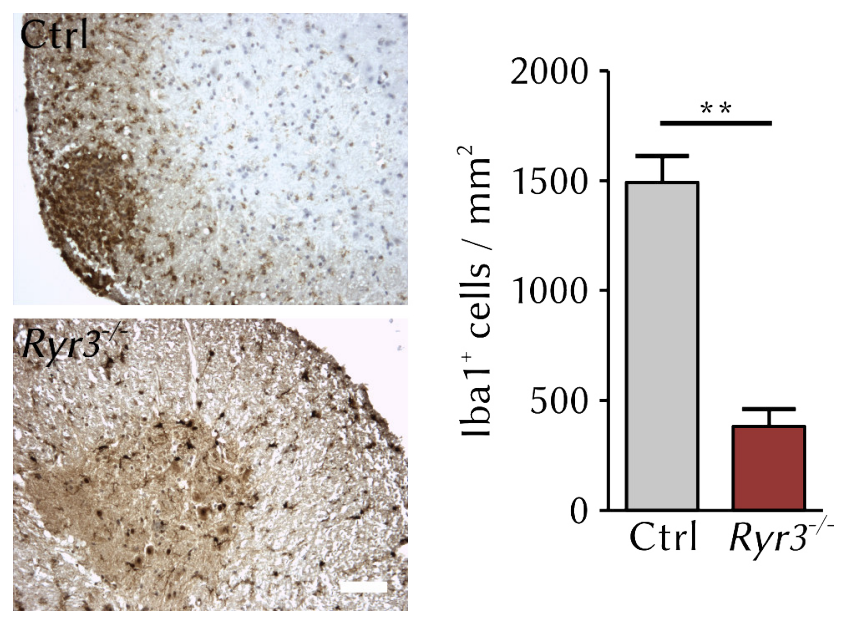

Fig. 3.18 | Less microglia co-localize at inflammatory sites in spinal cords of $\mathrm{Ryr}^{-/}$mice at the peak of EAE. Control $(n=4)$ and $R_{y r 3^{--}}(n=4)$ mice were immunized against $\mathrm{MOG}_{35-55}$. Spinal cords were isolated at the peak of EAE (d17 p. i.) and used for paraffin sections. Antibody stainings were performed for microglia marker Iba1 and counterstained with Mayer's hemalum solution to visualize cell nuclei. For the statistical analysis, at least five sections from the cervical, thoraic and lumbar segment were investigated for each spinal cord. Bars represent mean $(+S E M)$. Data were statistically tested using a two-tailed Student's $t$-test $\left({ }^{* *} P \leq 0.01\right)$. Representative images are shown from animals with a clinical score of 6.0 (control) and $3.5\left(\right.$ Ryr3 $\left.^{-/}\right)$. 
Autoimmune inflammation of the CNS results in demyelination and axonal degradation. The extent of demyelination was assessed at the peak of EAE by Luxol fast blue-Periodic acid-Schiff stain (LFB-PAS; Fig. 3.19, A), while axon degradation was investigated by means of Bielschowsky's silver stain (BSS) in the chronic phase of EAE, 30 days after immunization (Fig. 3.19, B). Spinal cord sections of $R y r 3^{-/}$mice showed a significant reduction in demyelination and axonal pathology.

A
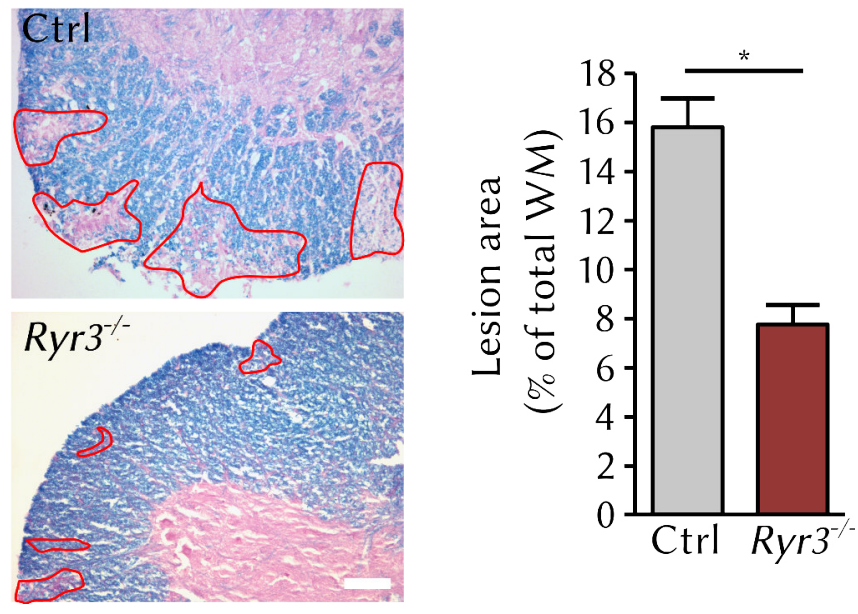

B
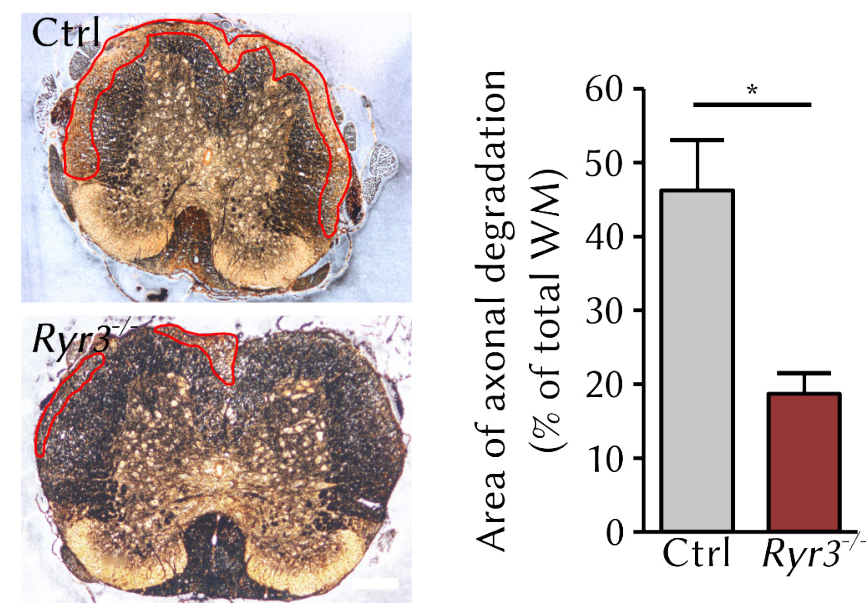

Fig. 3.19 | Demyelination and axonal loss are significantly reduced in $R y r 3^{-/}$mice. Control $(n=4)$ and Ryr3-/- $(n=4)$ mice were immunized against $\mathrm{MOG}_{35}{ }^{-55}$ peptide. (A) Spinal cords were isolated at the peak of EAE (d17 p. i.) and used for paraffin sections. To evaluate the amount of demyelination, slides were stained with LFB solution to detect myelin, combined with a PAS reaction to visualize exposed glycoproteins in the demyelinated regions. The percentage of demyelination was calculated for the area of the white matter. (B) Spinal cords were isolated at $\mathrm{d} 30 \mathrm{p}$. i. for detection of axonal degradation by means of Bielschowsky's silver stain that gives nerve fibers a dark color. The percentage of axonal loss was calculated for the area of the white matter. For the statistical analysis, at least five 
sections from the cervical, thoracic and lumbar segment were investigated for each spinal cord. Bars represent mean $(+S E M)$. Data were statistically tested using a two-tailed Student's $t$-test $\left({ }^{* *} P \leq 0.01,{ }^{*} P \leq 0.05\right)$. Representative images are shown from animals with a clinical score of 6.0 (control) and $3.5\left(\right.$ Ryr $\left.^{-/-}\right)$in $(\mathbf{A})$, and a clinical score of 5.0 (control) and $3.0\left(R_{\left.y r 3^{-/}\right)}\right)$in $(\mathbf{B})$.

\subsubsection{Spontaneous EAE in $\mathrm{Ryr}^{-/} \times 2 \mathrm{D} 2 \times \operatorname{IgH}^{\mathrm{MOG}}$ mice}

Induction of EAE is generally performed by active immunization of mice against myelin antigens, e. g. $\mathrm{MOG}_{35-55}$ applied in strong immune adjuvants, or by the injection of pre-activated myelin specific T lymphocytes. Yet, it has been reported that mice that were generated by crossing MOG-specific T cell receptor transgenic 2D2 $\left(\mathrm{TCR}^{\mathrm{MOG}}\right)$ mice with $\mathrm{IgH}^{\mathrm{MOG}}$ mice (harbouring MOGspecific B cells) develop EAE spontaneously (BETELLI et al., 2006, KRISHNAMOORTHY 2006). To investigate how deletion of Ryr3 influences the course of spontaneous EAE (spEAE), Ryr $3^{-1} \times 2 \mathrm{D} 2$ mice were crossed with $\mathrm{IgH}^{\mathrm{MOG}}$ mice and followed several months for the occurrence of EAE symptoms (Fig. 3.20). As in the previous experiments, Ryr $3^{+/-}$littermates served as control animals.

Ryr3 ${ }^{-/}$developed spEAE about 80 days after birth, whereas control animals developed first clinical symptoms already with an average age of 48 days (Fig. 3.20, B). From the group of $R y r 3^{-/}$animals $40 \%$ developed no disease at all, while only $20 \%$ of control animals remained without clinical symptoms at the end of the observation period (Fig. 3.20, C). Compared to control animals, Ryr $3^{-/}$mice developed less severe EAE symptoms (Fig. 3.20, A). Similar to the EAE induced by active immunization, Ryr $3^{-/}$and control animals showed an identical clinical course of EAE during disease onset, but differed at the peak and in the chronic phase of the disease. While control animals developed disease with full paralysis of the hind limbs, gang ataxia was the most severe symptom in Ryr3 deficient animals. 


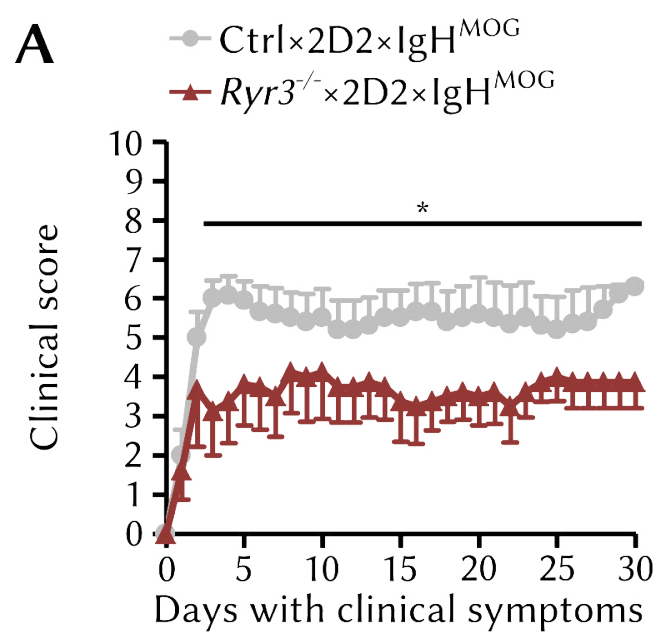

B

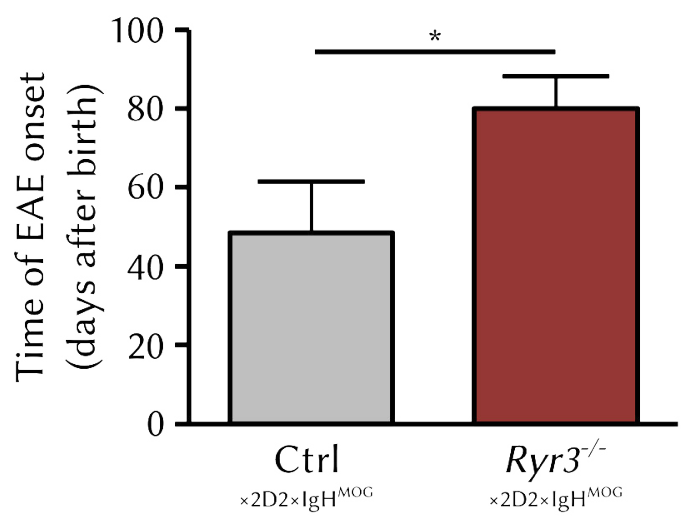

C

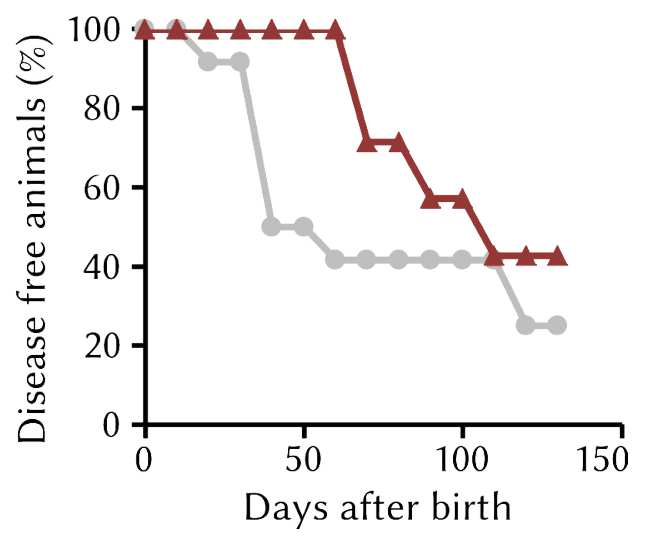

Fig. 3.20 Spontaneous EAE in Ryr3 deficient mice. Control $(n=5)$ and $R y r 3^{--}$mice $(n=5)$ were monitored daily for the (spontaneous) development of EAE symptoms. (A) EAE disease course of $\mathrm{Ryr}^{-1-} \times 2 \mathrm{D} 2 \times \lg \mathrm{H}^{\mathrm{MOG}}$ (red line) and control mice (grey line). (B) Day of onset of each group. (C) Percentage of disease free animals. In all panels the mean (+SEM) of three independent experiments is shown. Statistics were carried out using the Mann-Whitney $U$ test for clinical courses $\left(\mathbf{A},{ }^{*} P \leq 0.05\right)$ and a two-tailed Student's $t$-test $\left(\mathbf{B} ;{ }^{*} P \leq 0.05\right)$.

\subsubsection{Histology of $\mathrm{Ryr}^{--} \times 2 \mathrm{D} 2 \times \mathrm{IgH}^{\mathrm{MOG}} \mathrm{EAE}$ animals}

Spinal cord sections of $\mathrm{Ryr}^{--} \times 2 \mathrm{D} 2 \times \operatorname{Ig} \mathrm{H}^{\mathrm{MOG}} \mathrm{EAE}$ mice were prepared at the end of the observation period (Fig. 3.21). No remaining immune cell infiltrates-either positive for CD3 or MAC3-were found in spinal cord, neither in control nor in $R y r 3^{--}$mice at this time point of EAE (not shown). Yet, demyelination was significantly reduced in $R y r 3^{--\alpha}$ mice, as well as the intensity of axonal degradation. 
A
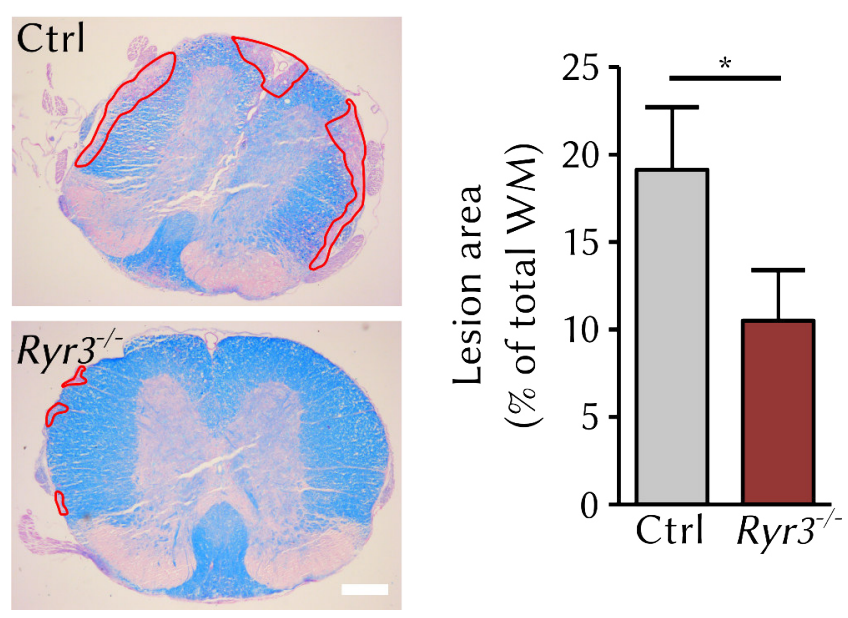

B
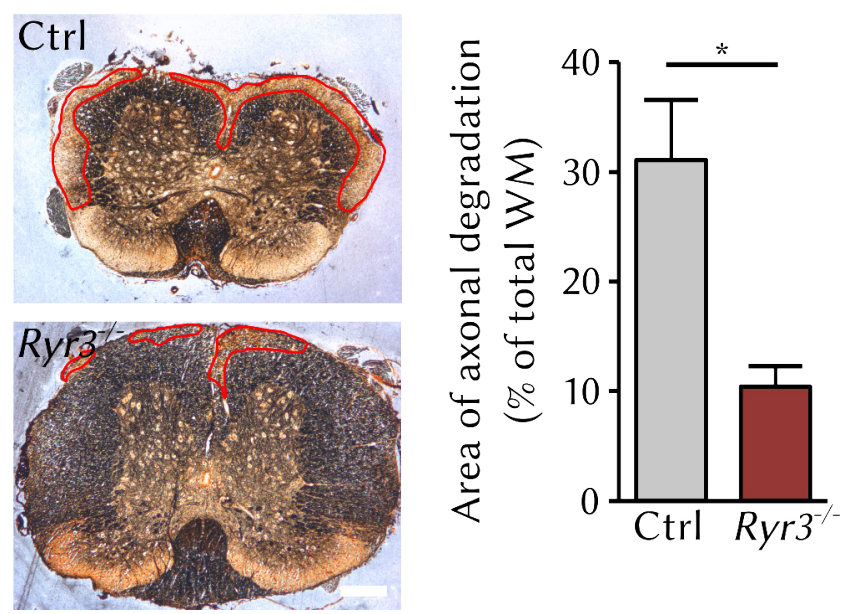

Fig. 3.21 Demyelination and axonal loss are reduced in $R y r^{-1-} \times 2 \mathrm{D} 2 \times \lg \mathrm{H}^{\mathrm{MOG}}$ mice. Spinal cords ( $n=4$ for each group) were isolated at the end of the observation period (d30 after spEAE onset) and used for paraffin sections. (A) shows the evaluation of demyelination. Samples were stained with luxol fast blue solution to detect myelin, combined with a periodic acid-Schiff reaction to visualize exposed glycoproteins in the deymelinated regions. The percentage of demyelination was calculated for the area of the white matter. (B) shows the evaluation of axonal degradation by means of Bielschowsky's silver stain. The percentage of axonal loss was calculated for the area of the white matter. For the statistical analysis, at least five sections from the cervical, thoraic and lumbar segment were investigated for each spinal cord. Bars represent mean (+SEM). Data were statistically tested using a two-tailed Student's $t$-test $\left({ }^{*} P \leq 0.05\right)$. Representative images are shown from animals with a clinical score of 6.0 (control) and $3.0\left(\right.$ Ryr $\left.^{-/}\right)$.

\subsubsection{Analysis of the immune system of $R y r 3^{-/-}$mice}

The ablation of Ryr3 had beneficial effects on the progression of EAE, either induced by active immunization or under spontaneous conditions. In addition, the data from bone marrow and fetal liver chimeras strongly argue that this extenuation was likely mediated by the deletion of RyR3 in cells of the CNS rather than loss of RyR3 in hematopoietic cells. However, chimeric 
mice never display a complete reconstitution of hematopoietic cells. Therefore, we analyzed the immune system of Ryr3 deficient mice in order to reveal or exclude the role of Ryr3 expression in immune cells in described results of EAE experiments.

First of all, thymus and spleen from $R y r 3^{--}$mice were indistinguishable from those of heterozygous control littermates by visual inspection and did not differ in organ weight or cellularity (Fig. 3.22).
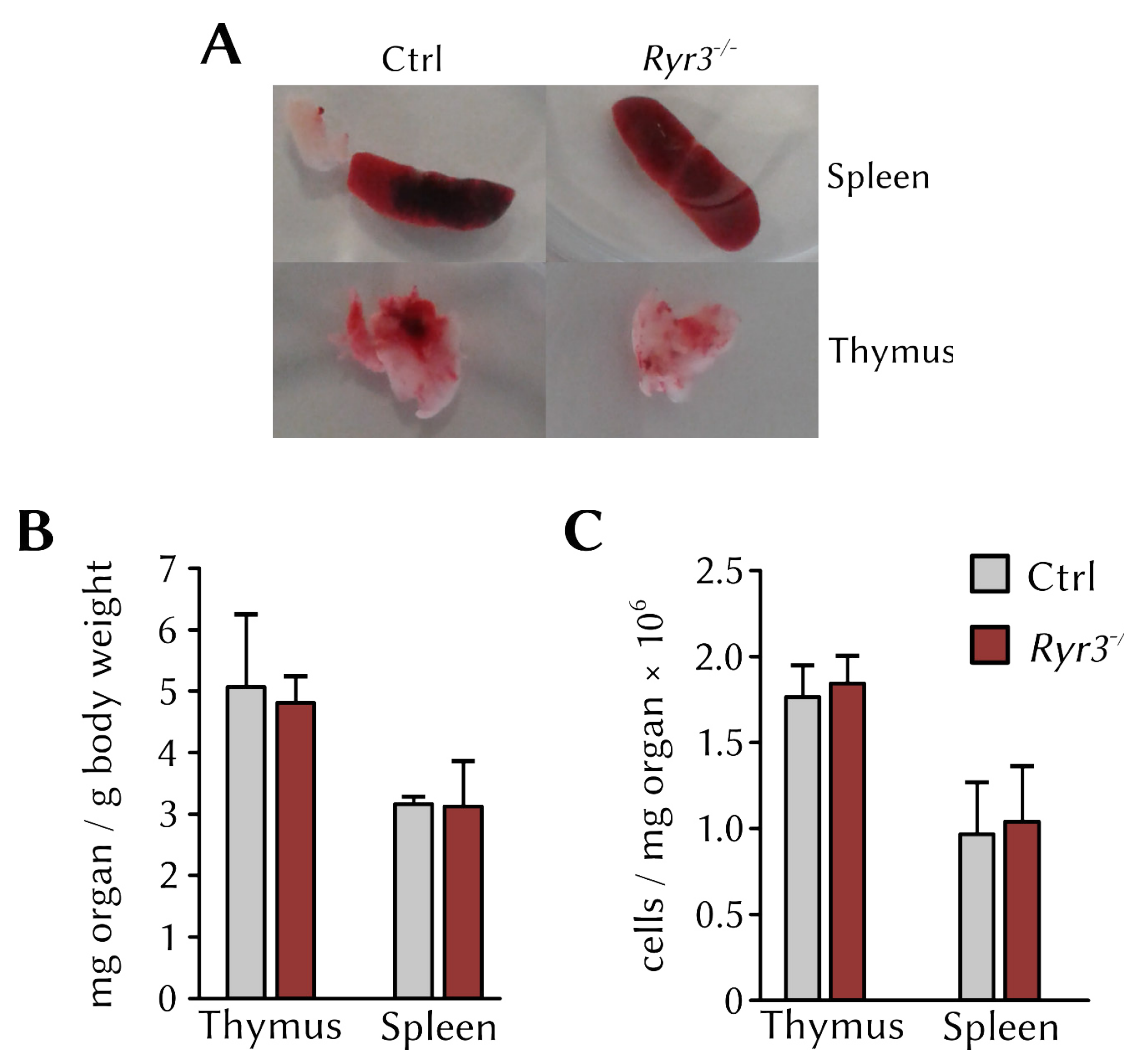

Fig. 3.22 | Analysis of hematopoietic organs of $R y r 3^{--}$mice. In comparison with control mice, thymus and spleen of $\mathrm{Ryr}^{-/}$mice were not altered in size (A), weight (B) and cellularity $(\mathbf{C})$. Bars represent the mean (+SEM) from three independent experiments.

Secondly, it was investigated if deficiency of Ryr3 had an impact on T cell development in the thymus. Therefore, thymocytes from Ryr $3^{-/}$mice were stained for CD4 and CD8 surface markers (Fig. 3.23). Ablation of Ryr3 had no obvious effect on the frequency of $\mathrm{CD}^{+}$or $\mathrm{CD} 8^{+}$single positive, as well as double positive $\left(\mathrm{CD}^{+} \mathrm{CD}^{+}\right)$or double negative $\left(\mathrm{CD} 4^{-} \mathrm{CD} 8^{-}\right)$thymocytes. 

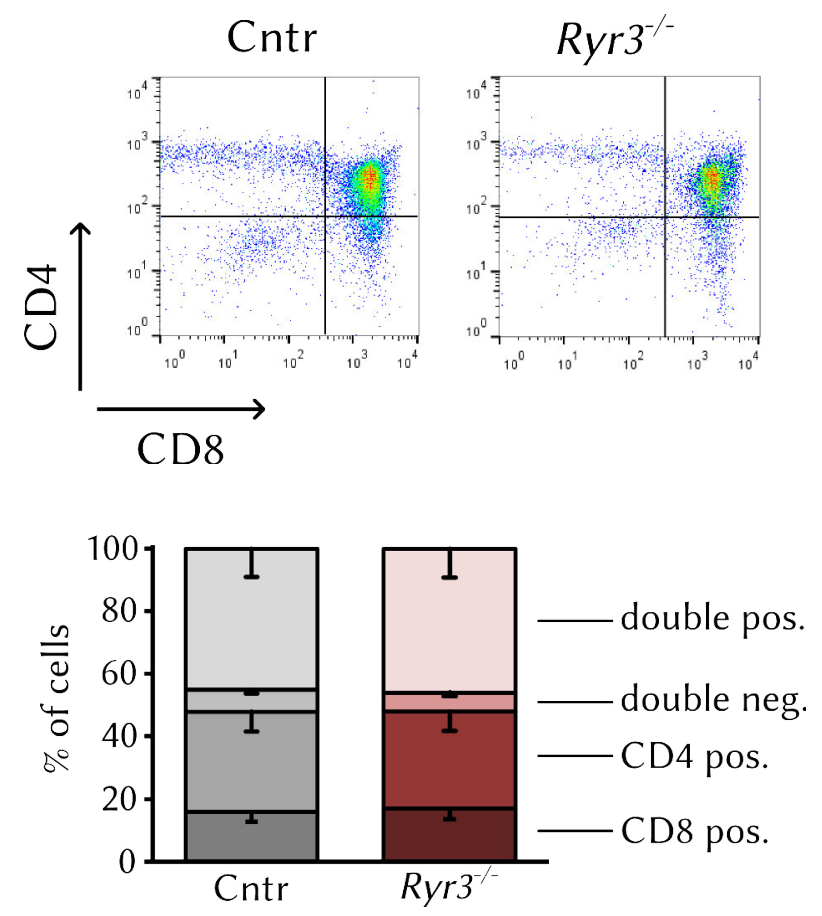

Fig. 3.23 The frequency of $\mathrm{CD}^{+}$and $\mathrm{CD}^{+}$cells in the thymus of $R y r 3^{--}$mice is similar to that of controls. Single cell suspensions of thymocytes were stained and analyzed via flow cytometry for the expression of surface markers CD4 and CD8. Depicted are representative flow cytometry data (upper panel) and the quantification from three individually performed experiments (lower panel; bars represent mean+SEM).

Furthermore, the composition of the peripheral immune system was investigated in spleens and lymph nodes of $R y r 3^{-1-}$ mice. The organs were analyzed for the frequency of $\mathrm{CD} 4^{+}$and $\mathrm{CD} 8^{+} \mathrm{T}$ cells, naïve and effector $\mathrm{CD} 4$ $\mathrm{T}$ cells, the ratio between $\mathrm{T}$ and $\mathrm{B}$ cells and expression of the surface activation markers CD25 and CD69 (Fig. 3.24 and 3.25). The status of the immune system in lymph nodes was similar in $R y r 3^{--}$and control mice. However, in $R y r 3^{--}$mice there was a shift in the ratio of $\mathrm{CD}^{+}$to $\mathrm{CD} 8^{+}$cells towards the cytotoxic $\mathrm{T}$ cell population. This was also observed in the spleen, where this shift was even more pronounced. Apart from this, the immune system of $R y r 3^{-/}$was virtually indistinguishable from that of controls. 


\section{Results}

Lymph nodes
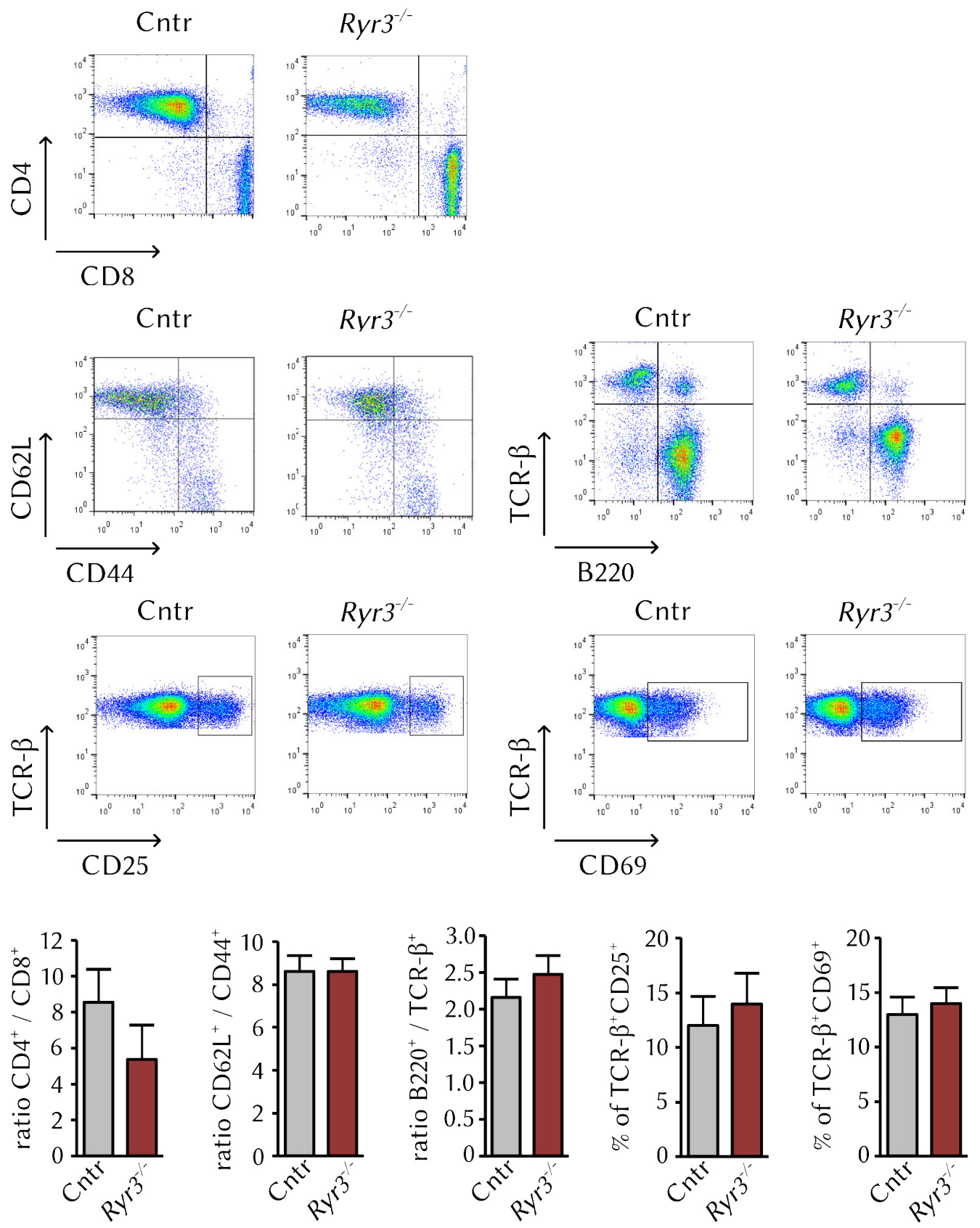

Fig. 3.24 | The composition of the immune system in LNs of $R y r 3^{-/-}$mice is similar to that of control mice. Single cell suspensions of lymph nodes from $R y r 3^{-/-}$mice were stained and analyzed via flow cytometry for expression of surface markers CD4 and CD8, CD62L and CD44, TCR- $\beta$ and B220, CD25 and CD69. Depicted are representative flow cytometry data (upper panel) and the quantification from three individually performed experiments (lower panel; bars represent mean+SEM). 


\section{Results}

Spleen
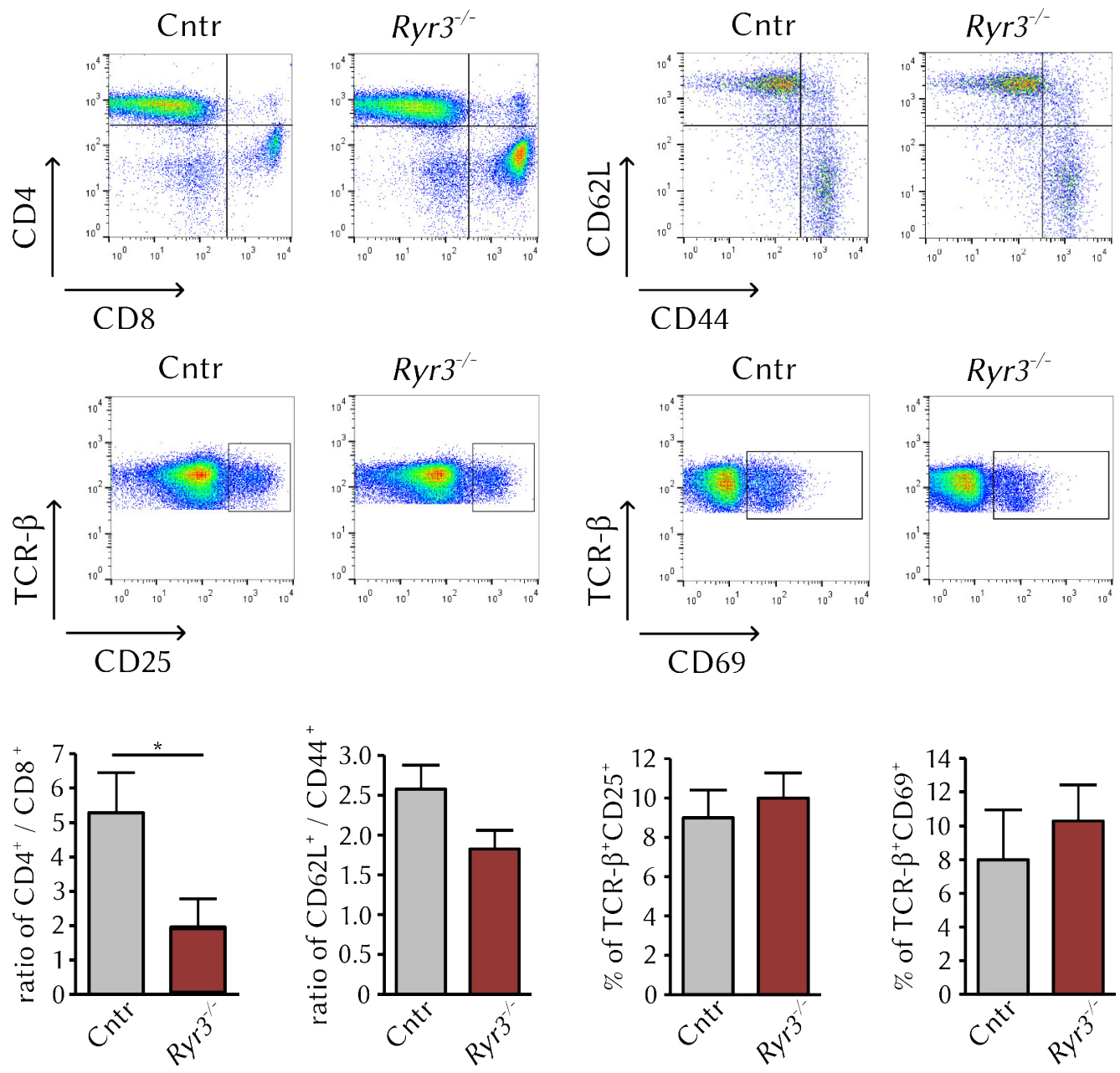

Fig. 3.25 The composition of the immune system in spleens of $R y r 3^{-/-}$mice is similar to that of control mice. Single cell suspensions of spleens from $R y r 3^{-/-}$mice were depleted from erythrocytes and stained and analyzed via flow cytometry for expression of surface markers CD4 and CD8, CD62L and CD44, CD25 and CD69. Depicted are representative flow cytometry data (upper panel) and the quantification from three individually performed experiments (lower panel; bars represent mean+SEM). Statistical analysis was performed using a two-tailed Student's $t$-test $\left({ }^{*} P \leq 0.05\right)$. 


\subsubsection{Proliferation of $R y r 3^{-/-}$lymphocytes}

$R y r 3^{-/}$lymphocytes were tested for their proliferation abilities in response to stimulation with anti-CD3 antibodies or $\mathrm{MOG}_{35-55}$ peptide (on the 2D2 transgenic background), respectively (Fig. 3.26). Lymph node cells proliferated in a dose dependent manner to $48 \mathrm{~h}$ stimulation with anti-CD3 antibodies. However, no differences were observed between $R y \mathrm{r}^{-/}$and control cells (Fig. 3.26, A). Little, but yet significant reduction in proliferation was observed when lymphocytes were strongly stimulated for $48 \mathrm{~h}$ with anti-CD3/anti-CD28 antibodies. Lymphocytes from mice with 2D2 $\left(\mathrm{TCR}^{\mathrm{MOG}}\right)$ background proliferated significantly less when stimulated with $1.0 \mu \mathrm{g} / \mathrm{ml} \mathrm{MOG}_{35-55}$ peptide, but not with $10 \mu \mathrm{g} / \mathrm{ml}$, where only tendency levels in the reduction of proliferation were observed (Fig. 3.26, B).

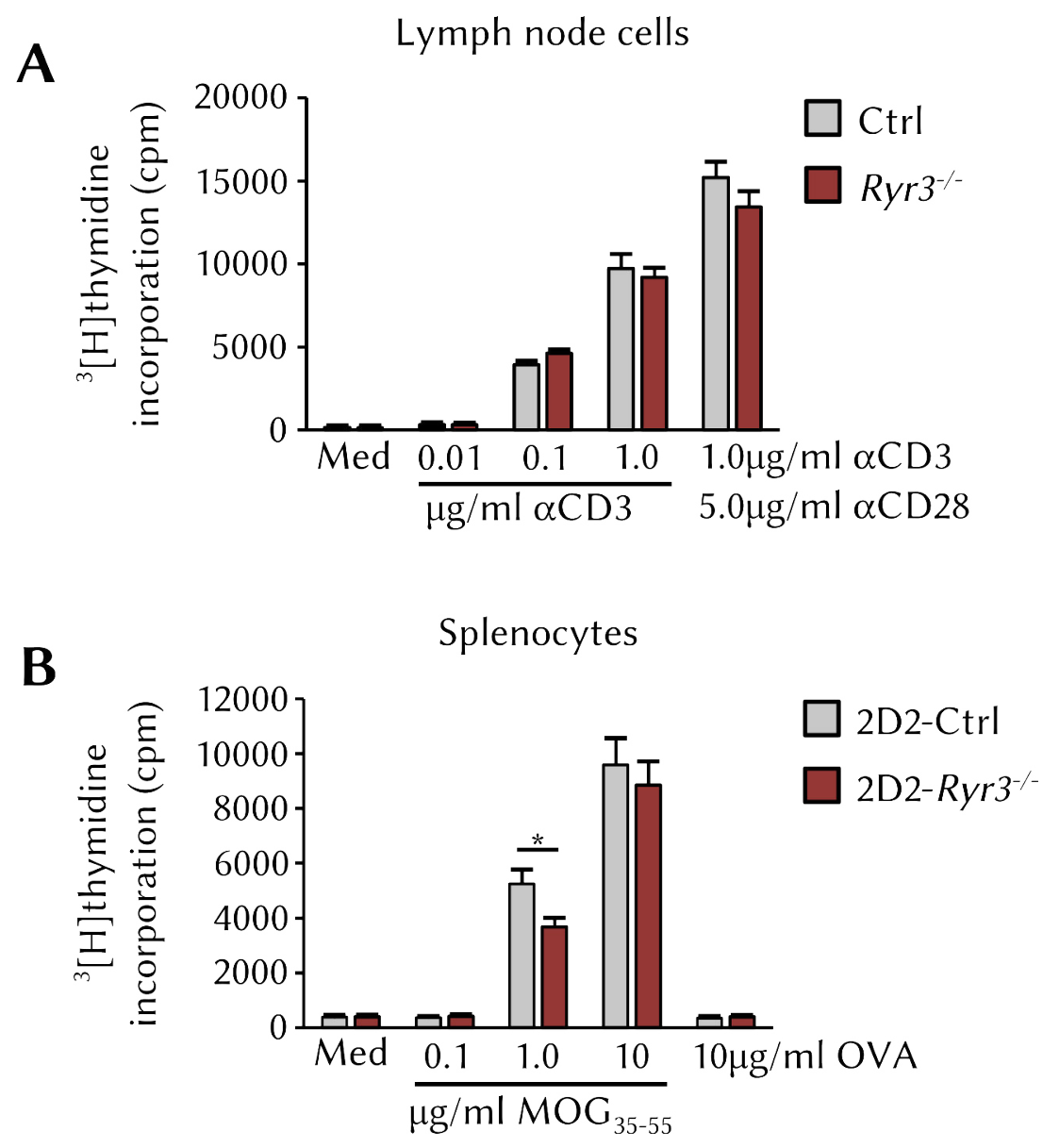

Fig. 3.26 | The knockout of Ryr3 does not severely alter the proliferative response of lymphocytes or splenocytes. Cells were isolated from LNs of $R y r 3^{-/-}$mice (A), and spleen of 2D2-Ryr3 $3^{-/}$mice (B). From single cell suspensions, $3 \times 10^{5}$ cells per well were stimulated for $48 \mathrm{~h}$ with anti-CD3 and/or anti-CD28 antibodies (A), or $\mathrm{MOG}_{35-55}$ peptide or ovalbumin (OVA) (B) in indicated concentrations before chasing with ${ }^{3}[\mathrm{H}]$ thymidine for another $16 \mathrm{~h}$ and measurement of ${ }^{3}[\mathrm{H}]$ thymidine incorporation. Medium (Med) served as negative control. Each condition was analyzed in triplicates. Bars represent the mean (+SEM) of three independent experiments and were compared using a two-tailed Student's $t$-test $\left({ }^{*} P \leq 0.05\right)$. 


\subsubsection{In vivo proliferation of $R y r 3^{-/-} \mathrm{T}$ cells}

As a consequence of immunization, naïve $\mathrm{T}$ cells become activated by dendritic cells through TCR stimulation. This stimulus results in rapid T cell proliferation in the draining lymph nodes (JENKINS et al., 2001).

To test how $\mathrm{T}$ cells from $R y r 3^{--}$mice would proliferate in the secondary lymphoid organs in vivo, CFSE-labeled, $\mathrm{RFP}^{+} \mathrm{CD} 4^{+} \mathrm{T}$ cells from either $R y r 3^{-1-}$ or control mice were transferred into $\mathrm{C} 57 \mathrm{BL} / 6$ recipient mice. Analysis of T cell proliferation (CFSE dilution) was performed $48 \mathrm{~h}, 60 \mathrm{~h}, 72 \mathrm{~h}$ and $96 \mathrm{~h}$ after immunization against $\mathrm{MOG}_{35-55}$ peptide for the draining (inguinal and popliteal LNs) and for the non-draining lymph nodes (cervical and axial LNs; Fig. 3.27). Even though Ryr3 deficient T cells proliferated less in draining lymph nodes than control $\mathrm{T}$ cells at every investigated time point, attenuation was only significant $96 \mathrm{~h}$ after immunization. No difference in proliferation between $R y r 3^{--}$and control cells was observed in the nondraining lymph nodes.

draining LNs

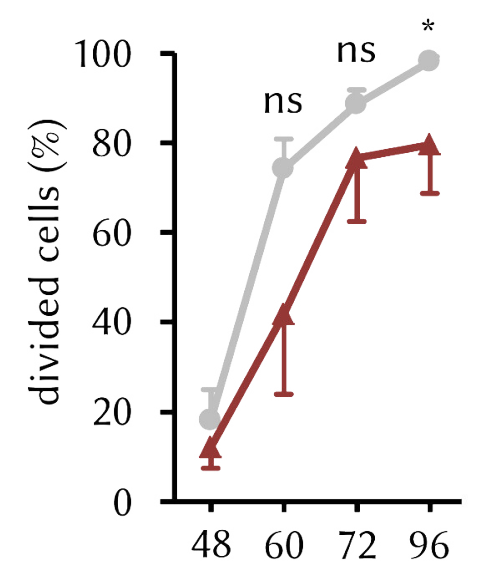

Time p. i. (h) non-draining LNs

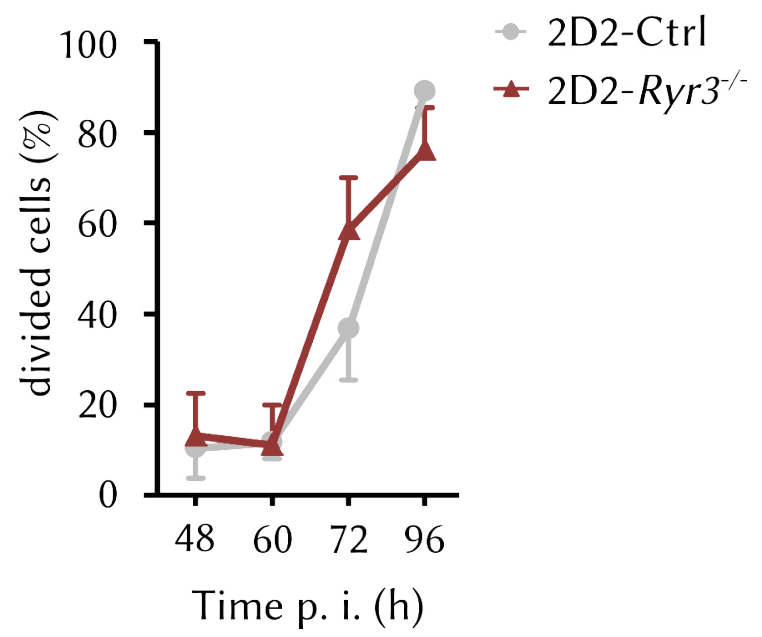

Fig. 3.27 | Proliferation of MOG-specific T cells upon immunization is not affected by Ryr3 deficiency. An equal amount of isolated $\mathrm{CD} 4^{+}$MOG peptide-specific $\mathrm{T}$ cells was labeled with CFSE and injected i.v. into C57BI/6 host animals. After $48 \mathrm{~h}$, mice were immunized against $\mathrm{MOG}_{35-55}$ peptide (200 ng PTX d0 and d2 p. i.). Single cell suspensions from the draining and non-draining lymph nodes were prepared $48 \mathrm{~h}, 60 \mathrm{~h}, 72 \mathrm{~h}$ and $96 \mathrm{~h}$ after immunization. The dilution of CFSE was analyzed by flow cytometry for the $\mathrm{CD} 4{ }^{+} \mathrm{RFP}^{+}$cell population. Bars represent the mean (+SEM) of two independent experiments with two mice per time point and group. Statistics were performed using a two-tailed Student's $t$-test $\left({ }^{*} P \leq 0.05\right.$; ns $P \geq$ $0.05)$. 


\subsubsection{Encephalitogenic potential of Ryr3 deficient $T$ cells}

In order to investigate the encephalitogenic potential of Ryr3 deficiant T cells, we transfered MOG-specific Ryr $3^{-/}$cells $\left(R y r 3^{--} \times 2 \mathrm{D} 2\right)$ in OT II mice, followed by immunization against $M \mathrm{G}_{35-55}$ peptide. T cells from OT II mice are reactive against ovalbumin. This allowed the investigation how MOGspecific Ryr $3^{-\mathrm{T}}$ cells contribute to EAE in an otherwise EAE resistant host. We observed that EAE in mice that received $R y r 3^{--} \times 2 \mathrm{D} 2 \mathrm{~T}$ cells developed not differently from controls (Fig. 3.28), supporting our previous results indicating that Ryr3 deletion does not impair $\mathrm{T}$ cell function or the ability of $\mathrm{T}$ cells to become encephalitogenic.

A

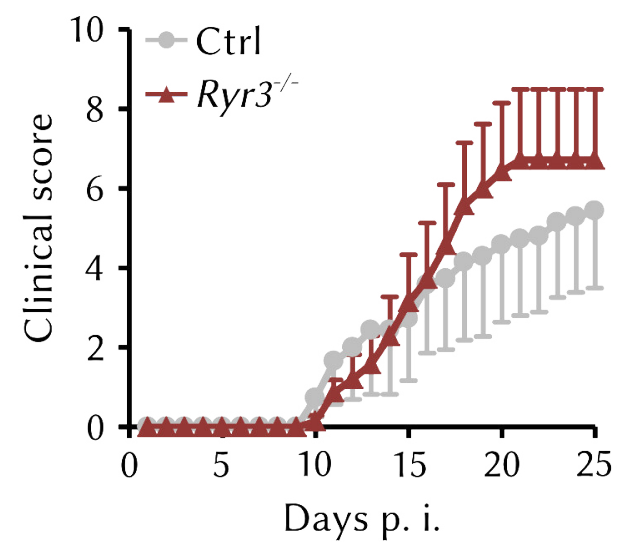

C

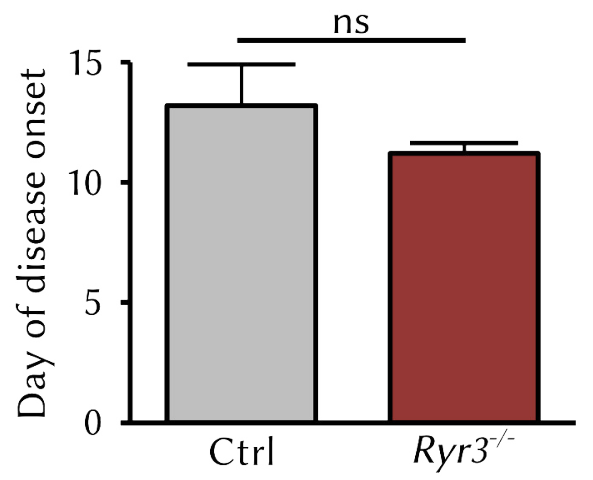

B

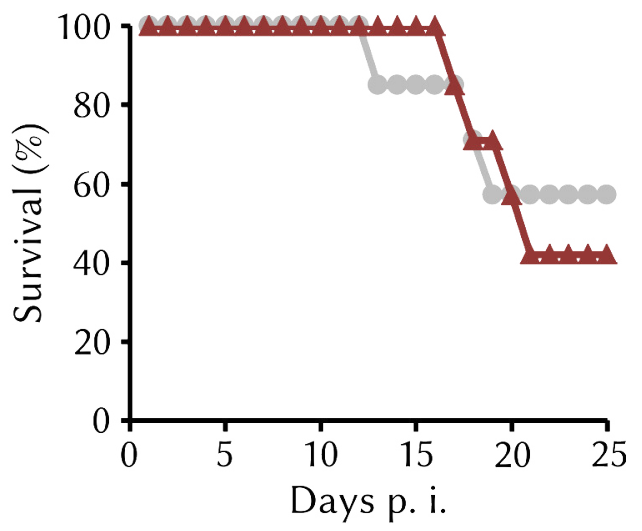

D

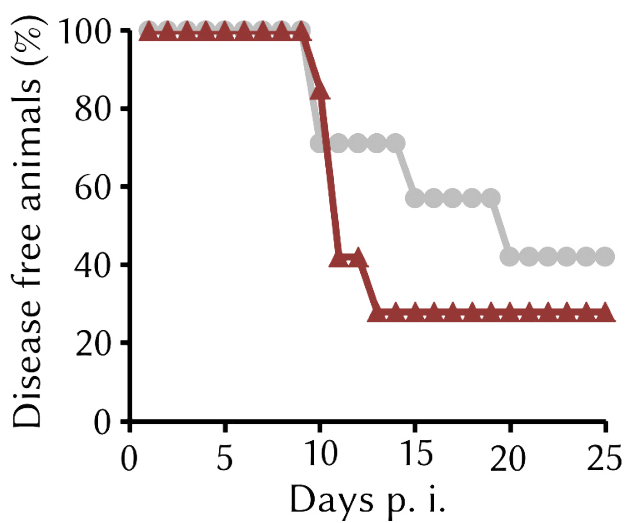

Fig. 3.28 | The encephalitogenic potential of MOG-specific T cells is not affected by Ryr3 deficiency. An equal amount of Ryr3 $3^{-} \times 2 \mathrm{D} 2 \mathrm{~T}$ cells and respective controls was transferred into OT II mice $48 \mathrm{~h}$ prior immunization against $\mathrm{MOG}_{35-55}$ peptide. (A) EAE disease course of OT II mice that received $R y r 3^{--} \times 2$ D2 cells (red line) and control cells (grey line). (B) shows the percentage of survival of the animals. (C) Day of onset of each group. (D) Percentage of disease free animals. In all panels the mean $(+S E M)$ of three independent experiments is shown. Statistics were carried out using the Mann-Whitney $U$ test for clinical courses (A, $\left.{ }^{*} P \leq 0.05\right)$ and a two-tailed Student's $t$-test $\left(\mathbf{B} ;{ }^{*} P \leq 0.05\right)$. 


\subsubsection{Antigen recall assay}

After priming in the secondary lymphoid organs, $\mathrm{T}$ cells start to proliferate and gain their migratory phenotype that allows them to enter the blood circulation. In case of $\mathrm{MOG}_{35-55}$ peptide-induced $\mathrm{EAE}, \mathrm{T}$ cells cross the $\mathrm{BBB}$ and infiltrate into the CNS, where they re-encounter their specific antigen and become reactivated and promote inflammation.

Lymphocytes from draining lymph nodes and splenocytes were tested for their antigen recall response at day 8 post immunization. The cells were isolated and restimulated with $\mathrm{MOG}_{35-55}$ peptide and assayed $48 \mathrm{~h}$ later (Fig. 3.29). As observed before lymphocytes and splenocytes proliferated in a dose dependent manner to $\mathrm{MOG}_{35-55}$ peptide stimulation, but with no significant difference between $R y r 3^{-/}$and control cells.

A

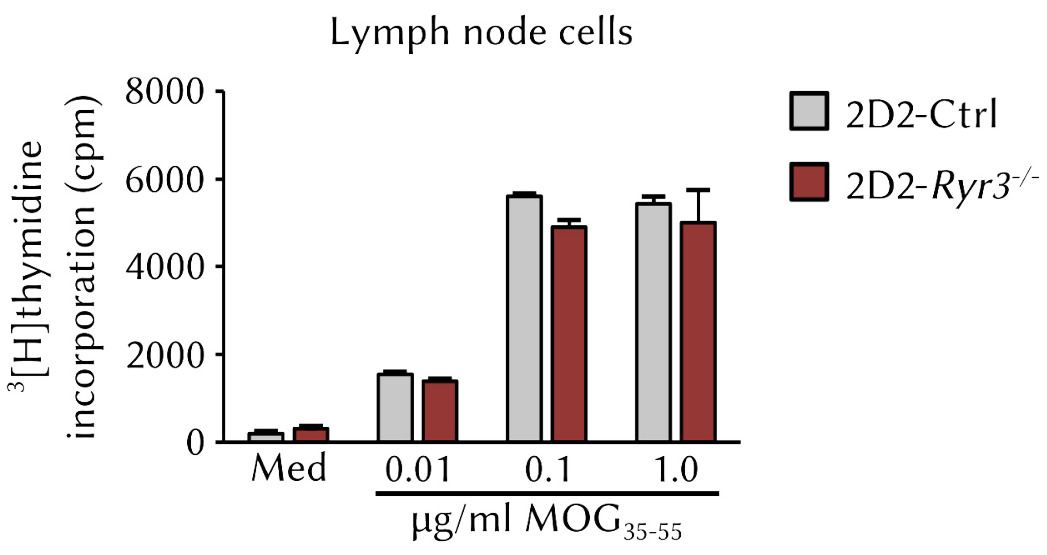

B

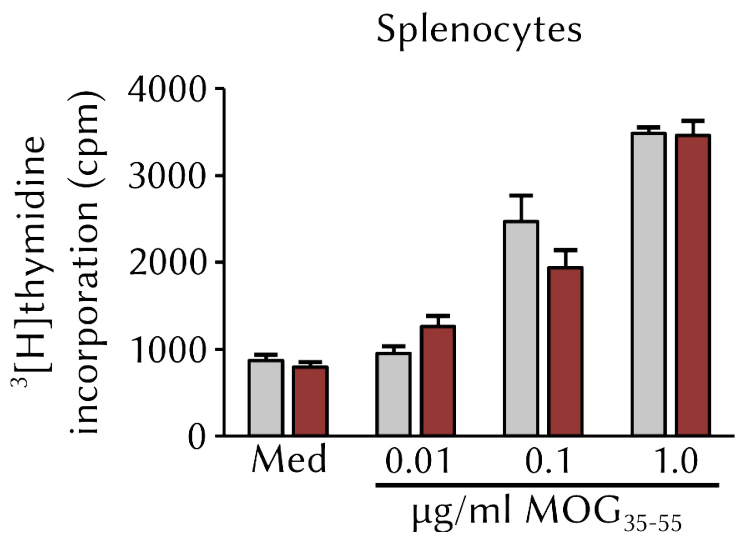

Fig. 3.29 $\mid R y r 3^{-1 /}$ lymphocytes from the periphery are not impaired to antigen recall after immunization. MOG peptide-specific Ryr $3^{-1-}$ and control mice were immunized against $M \mathrm{OG}_{35-55}$ peptide. At d8 p. i., $3 \times 10^{5}$ cells per well from single cell suspensions of (A) LNs and (B) spleen were stimulated for $48 \mathrm{~h}$ with $\mathrm{MOG}_{35-55}$ peptide in indicated concentrations before chasing with ${ }^{3}[\mathrm{H}]$ thymidine for another $16 \mathrm{~h}$ and measurement of ${ }^{3}[\mathrm{H}]$ thymidine incorporation. Medium (Med) served as negative control. Each condition was analyzed in triplicates. Bars represent the mean (+SEM) of three independent experiments. 


\subsection{The function of RyR3 in astrocytes during the course of EAE}

\subsubsection{Expression of RyR3 in primary murine astrocytes}

Astrocytes and microglia play active and crucial roles during EAE in several ways, such as antigen presentation, chemokine and cytokine production, and the provision of a suitable environment for $\mathrm{T}$ cell attraction and activation (RAIVICH, 2005, NAIR et al., 2008). Primary cultures of astrocytes and microglia were analyzed for expression of Ryr3 mRNA. In contrast to the steady state (Fig. 3.30, A), highly elevated levels of Ryr3 mRNA were found in activated astrocytes, whereas activation of microglia resulted only in a minor increase in Ryr3 mRNA expression (Fig. 3.30, B). RyR3 protein was detectable in astrocytic cultures by immunostaining presumably in the ER compartment (Fig. 3.30, C).

A

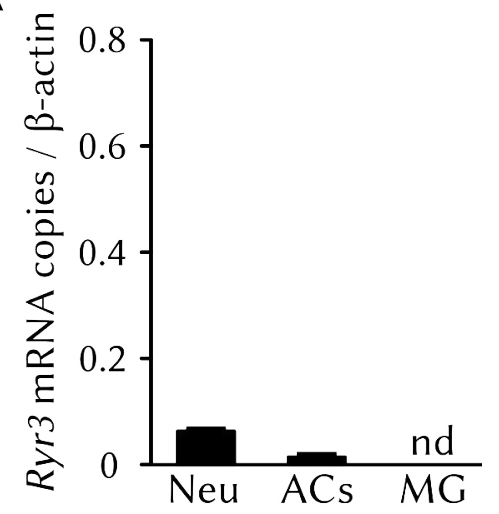

B

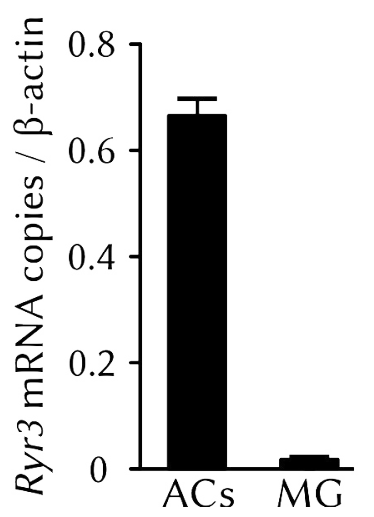

C
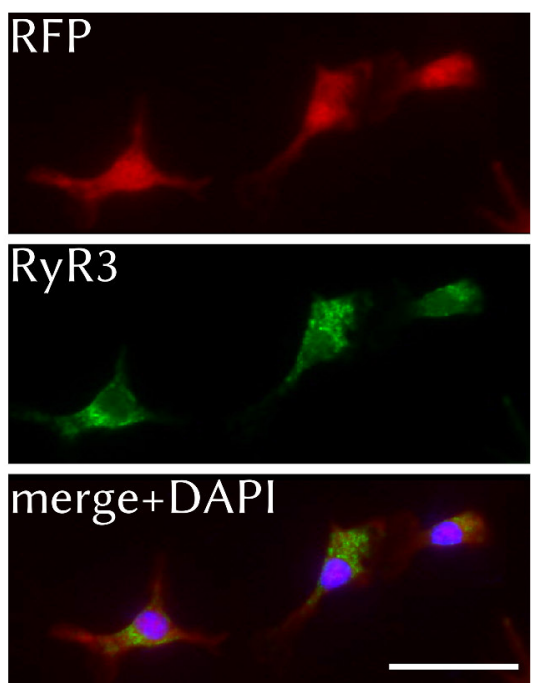

Fig. 3.30 $\mid$ Ryr3 mRNA is highly expressed in activated astrocytes. Cultures of (A) unstimulated and (B) LPS stimulated (100 ng/ml) astrocytes (ACs) and microglia (MG) were analyzed for Ryr3 mRNA expression. Expression of Ryr3 mRNA in midbrain neurons (Neu) served as a reference. Bars represent the mean (+SEM) from three independent experiments. RNA lysates from midbrain neurons were a kind gift from Anna-Elisa Roser, Dept. of Neurology, University Medicine Göttingen. (C) Functional RyR3 is expressed in astrocytes. Primary cultures of astrocytes (RFP) were stimulated with LPS $(100 \mathrm{ng} / \mathrm{ml})$ and stained against RyR3 (green). Nuclei were visualized with DAPI (blue). Scale bar represents $50 \mu \mathrm{m}$. 


\subsubsection{Ryr $3^{-/-}$astrocytes show laltered $\mathrm{Ca}^{2+}$ signaling responses}

Astrocytes are linked in a network via intercellular channels also known as gap junctions, which allow the fast passage of ions and small molecules between cells. Stimulation of astrocytes evokes an increase of intracellular $\mathrm{Ca}^{2+}$ that propagates to neighboring cells via the gap junctions, resulting in progressive $\mathrm{Ca}^{2+}$ waves that spread throughout the astrocytic network. ATP is a potent stimulator of intracellular $\mathrm{Ca}^{2+}$ signals in astrocytes (JEREMIC et al., 2001) therefore we used this naturally occurring compound to investigate $\mathrm{Ca}^{2+}$ signals in $\mathrm{Ryr}^{-/}$, and heterozygous control astrocytes. Primary astrocytes from neonatal mice were loaded with the membrane permeable $\mathrm{Ca}^{2+}$ dyes Fluo-4 and Fura- 2 as described (chapter 2.8.1) and stimulated with $30 \mu \mathrm{M}$ ATP. The resulting $\mathrm{Ca}^{2+}$ response was imaged for additional $20 \mathrm{~min}$ (Fig. 3.31).

Neither control nor Ryr3 ${ }^{-/}$astrocytes showed spontaneous $\mathrm{Ca}^{2+}$ fluxes when imaged after treatment with calcium buffer as vehicle control. Substantial $\mathrm{Ca}^{2+}$ signaling was detected when control cells were stimulated with $30 \mu \mathrm{M}$ or $50 \mu \mathrm{M}$ ATP. A strong peak was observed 5-10 sec after ATP application and oscillating patterns in $\mathrm{Ca}^{2+}$ signaling were detected in some cells starting after about $5 \mathrm{~min}$ and continued until the end of the measuring. An attenuated form of this initial peak and fewer oscillations-or oscillations with lower amplitudes-were observed in $R y r^{-/-}$astrocytes. No initial spark was observed when astrocytes, either controls or $R y r 3^{--}$, were stimulated with $12.5 \mu \mathrm{M}$ ATP. However, some control cells began to oscillate after about 10-12 min, which was not observed in Ryr $3^{-/-}$cells. 


\section{Results}

Vehicle
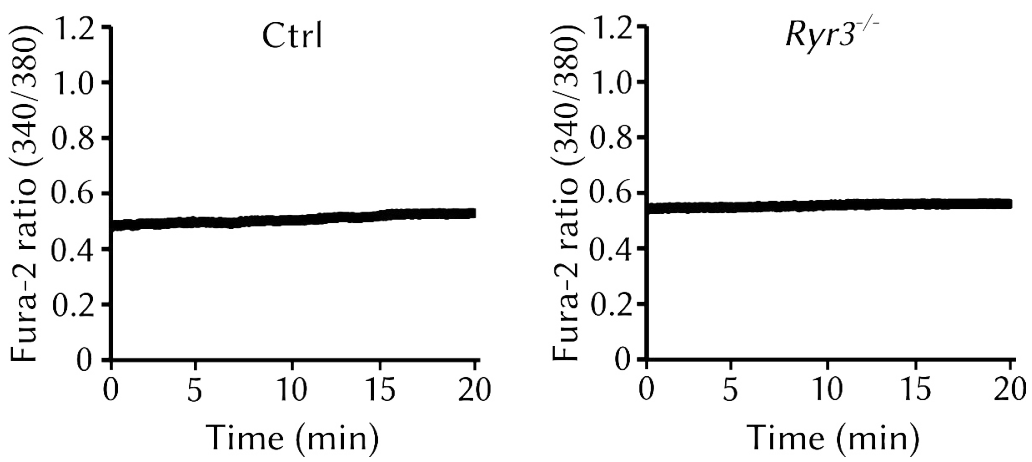

$12.5 \mu \mathrm{M}$ ATP
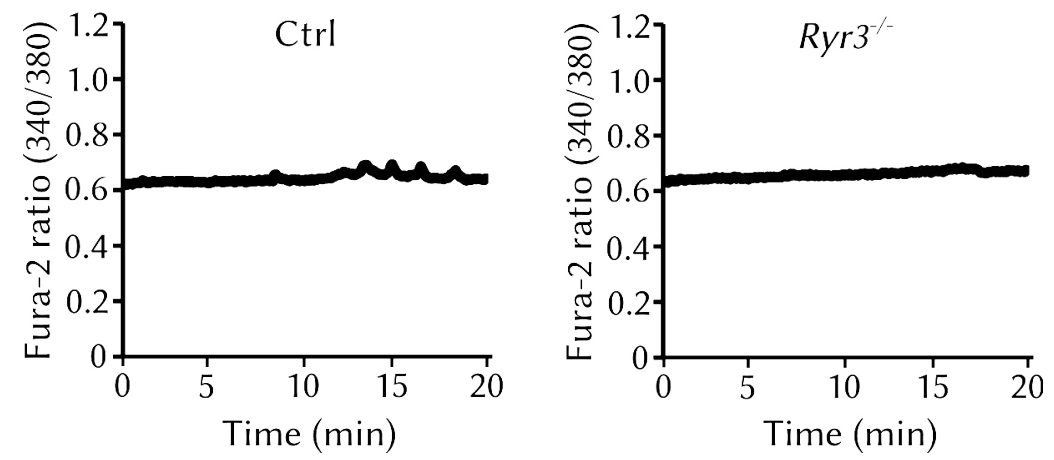

$30 \mu \mathrm{M}$ ATP
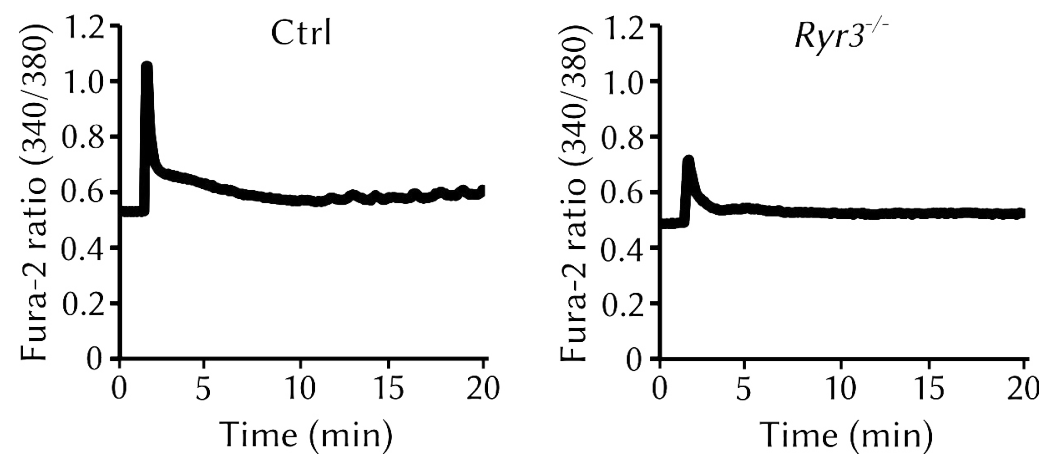

$50 \mu \mathrm{M}$ ATP
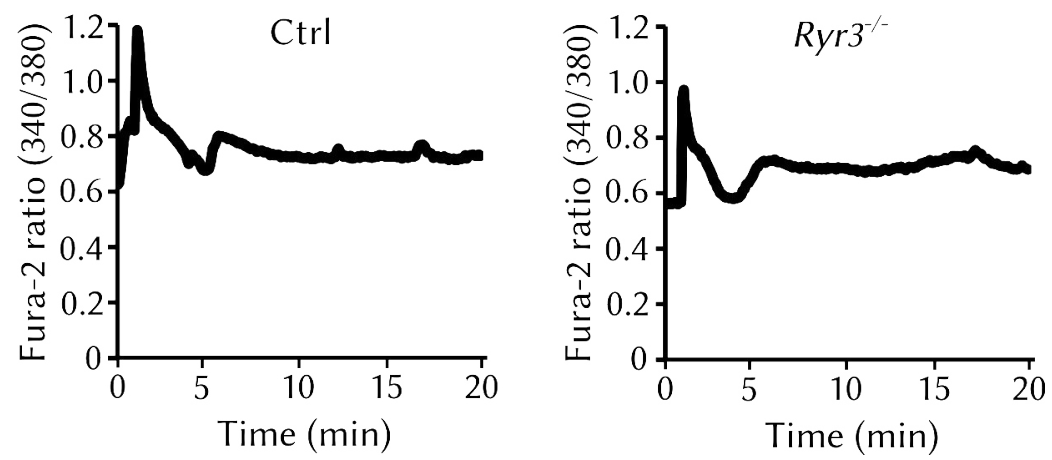

Fig. 3.31 $\mid \mathrm{Ryr}^{3-}$ astrocytes show altered $\mathrm{Ca}^{2+}$ signals in response to ATP stimulation. 
Astrocytes were loaded with the $\mathrm{Ca}^{2+}$ dyes Fluo-4 and Fura-2. The Fura-2 ratio (340/380 nm) was imaged over total $20 \mathrm{~min}$. After $1 \mathrm{~min}$, the cells were stimulated with ATP. Calcium buffer served as vehicle control. Depicted are the means of acquired $\mathrm{Ca}^{2+}$ signals of all cells within the measuring field.

\subsection{3 $R$ yr $^{-/-}$astrocytes secrete less glutamate upon stimulation}

Glutamate is an excitatory transmitter which is released by astrocytes to modulate the functions of nearby neurons (MALARKEY AND PARPURA, 2008) and can be mediated by $\mathrm{Ca}^{2+}$ dependent exocytosis (PARPURA et al., 1994). HUA et al. reported in 2004 that the $\mathrm{Ca}^{2+}$ that was necessary for the glutamate release came mainly from internal stores and that an activation of $\mathrm{IP}_{3} \mathrm{Rs}$ and RyRs was required. Primary astrocytes from $R y r^{-/-}$mice were stimulated and analyzed for their release of glutamate (Fig. 3.32).

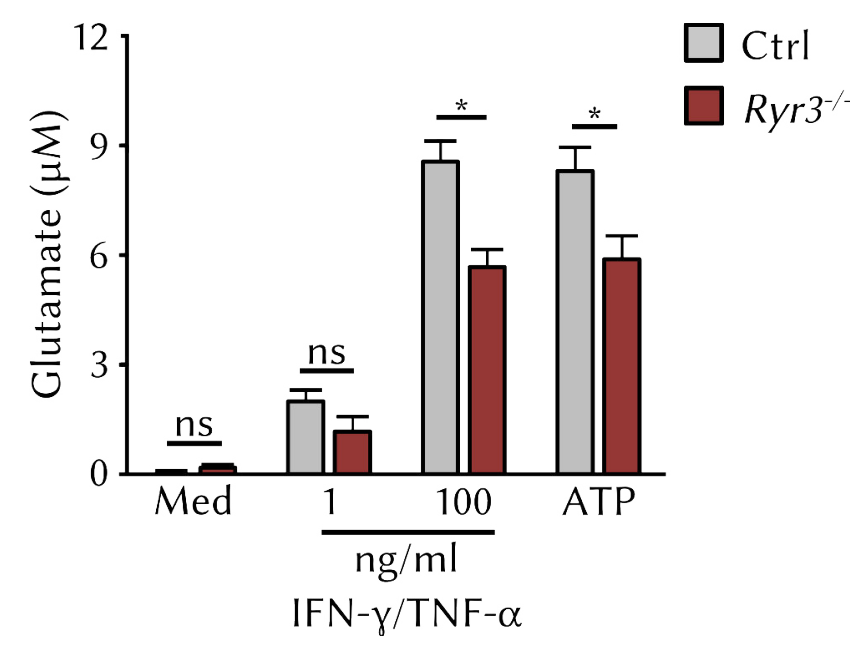

Fig. 3.32 | Glutamate release is reduced in $R y r 3^{--}$astrocytes. Primary astrocytes were stimulated with indicated concentrations of IFN- $\gamma /$ TNF- $\alpha$ or $30 \mu \mathrm{M}$ ATP for $1 \mathrm{~h}$ or left untreated (medium control; Med). Levels of glutamate in the medium of astrocytes were determined by colorimetric quantification. Bars represent the mean (+SEM) of three independent experiments. Statistical analysis was performed using a two-tailed Student's $t$ test $\left({ }^{*} P \leq 0.05\right.$, ns $\left.P \geq 0.05\right)$. 


\subsection{4 $\mathrm{Ryr}^{-/}$primary astrocytes produce lower amounts of CCL2, CCL5, CXCL10 and TNF- $\alpha$ in vitro}

In general, astrocytes support neuronal transmission, maintain neuronal integrity and control homeostasis of the BBB. In case of neuroinflammation they can exert both neuroprotective or neurotoxic functions by the production of chemokines and cytokines (LIEBERMAN et al., 1989, CHOI et al., 2014). LPS are large bacteria derived endotoxins that cause strong immune responses and are known to induce chemokine and cytokine production in astrocytes (LIEBERMAN et al., 1989). To investigate whether $R y r 3^{-/}$astrocytes responded differently from control astrocytes to strong stimuli, LPS was applied to primary cultures of cortical astrocytes and RNA was isolated after $4 \mathrm{~h}$ and $24 \mathrm{~h}$ of stimulation to analyze the expression of Ccl2, Ccl5, Cxcl10 and Tnfa mRNA (Fig. 3.33). First of all it was observed that both control and Ryr $^{-/-}$astrocytes did respond to LPS, either applied for $4 \mathrm{~h}$ or $24 \mathrm{~h}$. However, there was a substantial reduction in Ccl2, Ccl5 and Tnfa mRNA expression after $4 \mathrm{~h}$ in $\mathrm{Ryr}^{-/}$astrocytes, while no significant difference was found for the expression of Cxcl10 mRNA. The same tendency was observed in astrocytes that were stimulated with LPS for $24 \mathrm{~h}$. Only background levels of expression were detected after the same time period in control (medium) stimulated cells. 


\section{Results}

CCL2

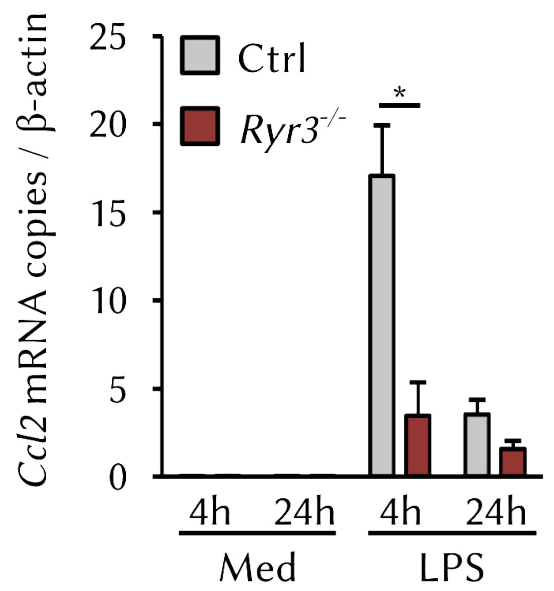

CXCL10

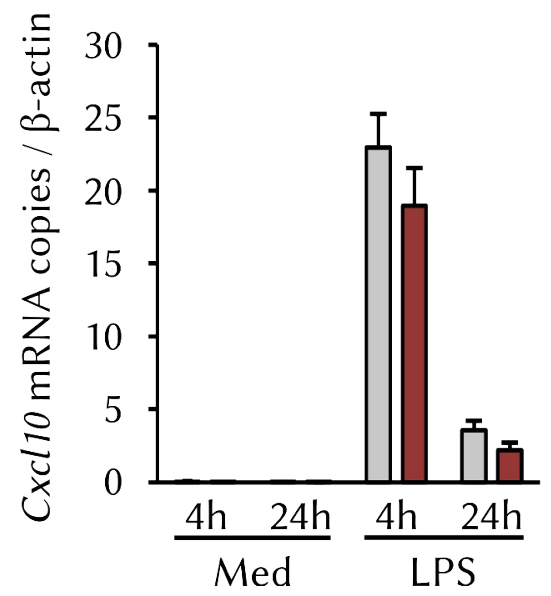

CCL5

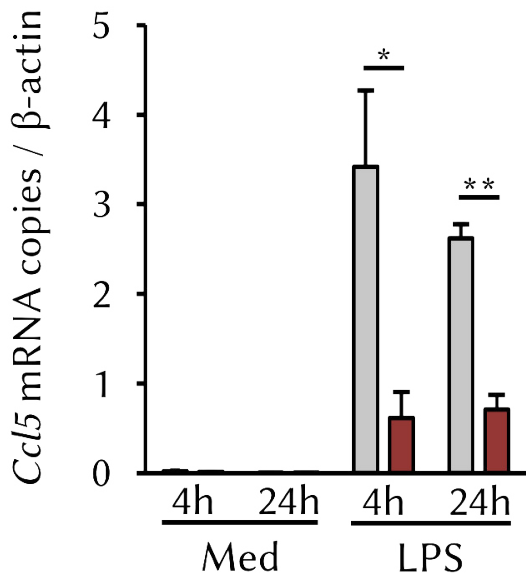

TNF- $\alpha$

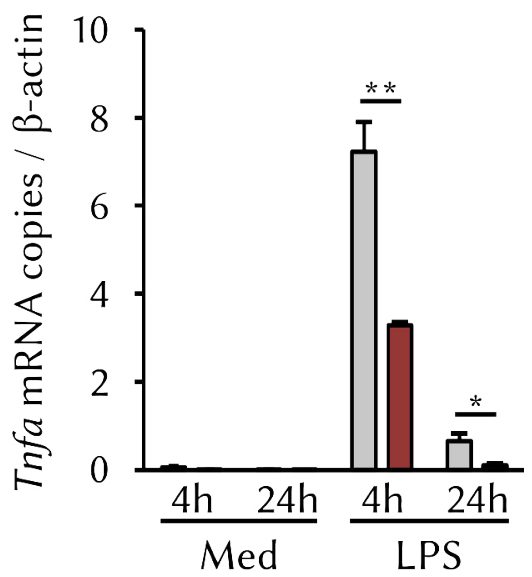

Fig. 3.33 | Chemokine and cytokine mRNA expression in response to LPS stimulation is reduced in $\mathrm{Ryr}^{-/-}$astrocytes. Primary astrocytes were stimulated with $100 \mathrm{ng} / \mathrm{ml} \mathrm{LPS}$ for $4 \mathrm{~h}$ or $24 \mathrm{~h}$ or left untreated (medium control; Med). Ryr $3 \mathrm{mRNA}$ levels were determined by realtime PCR analysis. Bars represent the mean (+SEM) of three independent experiments. Statistical analysis was performed using a two-tailed Student's $t$-test $\left({ }^{* *} P \leq 0.01,{ }^{*} P \leq 0.05\right)$.

During EAE, IFN- $\gamma$ and TNF- $\alpha$ were secreted by infiltrating encephalitogenic Th1 cells in order to promote macrophage recruitment, and higher levels of these cytokines were found in the CSF of MS patients (KROENKE et al., 2008). Thus it was investigated how astrocytes would respond to these stimuli (Fig. 3.34). In addition, the cells were treated with ATP, which induced powerful $\mathrm{Ca}^{2+}$ signals, and glutamate, a transmitter that was secreted by astrocytes themselves upon stimulation as described (Fig. 3.31 and Fig. 3.32). 


\section{Results}
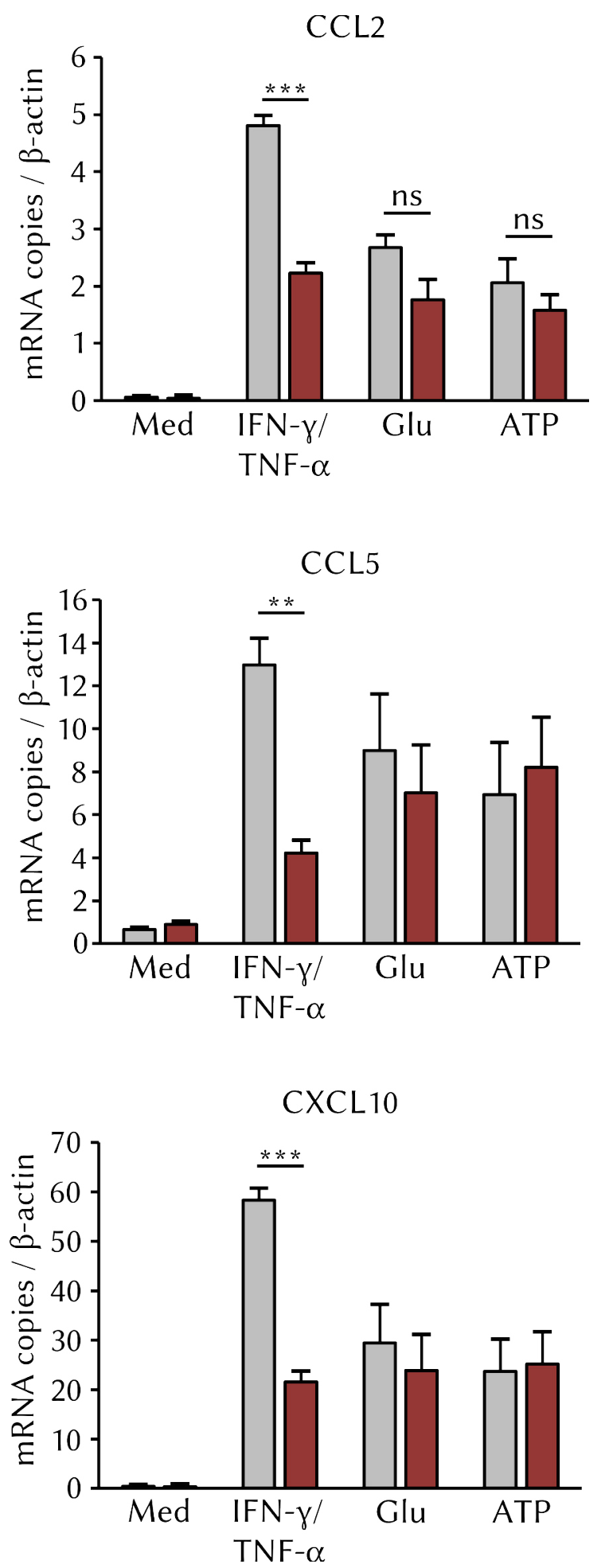

Fig. 3.34 | Chemokine and cytokine mRNA expression is reduced in $R y r 3^{-/-}$astrocytes after stimulation with IFN- $\gamma / \mathrm{TNF}-\alpha$. Primary astrocytes were stimulated with $100 \mathrm{ng} / \mathrm{ml}$ IFN- $\gamma /$ TNF- $\alpha, 100 \mu \mathrm{M}$ glutamate (Glu), $30 \mu \mathrm{M}$ ATP or left untreated (medium control; Med) for $1 \mathrm{~h}$. Ryr3 mRNA levels were determined by real-time PCR analysis. Bars represent the mean (+SEM) of three independent experiments. Statistical analysis was performed using a two-tailed Student's $t$-test $\left({ }^{* *} P \leq 0.001,{ }^{* *} P \leq 0.01\right.$, ns $\left.P \geq 0.05\right)$. 


\subsubsection{Astrocytes isolated from spinal cords of $R y r 3^{-/-}$mice produce lower amounts of CCL2, CCL5 and CXCL10 at the onset of EAE}

During the onset of EAE, chemokines regulate the migration of immune cells towards sites of inflammation and contribute to leukocyte infiltration into the CNS parenchyma (KUNKEL AND BUTCHER, 2002). Astrocytes have proven to be a potent producer of chemokines in the context of neuroinflammation, and particular in EAE (ENG et al., 1996). Since it was observed in vitro that $R y \mathrm{r}^{-/}$astrocytes were less responsive to stimuli and produced lower amounts of chemokines and cytokines, Ryr $3^{--}$astrocytes of EAE mice were investigated ex vivo at the onset of EAE. Spinal cords of EAE animals were isolated and split longitudinally. One half of the spinal cord tissue was used to isolate astrocytes via MACS purification, while the other half was used to purify $\mathrm{T}$ cells via negative selection. From both populations the RNA was extracted and analyzed by qPCR. Astrocytes were analyzed for Ccl2, Ccl5 and Cxcl10 mRNA expression (Fig. 3.35, A) and T cells for the expression of chemokine receptor Cxcr3, Cxcr4, Ccr5, Ccr6 and Ccr7 mRNA (Fig. 3.35, B). Animals from both control and $R y r 3^{-/-}$had a clinical score of 1.0 at the time point of tissue collection (d11 p. i.). There, astrocytes from $R y r 3^{-/-}$mice expressed significantly less Ccl2, Ccl5 and Cxcl10 mRNA compared to controls (Fig. 3.35, A). Additionally, T cells were investigated for expression of chemokine receptor mRNA. While no significant differences in mRNA expression levels were found between $R y r 3^{-/}$and control cells, levels of Cxcr3, Ccr6 and Ccr7 mRNA were by tendency lower in Ryr3 ${ }^{-/} \mathrm{T}$ cells. In neurodegenerative disorders, astrocytes are also known to express adhesion molecules, thus facilitating leukocyte entry into the CNS. Among these molecules, ICAM-1 and VCAM-1 were expressed by astrocytes (DIETRICH, 2002, GIMENEZ et al., 2004), but expression levels were similar between $R y$ r $^{-1-}$ and control astrocytes at the onset of EAE (Fig. 3.35, C).

A

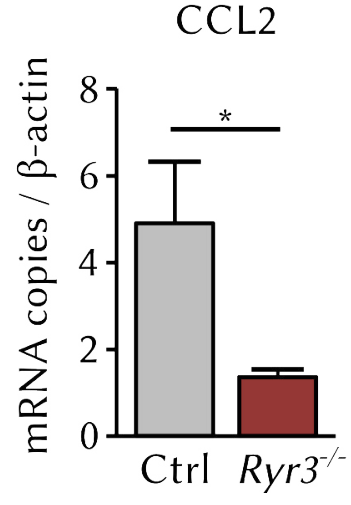

CCL5

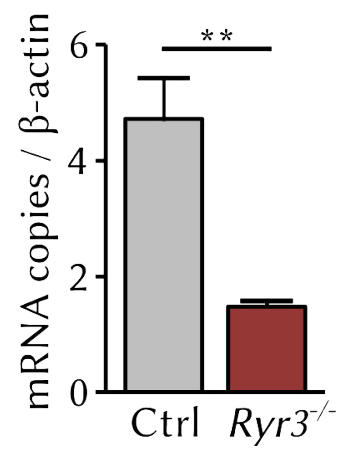

CXCL10

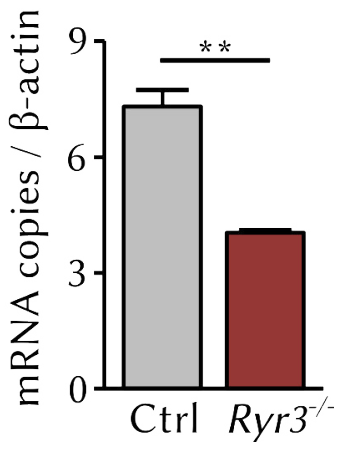


B

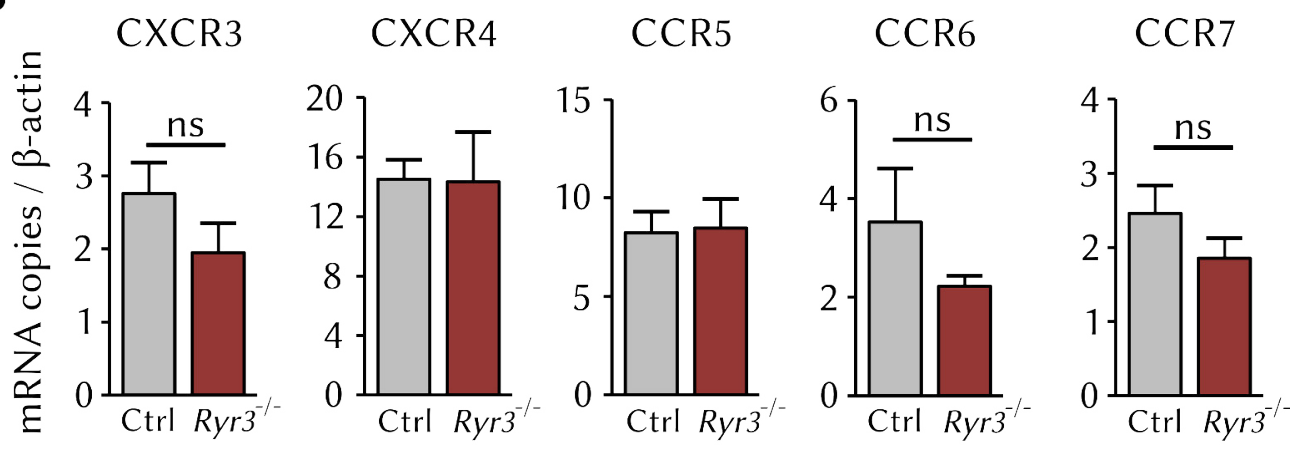

C
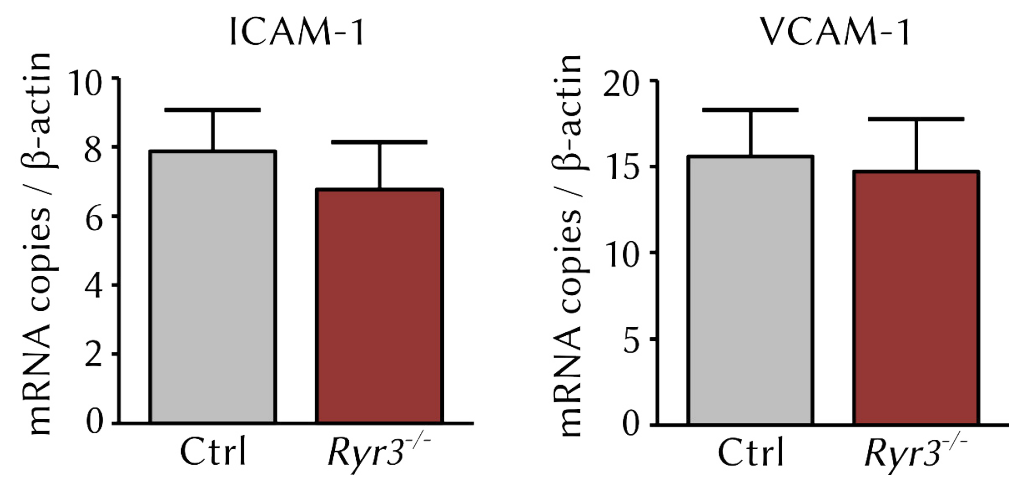

Fig. 3.35 | Chemokine and cytokine mRNA expression is reduced in $R y r 3^{-/}$astrocytes during EAE, while there were no changes in chemokine receptor mRNA expression in encephalitogenic T cells of the same animal. $R y r 3^{--}$and control mice were immunized against $\mathrm{MOG}_{35-55}$ peptide. Spinal cords were isolated from perfused animals at d11 p. i., and astrocytes and T cells were either isolated by MACS or purified by gradient centrifugation and negative selection. Lysates from isolated astrocytes were used for real-time PCR analysis for expression of $\mathrm{Ccl}$, Ccl5 and $\mathrm{Cxcl} 10$ mRNA (A), while T cells were analyzed for Cxcr3, Cxcr4, Ccr5, Ccr6 and Ccr7 mRNA expression (B). Bars represent the mean (+SEM) of three independent experiments. Statistical analysis was performed using a two-tailed Student's $t$-test $\left({ }^{*} P \leq 0.01,{ }^{*} P \leq 0.05\right.$, ns $\left.P \geq 0.05\right)$.

\subsubsection{Activation status and quantity of infiltrating $R y r 3^{-/-} \mathrm{T}$ cells}

At the peak (d17 p. i.) of the EAE, fewer T cells and macrophages were found in spinal cords of $R y \mathrm{r}^{-/-}$mice (Fig. 3.17). It was also found that $R y \mathrm{r}^{-1-}$ astrocytes produced less chemokines at the onset of EAE as well as upon stimulation with Th1 related cytokines (Fig. 3.34; Fig. 3.35, A). Thus the activation status and the quantity of $\mathrm{T}$ cells during the acute phase of EAE was investigated in the spinal cord (d14 p. i.; Fig. 3.36). While Ryr $3^{-/}$and control $\mathrm{CD}^{+} \mathrm{T}$ cells were found equally activated within the spinal cord, the total $\mathrm{CD}^{+}$cell count was reduced significantly. However, the activation status and quantity of $\mathrm{CD}^{+} \mathrm{T}$ cells was similar between $R y r 3^{--}$and controls in the lymph nodes and spleen before disease onset (d8 p. i.; Fig. 3.37), indicating that fewer $\mathrm{T}$ cells-even though equally activated-home into the CNS. 


\section{Results}
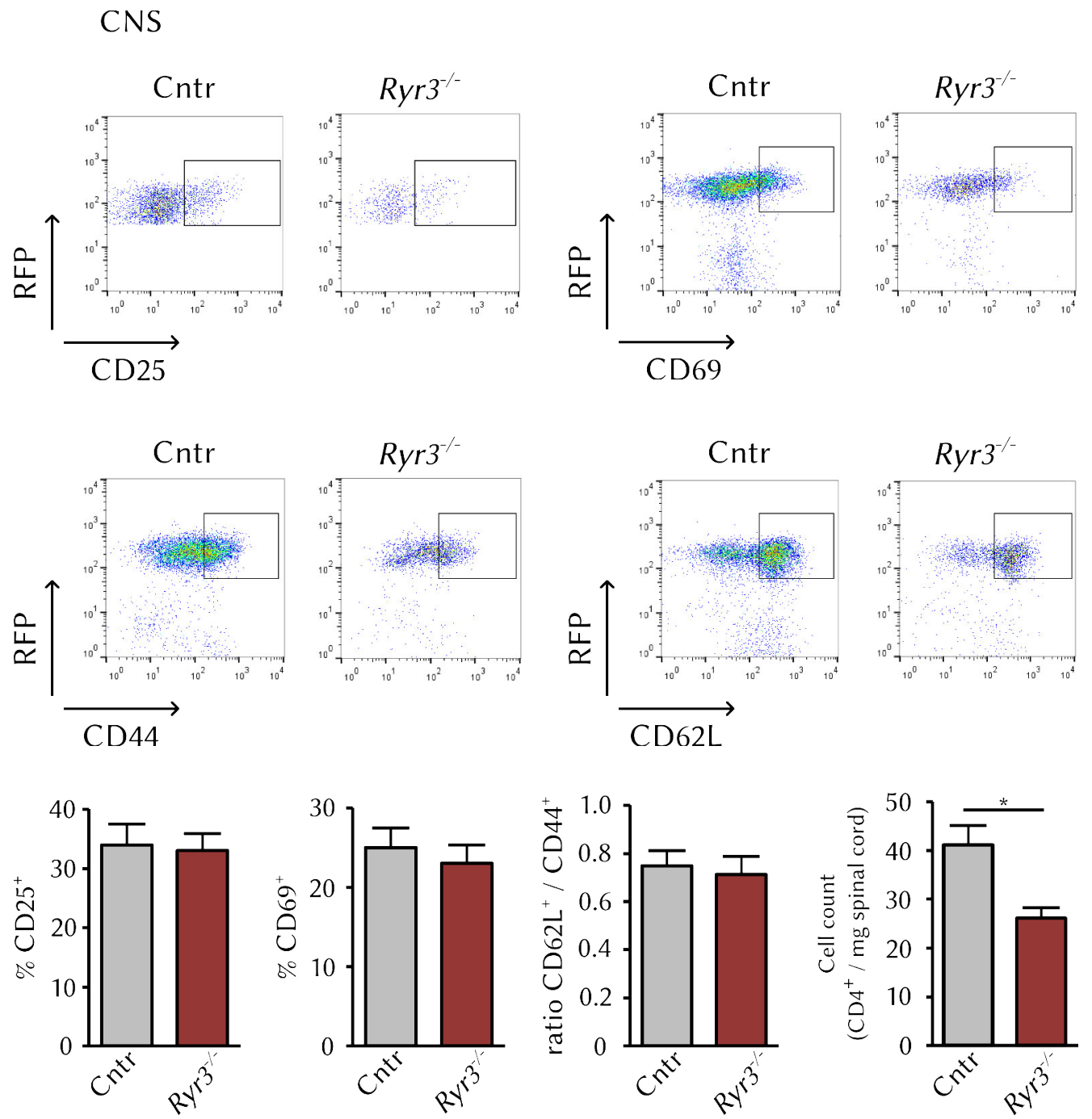

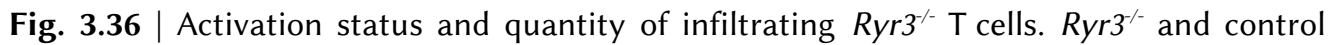
mice (each $n=3$ ) were immunized against $M_{30 G}$ peptide. Spinal cords were isolated from PBS perfused animals at d14 p. i., and lymphocytes were isolated by gradient centrifugation. Cells were stained and analyzed by flow cytometry for the activation markers CD25, CD69 and CD44 as well as the frequency of naïve T cells (CD62L expression). For the analysis, cells were gated on the $\mathrm{CD} 4^{+}$population. The absolute number of $\mathrm{CD} 4^{+}$ cells within the spinal cord was quantified with the help of counting beads and calculated on the organ weight. Bars represent mean+SEM. Statistical analysis was performed using a two-tailed Student's $t$-test $\left({ }^{*} P \leq 0.05\right)$. 


\section{Results}

\section{Lymph nodes}
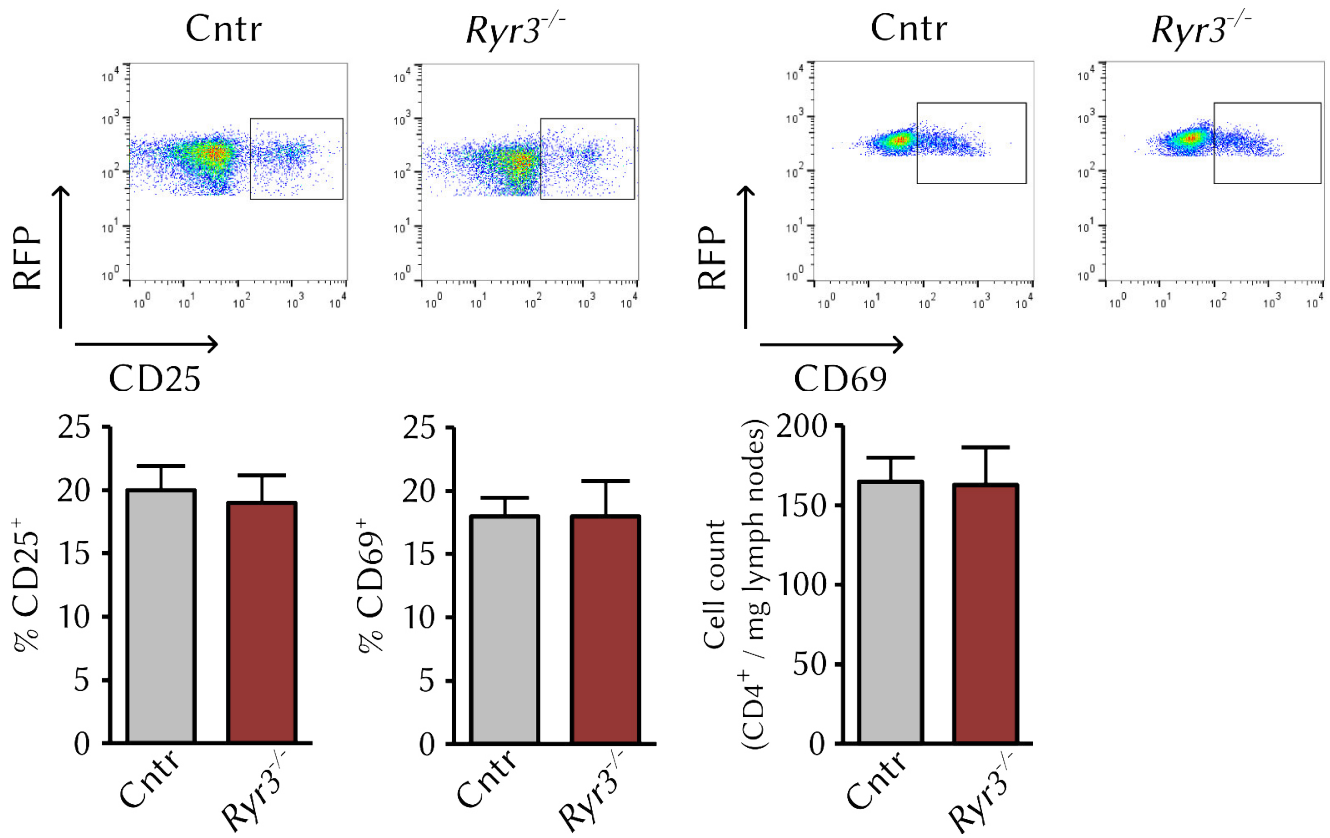

\section{Spleen}
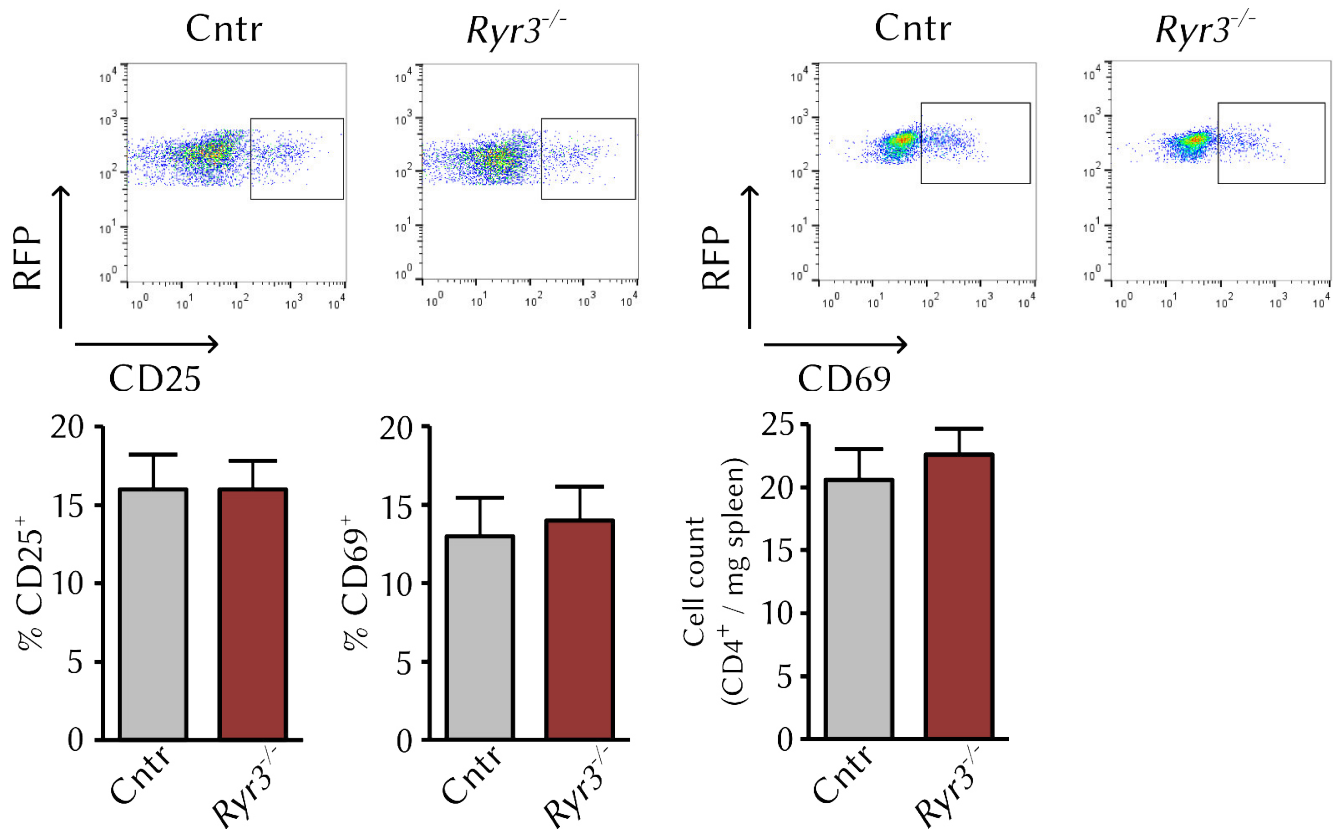

Fig. 3.37 | The quantity and activation status of T cells in the periphery is not altered in Ryr $^{-/}$animals before EAE onset. Ryr3 $3^{-/-}$and control mice (each $n=3$ ) were immunized against $\mathrm{MOG}_{35-55}$ peptide. Lymph nodes and spleen were isolated from PBS perfused animals at $\mathrm{d} 8 \mathrm{p}$. i., homogenized and depleted for erythrocytes. Cells were stained and analyzed by flow cytometry for the activation markers CD25 and CD69. The absolute number of $\mathrm{CD}^{+}$cells within lymph nodes and spleen was quantified with the help of counting beads and calculated on the organ weight. For the analysis, cells were gated on the $\mathrm{CD} 4^{+}$population. Bars represent mean+SEM. 


\subsubsection{T cell migration towards $R y r 3^{-/}$astrocytes conditioned medium in vitro}

To determine whether the lower chemokine production in Ryr $3^{--}$astrocytes affected the migration capability of $\mathrm{T}$ cells, in vitro testing by means of transwell migration assays was employed (Fig. 3.38). Supernatants from stimulated $\mathrm{Ryr}^{-/}$and control astrocytes were used as testing agents for encephalitogenic WT T cells. It was observed that fewer T cells migrated to supernatants of $R y \mathrm{rr}^{-/}$astrocytes that had been stimulated with IFN- $\gamma / \mathrm{TNF}-\alpha$ compared to control supernatants. The same effect was seen in the assay using glutamate stimulated astrocyte supernatants. Migration towards supernatants of ATP treated Ryr $3^{-/-}$astrocytes was comparable to that of ATP stimulated control astrocytes.

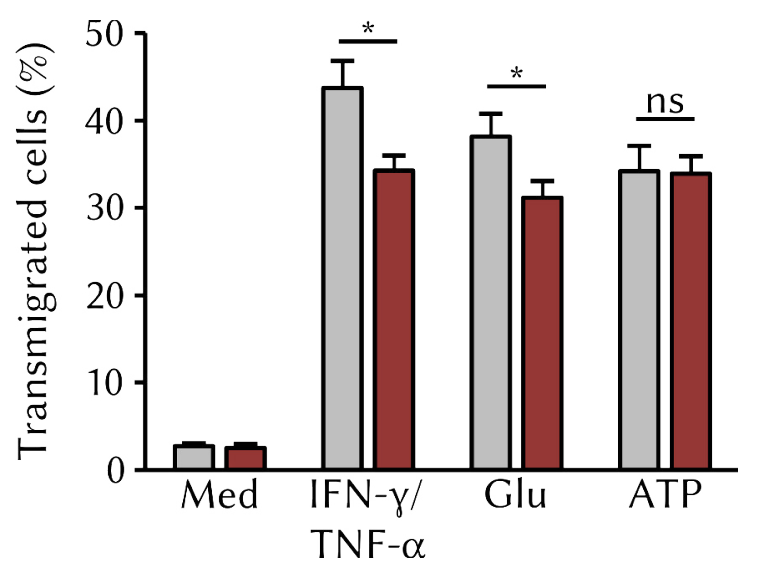

Fig. 3.38 | WT T cells transmigrate less towards $R y r 3^{-/-}$astrocytes derived supernatant containing medium. Ryr3 $3^{--}$and control astrocytes were stimulated with $100 \mathrm{ng} / \mathrm{ml}$ IFN- $\gamma /$ TNF- $\alpha, 100 \mu \mathrm{M}$ glutamate (Glu), $30 \mu \mathrm{M}$ ATP or left untreated (medium control; Med) for $2 \mathrm{~h}$. Supernatants were collected and 1:10 dilutions were used as testing agents. WT T cells were isolated from draining $L N s$ of immunized animals at $d 9 \mathrm{p}$. i. and allowed to transmigrate for $5 \mathrm{~h}\left(1 \times 10^{4} \mathrm{~T}\right.$ cells/well $)$. The frequency of transmigrated cells was determined by flow cytometry. Bars represent the mean (+SEM) of three independent experiments. Statistical analysis was performed using a two-tailed Student's $t$-test $\left({ }^{*} P \leq\right.$ 0.05 , ns $P \geq 0.05$ ).

\subsubsection{MHCII expression is not altered in $R y r 3^{-/-}$astrocytes and microglia}

Under neuroinflammatory conditions, microglia and under some conditions also astrocytes up-regulate MHC-II molecules for optimal APC function and T cell restimulation in the CNS (RANSOHOFF AND ESTES, 1991). However, $\mathrm{Ryr}^{-/}$astrocytes and microglia did not differ from controls in their level of MHC-II expression upon IFN- $\gamma$ stimulation (Fig. 3.39). 
A

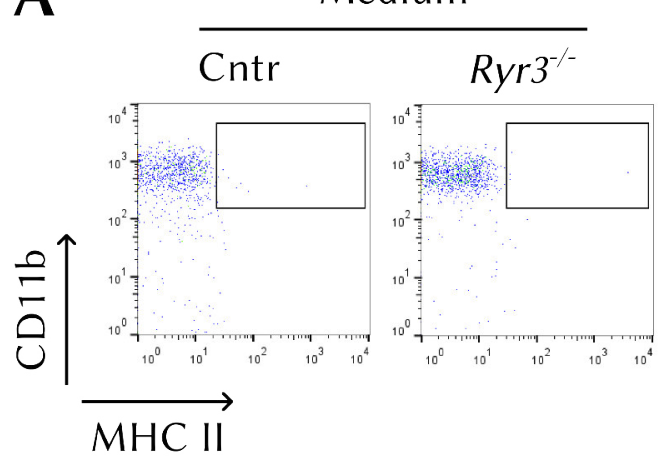

B

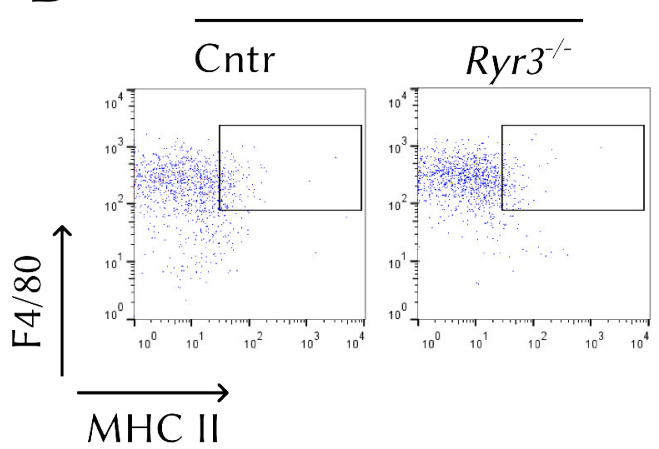

C Astrocytes

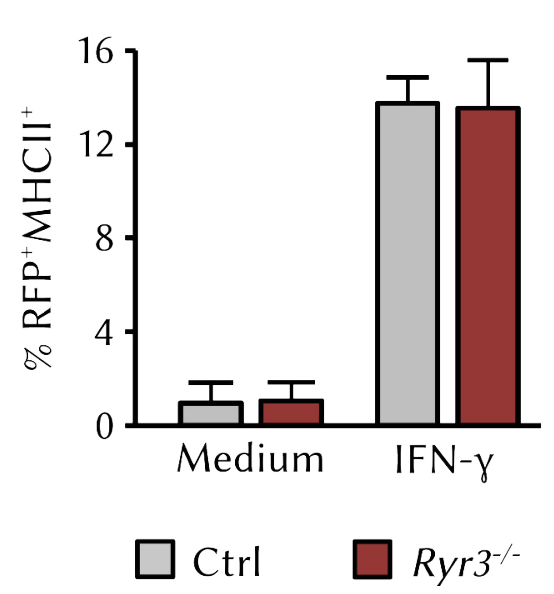

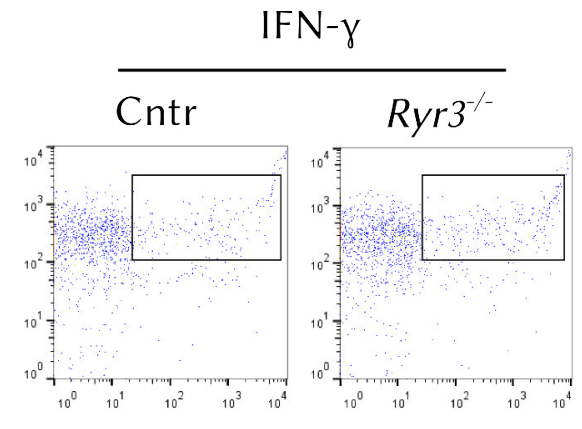

IFN- $\gamma$

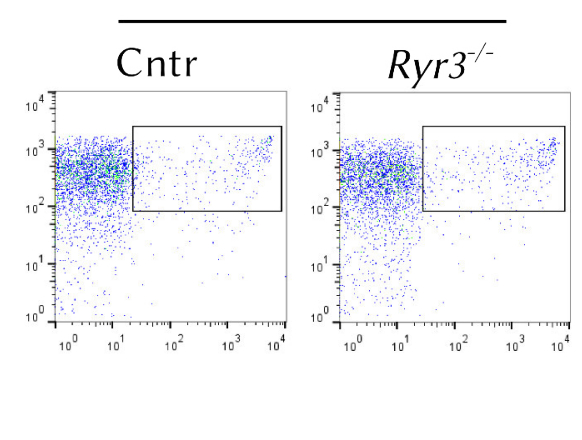

Microglia

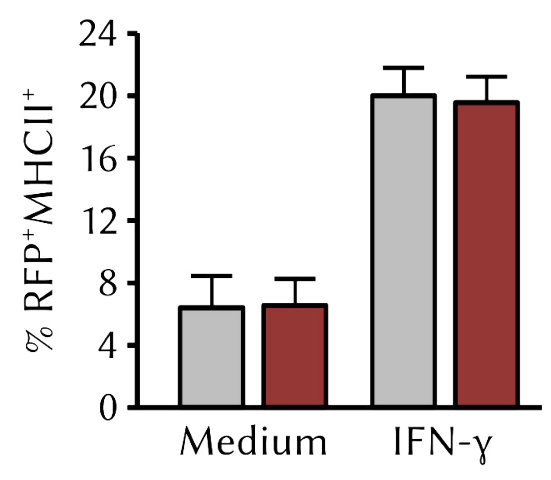

Fig. 3.39 $\mid \mathrm{MHCll}$ expression in Ryr3 $3^{-/}$primary astrocytes and microglia is not altered compared to controls. MHCII expression was assessed in $\mathrm{CD} 11 \mathrm{~b}^{+}$astrocytes $(\mathrm{A})$ and $\mathrm{F} 4 / 80^{+}$ microglia (B) by flow cytometry after $24 \mathrm{~h}$ stimulation with $100 \mathrm{ng} / \mathrm{ml} \mathrm{IFN}-\gamma$. 


\subsubsection{Dantrolene treated C57B1/6 WT mice develop attenuated EAE}

The muscle relaxant dantrolene exhibits its effect by the selective blockage of RyR1 and RyR3 (with preference for RyR1), and is used in the clinic for the treatment of malignant hyperthermia $(\mathrm{MH})$. As for its specificity for Ryr1 and RyR3-but not RyR2-it came into focus for this study as a pharmacological tool to interfere with RyR signaling during EAE. A cohort of WT C57Bl/6 mice was immunized against $\mathrm{MOG}_{35-55}$ peptide. The mice were treated once a day with $20 \mathrm{mg} / \mathrm{kg}$ dantrolene in $10 \%$ DMSO in PBS, or received $10 \%$ DMSO as a vehicle control. The treatment was carried out starting on the day of immunization and was terminated when the first clinical symptoms appeared in control mice (Fig. 3.40 A, C and D). First clinical symptoms appeared at about day 12 after immunization in control mice, two days before first signs of EAE were observed in the group of dantrolene treated animals (Fig. 3.40, C). In the control group, the course of EAE peaked on day 19 with an average score of about 6, whereas dantrolene treated mice developed a delayed and significantly ameliorated disease (Fig. 3.40, A). It was found that weight loss occurred in both groups of mice, but was less pronounced in dantrolene treated group of mice (Fig. 3.40, B). In addition to the clinical data, histological analysis on the tissue collected $\mathrm{d} 25$ p. i. showed that demyelination and the severity of axon damage were strongly reduced in spinal cords of dantrolene treated mice (Fig. 3.40, E and F). 


\section{Results}

A $\rightarrow$ DMSO

$\leftarrow$ Dantrolene
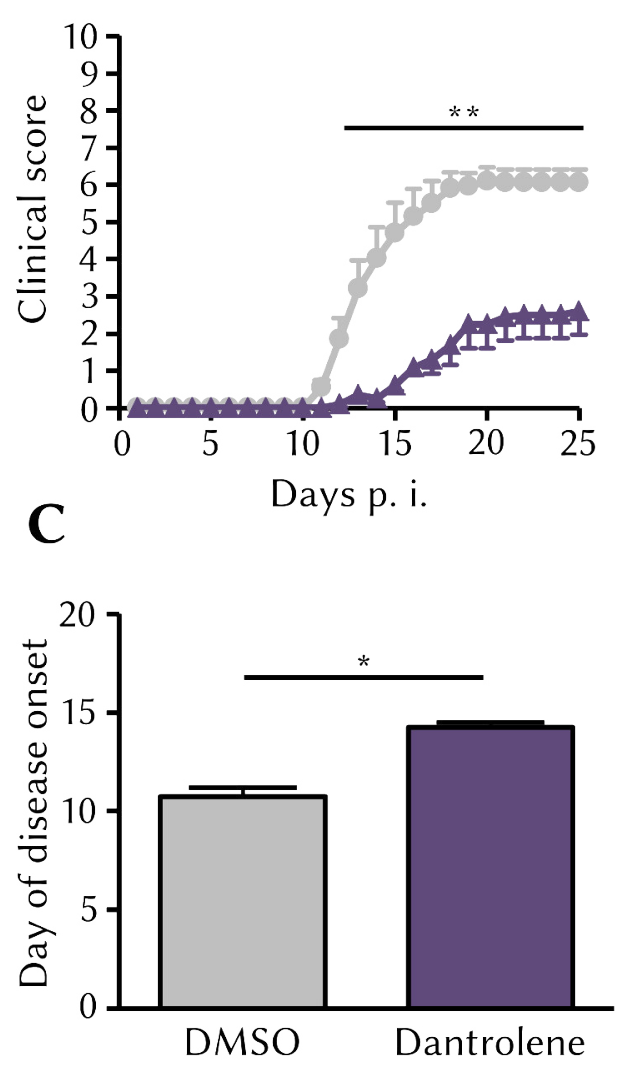

B
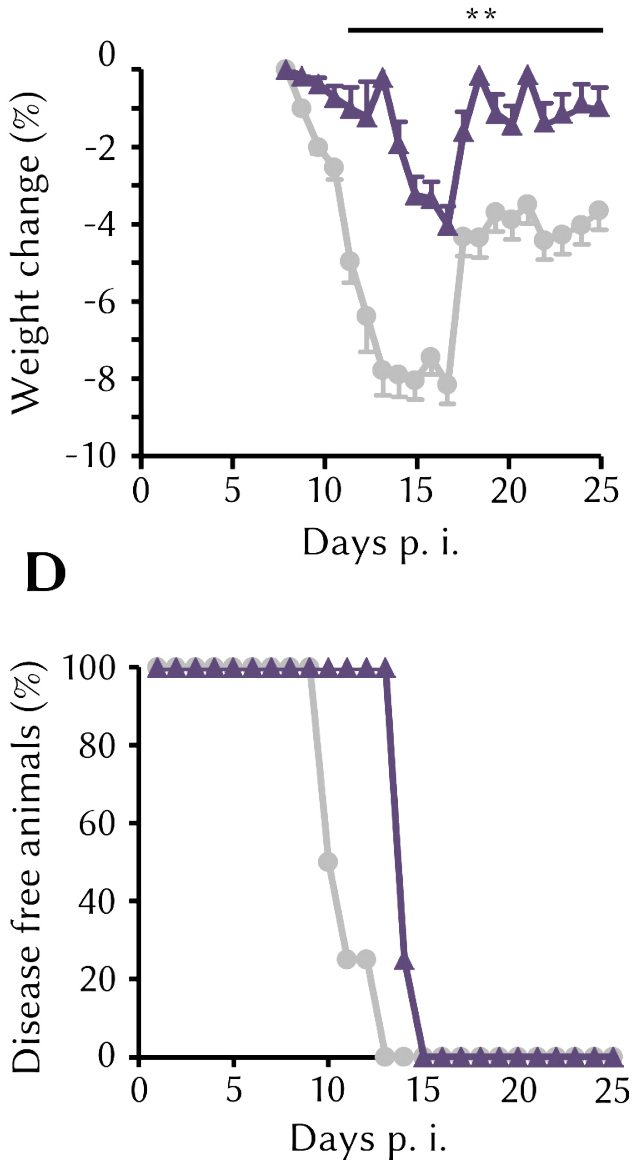

Fig. 3.40 A-D | Dantrolene treated mice develop strongly attenuated and delayed EAE. Mice ( $n=10$ per group) were immunized against $M O_{35-55}$ peptide. Dantrolene solved in $10 \%$ DMSO was applied i.p. at $20 \mathrm{mg} / \mathrm{kg}$ daily starting at $\mathrm{d} 0$ until disease onset of mice of the control group. Injections of $10 \%$ DMSO served as controls. (A) EAE disease course, and (B) weight change course of dantrolene treated mice (purple line) and DMSO treated mice (grey line). (C) Day of disease onset. (D) Percentage of disease free animals. In all panels the mean (+SEM) of two independent experiments is shown. Statistics were carried out using the Mann-Whitney $U$ test for clinical courses $\left(\mathbf{A}, \mathbf{B} ;{ }^{* *} P \leq 0.01\right)$ and a two-tailed Student's $t$ test $\left(\mathbf{C} ;{ }^{*} P \leq 0.05\right)$. 


\section{Results}
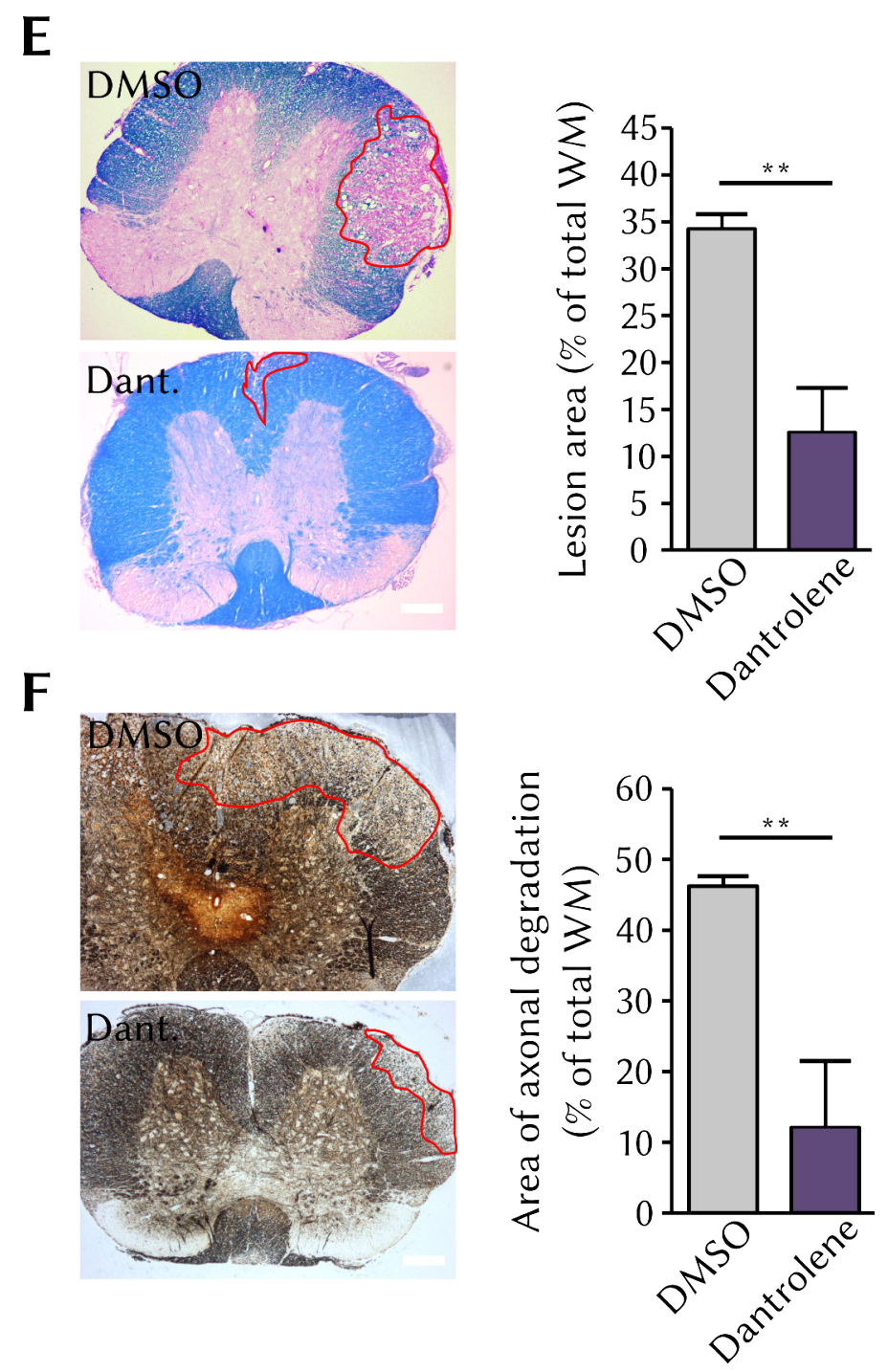

Fig. 3.40 (E) and (F) | Demyelination and axonal loss are reduced in dantrolene treated mice. Spinal cords ( $n=3$ for each group) were isolated at the end of the observation period (d25 p. i.) and used for paraffin sections. (E) shows the evaluation of demyelination. Samples were stained with luxol fast blue solution to detect myelin, combined with a periodic acidSchiff reaction to visualize exposed glycoproteins in the deymelinated regions. The percentage of demyelination was calculated for the area of the white matter. (F) shows the evaluation of axonal degradation by means of Bielschowsky's silver stain. The percentage of axonal loss was calculated for the area of the white matter. For the statistical analysis, at least five sections from the cervical, thoraic and lumbar segment were investigated for each spinal cord. Bars represent mean (+SEM). Data were statistically tested using a two-tailed Student's $t$-test $\left({ }^{* *} P \leq 0.01\right)$. Representative images are shown from animals with a clinical score of 7.0 (DMSO) and 3.0 (dantrolene treated). 


\section{Discussion}

\subsection{Expression of RyRs in effector T cells}

Present investigations on RyRs in $\mathrm{C} 57 \mathrm{Bl} / 6$ mice started with the evaluation of Ryr1 and Ryr3 mRNA expression in murine immune cells, including naïve $\mathrm{T}$ cells, effector T cells, resting B cells, activated B cells and dendritic cells. Ryr1 and Ryr3 mRNA was expressed in effector T cells, with notable higher levels of Ryr1 mRNA rather than Ryr3. No copies of Ryr1 or Ryr3 mRNA were found instead in naïve $\mathrm{T}$ or $\mathrm{B}$ cells and only minimal amounts of Ryr1 or Ryr3 mRNA were detected in dendritic cells (Fig. 3.1). RyRs are very large proteins-with over one hundred exons-making them the largest known ion channels. Even though the half-life is not known for RyR1 and RyR3, it is estimated for about eight days for RyR2 (SANTONASTASI AND WEHRENS, 2006). In comparison, the half-life of beta-actin, which is a commonly used housekeeping gene, is about $24 \mathrm{~h}$. It is thus very likely that sufficient mRNA levels of RyRs may only be detectable in (fast) dividing cells when lots of mRNA copies are produced like it happens during the proliferation of $\mathrm{T}$ cells, but not in cells that are resting or in a steady state.

The expression of RyR1 and RyR3 proteins in rat effector T cells, previously shown by CORDIGLIERI et al. (2010), was confirmed in this study in mouse effector T cells. The kinetic of RyR1 and RyR3 expression in splenic T cells was determined within the first $96 \mathrm{~h}$ upon stimulation with either antiCD3/CD28 antibodies or $\mathrm{MOG}_{35-55}$ peptide (Fig. 3.2). This result confirmed the assumption that Ryr mRNA is primarily detectable during phases of $\mathrm{T}$ cell proliferation rather than in unstimulated cells. In a support of the real-time PCR data, the expression of RyR1 and RyR3 proteins could be detected by fluorescent staining in effector T cells (Fig. 3.3).

\subsection{The role of RyR1 expression in T cells during EAE}

$\mathrm{T}$ cell activation relies on the fast increase in free intercellular $\mathrm{Ca}^{2+}$ that is initially triggered by $\mathrm{IP}_{3} \mathrm{Rs}$ and most probably, RyRs. The evidence of RyR1 and RyR3 expression in rat and murine effector $\mathrm{T}$ cells supported this hypothesis. We further addressed the importance of RyR1 for $\mathrm{T}$ cell activation with the help of RyR knockout mice. Ryr1 ${ }^{-1}$ (TAKESHIMA et al.,

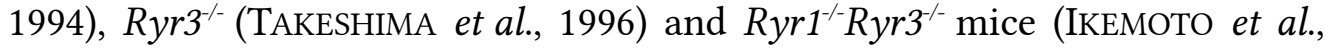


2008), each crossed to RFP reporter (expressed from Rosa26 locus) mice, provided the basis for the current study. However Ryr1 deficient, but not Ryr3, mice die soon after birth. However, as we were interested in RyR1 function in T cells, we bypassed these circumstances with the generation of chimeric mice (fetal liver chimeras, FLCs), by reconstitution of irradiated WT mice with embryonal $R y \mathrm{r}^{-/}$hematopoietic progenitor cells (chapter 2.4.2 and Fig. 3.4). To generate a comparable condition for the analysis of $R y r 3$ deficient or DKO T cells. Ryr $1^{+-} R y r 3^{+/-}$mice were mated with $R y r 1^{+-} R y r 3^{-/-}$and embryos of appropriate genotypes were used for FLC production. The distribution of the genotypes among the fetuses followed the Mendelian rules and resulted in $37.5 \%$ controls and Ryr $3^{-/-}$single KOs, but only $12.5 \%$ $R y r^{-/}$single KOs and double KOs. This has complicated generation of FLCs, as not in every mating all genotypes were present. In any case, expression of the RFP fluorescent reporter gene by the respective KO cells allowed us the validation of sufficient hematopoietic cell reconstitution that for B cell lineage usually exceeded $80 \%$, whereas for peripheral $\mathrm{T}$ cells remaining host derived population ranged $25-40 \%$. This underscores the need for congenic marker (RFP) to restrict the analysis to donor derived $\mathrm{T}$ cells. Comparing to control chimeras, the reconstitution with $R y r 1^{-1-}$ hematopoietic progenitor cells did not influence the weight or cellularity of thymus and spleen (Fig. 3.5). Neither it altered T cell development in the thymus (Fig. 3.6), nor the composition of the peripheral immune system (Fig. 3.7). The same was observed for $\mathrm{Ryr}^{-/-}$and Ryr-DKO. Altogether, Ryr1 and Ryr3 seem not to play a major role during $\mathrm{T}$ cell development, which is concordant with detectable expression of these receptors only in differentiated effector but not naïve $\mathrm{T}$ lymphocytes.

Binding of peptide-MHC complexes by TCRs of naïve T cells results in T cell activation (JENKINS et al., 2001), followed by rapid proliferation and differentiation into effector cells (SEDER AND AHMED, 2003). We analyzed T cells from $R y r 1^{--}, R y r 3^{--}$and $R y r-\mathrm{DKO} \rightarrow \mathrm{WT}$ FLCs for their ability to proliferate in response to anti-CD3 or anti-CD3/CD28 antibody stimulation (Fig. 3.9). Ryr-KO FLCs were compared with heterozygous control FLCs $\left(\right.$ Ryr $\left.^{1^{+-}} \mathrm{Ryr}^{+/} \rightarrow \mathrm{WT}\right)$ and showed decreased proliferation in response to TCR stimulation. Our results were supported by the data of our collaborating partners from the lab of Dr. A. Guse (UKE, Hamburg) on the role of RyR1 in calcium signaling during T cell activation (WOLF et al., 2015, manuscript in revision and Fig. 3.8): WOLF and colleagues demonstrated that $R y r 1^{-/}$played crucial role for the formation of early, initial intracellular $\mathrm{Ca}^{2+}$ signals in T cells upon stimulation of TCR. This finding is in agreement with results that indicated a possible role of RyR 1 for effector $\mathrm{T}$ cell activation in the rat (CORDIGLIERI et al., 2010). However, the additional knockout of Ryr3 had no further attenuating effect on $T$ cell proliferation (Fig. 3.9), and T cells lacking Ryr3 alone did not proliferate differently from controls (Fig. 3.9). These results again fit to the mRNA expression data and we concluded that RyR1in contrast to RyR3-is the more important isoform for T cell activation.

After priming and proliferation in the lymph nodes, $\mathrm{T}$ cells enter the blood 
circulation to search for antigen (GOVERMAN, 2009). We assumed that the reduced ability of $R y r^{-1-} \mathrm{T}$ cells to proliferate in response to TCR stimulation would also influence the clinical outcome of EAE. We induced EAE in Ryr ${ }^{-1}$ $\rightarrow$ WT FLCs by active immunization against $M_{35-55}$ peptide (Fig. 3.10) and observed that mice with Ryr1 deficiency in hematopoietic cells developed an attenuated disease course. We also observed a slight delay during the acute phase of EAE. However, the day of disease onset was not significantly altered in $R y r 1^{-1} \rightarrow$ WT FLCs. Since the majority of T cells in $R y r 1^{--} \rightarrow$ WT FLCs were lacking Ryr1, the delayed and attenuated disease course could be explained by a fewer number of postactivated $\mathrm{T}$ cells that leave the LNs where they proliferate upon immunization. This was supported by the lower frequency of T cells found in the CNS of $R y r 1^{-1} \rightarrow \mathrm{WT}$ FLCs at d14 of the disease and was accompanied by lower expression of the surface activation markers CD25 and CD69 on these cells (Fig. 3.13). Future experiments will show if the attenuation of EAE in $R y r 1^{-} \rightarrow$ WT FLCs is restricted to the deficiency of RyR1 in T cells. Even though the mRNA data concerning the expression of Ryr1 in immune cells do not support this possibility, it cannot be generally excluded that RyR1 plays functions in other hematopoietic cells. A potential objective for investigations might be the antigen presentation to $\mathrm{T}$ cells by dendritic cells in the LNs, since we showed that Ryr1 mRNA is expressed in these cells, even though at minimal levels (Fig. 3.1).

Next, EAE was induced in $R y r$-DKO $\rightarrow$ WT FLCs, which developed a similar attenuated disease course as observed in Ryr $^{1-} \rightarrow$ WT FLCs (Fig. 3.11). While EAE symptoms were significantly reduced in $R y r$-DKO $\rightarrow$ WT FLCs at the peak of EAE, the disease course showed no signs of a delay during the acute phase. In addition, some mice partially recovered during the chronic phase, which was not observed in $R y r^{-1} \rightarrow$ WT FLCs. This resulted in considerable deviations in the mean clinical score, that complicates conclusive interpretation of the EAE results in the chronic phase of $R y r-\mathrm{DKO} \rightarrow \mathrm{WT}$ experiments. However, T cells from $R y r$-DKO $\rightarrow$ WT FLCs were found in a lower number and also less activated in the CNS (Fig. 3.13). Anyway, the effect of the additional Ryr3 ablation was rather minimal. This became even more clear when we analysed EAE in $R y r 3^{-/} \rightarrow$ WT FLCs. Though these mice developed an EAE that was by tendency milder than in controls at the chronic stage of disease (Fig. 3.12), the difference to controls was minimal and not statistically significant. The results supported the in vitro observations (Fig. 3.36 and chapter 3.3.5, discussed later) that Ryr3 deletion alone does not have a strong impact on $\mathrm{T}$ cell function and thus on the EAE development.

We assume that amelioration of EAE symptoms in $R y r 1^{-1-} \rightarrow$ WT FLCs was mediated by Ryr1 deletion in T cells. Future experiments will show if this holds true for $\mathrm{T}$ cell activation in the lymph nodes, thus leading to fewer $\mathrm{T}$ cells that home for the CNS, or T cell reactivation within the CNS.

The generation of fetal liver chimeras allowed us the investigation of Ryr1 deletion, even though we could not breed $R y r 1^{-1-}$ mice. However, since 
reconstitution of hematopoietic cells was never $100 \%$, we could not rule out that our results were influenced by the remaining endogenous $\mathrm{T}$ cells that are WT for Ryr1. So, prospective experiments should be performed in OT II host mice whose $\mathrm{T}$ cells are specific against the non-self antigen ovalbumine (OVA) and do not respond to $\mathrm{MOG}_{35-55}$ immunization. By that, an influence of remaining endogenous $\mathrm{T}$ cells, that potentially harbor MBP-specific ones, on the outcome of EAE should be eliminated. A second approach to study RyR1 function would be the generation of a conditional KO for Ryr1. This would avoid early lethality and allow the investigator to control the usage of $R y \mathrm{r}^{-1-}$ at different stages of EAE in specific populaions. Since we were interested specifically in $\mathrm{T}$ cell function, a T cell specific $\mathrm{KO}$ for the Ryr1 gene would further specify the role of RyR1 in T cells during EAE.

\subsection{The role of RyR3 in EAE}

Homozygous Ryr3-KO mice are viable and fertile, allowing EAE experiments in adult non-chimeric animals. Mice with whole-body Ryr3 deletion showed a significantly ameliorated EAE course after active immunization against $\mathrm{MOG}_{35-55}$ peptide compared to $R y \mathrm{r}^{+/}$controls (Fig. 3.16). Heterozygous littermates served as suitable control animals since we found no differences in the clinical outcome of EAE between $R y r 3^{+/}$and $R y r 3^{+/+}$mice (not shown). Interestingly, the results differed from the EAE observed in $R y r 3^{--} \rightarrow$ WT FLCs and we assumed that deletion of Ryr3 in cells that did not derive from the hematopoietic lineage were responsible for disease attenuation.

Considerable expression of RyR3 was reported for the mammalian brain (MURAYAMA AND OGAWA, 1996), and we confirmed expression of Ryr3 mRNA for the total brain and the spinal cord tissues of $\mathrm{C} 57 \mathrm{Bl} / 6$ mice (Fig. 3.14). We investigated whether the observed attenuation of EAE in $R y r 3^{-/}$mice was due to the deletion of Ryr3 in the CNS and so we generated bone marrow chimeras (BMCs) by the transfer of $R y r 3^{+/+}$bone marrow cells into irradiated $R y{ }^{-/-}{ }^{-}$recipient mice. EAE in these animals proceeded similar to that of germ line $R y$ r $^{-/}$mice (Fig. 3.15). In any case, mice shared an identical onset and acute phase of EAE with the respective controls, while disease proceeded significantly milder at the peak and during the chronic phase of EAE.

Histological analysis revealed fewer infiltrating $\mathrm{T}$ cells and macrophages in the CNS of Ryr $^{-/}$mice (Fig. 3.17). We also detected fewer reactive microglia at the inflammatory sites (Fig. 3.18) and observed less demyelination as well as axonal loss (Fig. 3.19). Interestingly, while the frequency of CNS infiltrating T cells was significantly lower in $\mathrm{Ryr}^{3--}$ mice, the activation status of $\mathrm{T}$ cells was similar to that of controls (Fig 3.36) when we investigated the situation in the acute phase of EAE. 
Thymus and spleen developed similar in $R y r 3^{-/}$mice, and no alterations in thymic $T$ cell development were observed (Fig. 3.22 and Fig. 3.23). However, we found a shift in the ratio of $\mathrm{CD} 4^{+} / \mathrm{CD}^{+} \mathrm{T}$ cells towards the cytotoxic $\mathrm{T}$ cell population in lymph nodes and spleen of $R y \mathrm{r}^{-\sim}$. Apart from that, the composition of the immune system in lymph nodes and spleen of Ryr $3^{-/}$mice was similar to that of controls (Fig. 3.24 and Fig. 3.25). As well as observed in Ryr $3^{-} \rightarrow$ WT FLCs (Fig. 3.12), T lymphocytes from Ryr ${ }^{-1-}$ mice proliferated similar to controls upon TCR stimulation in vitro (Fig. 3.26). We could confirm this by the analysis of in vivo proliferation of transferred MOG-specific Ryr3 ${ }^{--}$T cells in the draining lymph nodes after immunization (Fig. 3.27). There was also no impairment in the ability of Ryr $^{-\alpha} \mathrm{T}$ cells to recall antigen in vitro after previous priming in the secondary lymphoid organs (Fig. 3.29). The latter result matched to unchanged $\mathrm{T}$ cell numbers in lymph nodes and spleen one day before EAE onset (Fig. 3.37). By transfer of MOG-specific 2D2 Ryr $3^{-/} \mathrm{T}$ cells into OT II mice (homozygous tg/tg genotype) we tested whether or not specific ablation of Ryr3 in T cells would affect EAE development upon immunization (Fig. 3.28). In OT II mice OVA-specific $T$ cells do not respond to MOG immunization making the animals resistant to active EAE unless supplemented with exogenous $\mathrm{T}$ cells. Under these conditions, EAE development would be exclusively driven by the transferred T cells. On the other hand, OT II mice harbor a normal immune system to assure for example normal priming of $\mathrm{T}$ cells in the lymph nodes or antigen presentation in the CNS. However, we observed no significant differences in the EAE between mice that received MOG-specific $R y r 3^{-/}$or control T cells.

We concluded, that Ryr3 deletion did not affect the proliferative response of $\mathrm{T}$ cells upon TCR dependent stimulation, either in vitro or in vivo, or their ability to leave the lymphoid organs in order to home for the CNS. Furthermore we demonstrated that $R y r 3^{--} \mathrm{T}$ cells were not altered in their activation status after restimulation in the CNS.

Spontaneous EAE is of great advantage to study autoimmune CNS disease without active immunization or transfer of in vitro activated encephalitogenic $\mathrm{T}$ cell blasts. It results from the presence of $\mathrm{T}$ cells and $\mathrm{B}$ cells that are both specific for the same autoantigen MOG. We crossed our $\mathrm{TCR}^{\mathrm{MOG}} \times \mathrm{Ryr}^{-/}$mice to $\mathrm{IgH}^{\mathrm{MOG}}$ mice to investigate spontaneous $\mathrm{EAE}$ in the context of Ryr3 deficiency. We demonstrated that $R y r 3^{-1-} \times \mathrm{TCR}^{\mathrm{MOG}} \times \mathrm{IgH}^{\mathrm{MOG}}$ mice developed $\mathrm{EAE}$ less frequently and later in life than $\mathrm{Ryr}^{3^{+-1}}$ $\times \mathrm{TCR}^{\mathrm{MOG}} \times \operatorname{IgH} \mathrm{IgG}^{\mathrm{MOG}}$ control mice. Furthermore, Ryr3 deficient animals had reduced EAE severity (Fig. 3.20) If we assume that Ryr3 deletion in T cells does not affect the clinical outcome of EAE, this result seemed to be surprising at first glance, since spontaneous EAE strongly relies on T cellB cell interactions. However, also in spontaneous model, Ryr3 was deleted systemically, and not specifically in T cells. So actually, the clinical data indirectly supported our initial hypothesis that deletion of Ryr3 in cells of the CNS mediated the observed EAE attenuation. 


\subsection{The importance of RyR3 in astrocytes}

Astrocytes are the major population of glia cells in the CNS and are involved in numerous processes within the CNS, such as brain homeostasis, neuronal support and the recycling of excess neurotransmitters. Together with endothelial cells, astrocytes are also involved in maintaining the integrity of the blood-brain barrier. There, astrocytes form specialized endfeet that are in close contact to the intraparenchymal blood vessels. In case of smaller injuries or infections, astrocytes may become activated by inflammatory factors such as cytokines and release neuromodulators such as chemokines themselves to recruit microglia and circulating immune cells to the pathological site. During severe neuroinflammation the sustained release of pro-inflammatory cytokines and chemokines may allow peripheral immune cells, that were recruited to the CNS by sensing chemokine gradients, the migration across the blood-brain barrier, thereby supporting the generation of chronic neuroinflammatory diseases.

Activated astrocytes respond with an increase of intracellular $\mathrm{Ca}^{2+}$ that can spread troughout the astrocytic network in oscillatory waves via gap junctions, thereby triggering the activation of neighboring astrocytes. In order to test whether or not RyR3 contributes to the generation of $\mathrm{Ca}^{2+}$ signals in cultures of primary astrocytes, we induced strong $\mathrm{Ca}^{2+}$ signals by the application of ATP and measured the $\mathrm{Ca}^{2+}$ response by subcellular $\mathrm{Ca}^{2+}$ imaging (Fig. 3.31) Astrocytes responded with a fast and sudden increase of intracellular $\mathrm{Ca}^{2+}$ to ATP, followed by oscillating $\mathrm{Ca}^{2+}$ signals in some cells. However, the $\mathrm{Ca}^{2+}$ response was attenuated in astrocytes lacking Ryr3. This was supported by the findings that $\mathrm{Ca}^{2+}$ dependent release of the common neurotransmitter glutamate was reduced in $\mathrm{Ryr} 3^{--}$astrocytes upon activation.

The sustained production of chemokines under inflammatory conditions plays a key role for the manifestation of chronic neuroinflammatory diseases, such as EAE or MS. We tested whether deletion of Ryr3 attenuated the ability of astrocytes to produce certain chemokines, including CCL2, CCL5 and CXCL10, which represent important chemoattractants for the recruitment of $\mathrm{T}$ cells and monocytes. In fact, production of these chemokines was notably reduced in $\mathrm{Ryr}^{-/}$astrocytes upon stimulation with the pro-inflammatory and $\mathrm{CD}^{+} \mathrm{T}$ cell related cytokines IFN- $\gamma$ and TNF- $\alpha$. (Fig. 3.34). We confirmed the attenuated ability of $R y r 3^{-/}$astrocytes to produce chemokines also under EAE conditions (Fig. 3.35). The lower frequency of $\mathrm{T}$ cells within the corresponding spinal cords (Fig. 3.36) supported the hypothesis that RyR3 is highly involved in the activation of astrocytes and their ability to produce and secrete chemokines for the recruitment of immune cells, without directly affecting the activation status of $\mathrm{T}$ cells. We demonstrated with the help of transwell migration assays that the reduction in chemokine secretion by $R y r 3^{-/}$astrocytes was sufficient to attenuate the ability of $\mathrm{T}$ cells to transmigrate across a membrane towards the supernatants of IFN- $\gamma$ and 
TNF- $\alpha$ stimulated $R y r 3^{-/}$astrocytes (Fig. 3.38).

Earlier reports demonstrated the ability of astrocytes to function as antigen presenting cells in the context of MHC-II expression under neuroinflammatory conditions. We could detect similar levels of MHC-II expression in $R y r 3^{-/}$and control astrocytes and assumed that attenuation of Ryr $3^{--}$EAE was not mediated by the disability of $R y r 3^{--}$astrocytes to act as antigen presenting cells in the CNS (Fig. 3.39). We found that MHC-II expression by microglia was not altered by Ryr3 deletion, assuming that antigen presentation was not further affected by the deficiency of $R y r 3^{-/}$.

\subsection{Pharmacological approaches to study RyRs}

Pharmacological targeting of the NAADP signaling pathway has been used in rat effector $\mathrm{T}$ cells and Lewis rat adoptive transfer EAE. CORDIGLIERI and colleagues showed that the treatment with BZ194, an analogue of nicotinic acid, ameliorates active and passive EAE in Lewis rats (2010). However, this compound has not yet been tested in clinical trials of any kind.

Inhibition of RyR function by the muscle relaxant dantrolene is the common therapy for patients suffering from malignant hyperthermia. We took advantage from the specificity of dantrolene for the RyR1 and RyR3 isoform and applied it to WT mice after immunization against $\mathrm{MOG}_{35-55}$ peptide. Dantrolene treated mice developed a strongly attenuated EAE course (Fig. 3.40). In fact, the reduction of clinical symptoms was greater than observed in the respective $\mathrm{KO}$ chimera experiments. This may be due cumulative effect of inhibition of Ryr1 in T cells and Ryr3 in astrocytes. Furthermore, in fetal liver chimeric mice a substantial fraction of recipient-derived, and thus Ryr1proficient $\mathrm{T}$ cells, may account for a less pronounced $\mathrm{EAE}$ ameliorating effect comparing to drug treatment effect. As the dantrolene was applied systemically, effects of this drug on other cells or organs cannot be ruled out. Future experiments using the treatment of Ryr1-KO FLCs and Ryr3 germline $\mathrm{KO}$ mice and respective controls with dantrolene should help to clarify the inhibition of which RyR isotype has a dominant role in the therapeutic effect of this drug on the EAE progression. 


\section{Discussion}

\subsection{Conclusion}

Our study suggests a putative role for RyRs in $\mathrm{MOG}_{35-55}$ peptide EAE in two different ways: While the RyR1 isoform is highly expressed in T cells and obviously contributes to $\mathrm{T}$ cell activation in vitro as well as in vivo, $\mathrm{Ca}^{2+}$ signaling via RyR3 crucially contributes to chemokine production in astrocytes during the onset and acute phase of EAE, thereby mediating $\mathrm{T}$ cell and monocyte recruitment to the CNS.

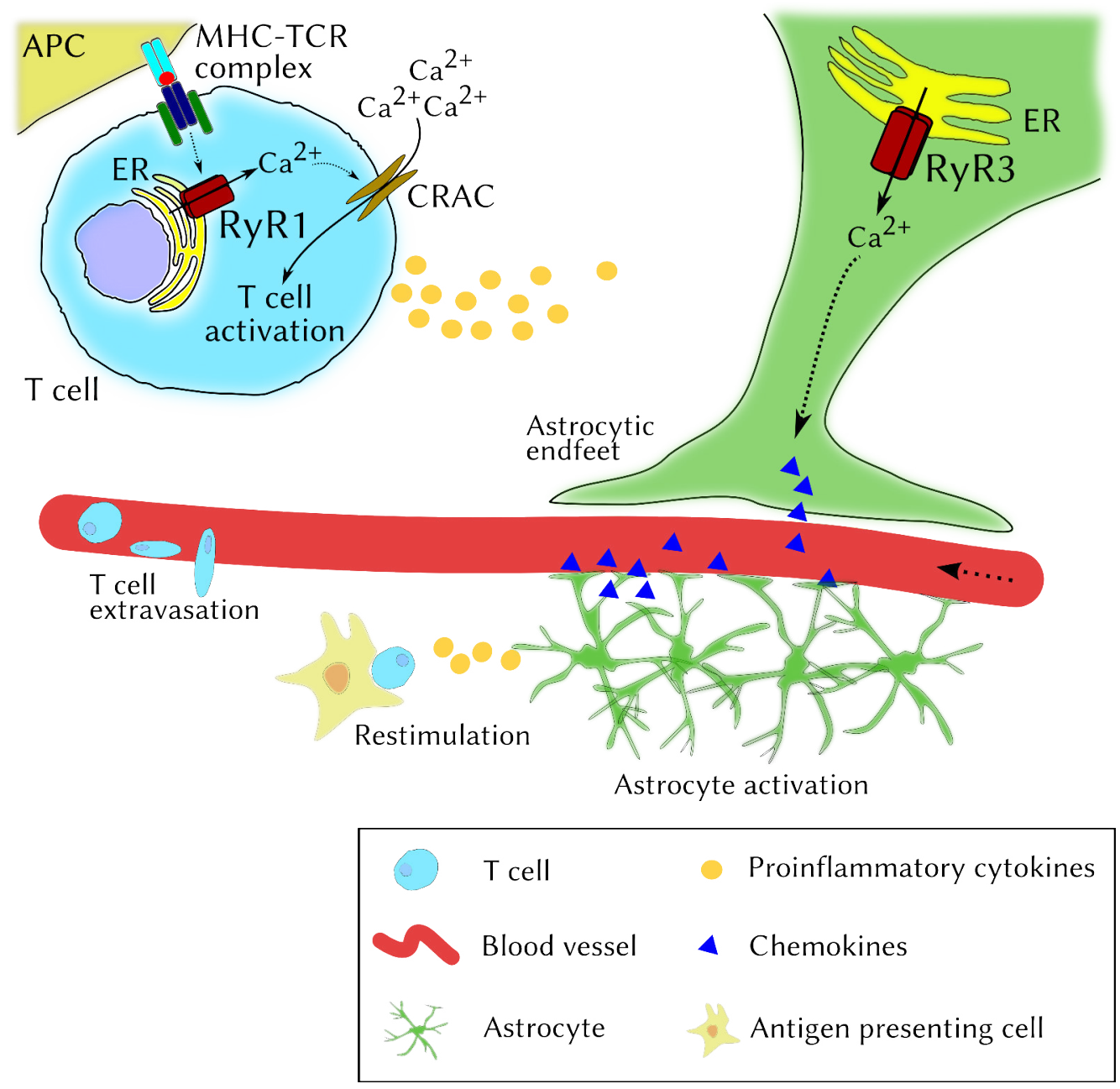

Fig. 4.1 | Suggested roles of RyR1 and RyR3 during the development of autoimmune diseases of the CNS: While RyR1 contributes to T cell activation in the periphery and/or in the CNS, RyR3 is expressed in astrocytes where it is involved in the production of chemoattractants for $\mathrm{T}$ cell and monocyte recruitment. 


\section{Summary}

T cell activation requires the elevation of free intracellular $\mathrm{Ca}^{2+}$, which is mediated by certain $\mathrm{Ca}^{2+}$ release channels. During the last years it has become increasingly clear that ryanodine receptors (RyRs) play a crucial role for the generation of intracellular $\mathrm{Ca}^{2+}$ signals in $\mathrm{T}$ cells and thus contribute to $\mathrm{T}$ cell activation.

The development of CNS autoimmune diseases like multiple sclerosis (MS) or its animal model experimental autoimmune encephalomyelitis (EAE) relies on the activation of auto-reactive $\mathrm{T}$ cells that are directed against CNS antigens. In the present study we addressed the question how RyRs contribute to the development of autoimmune diseases. We found that the RyR1 isoform is expressed in effector, but not in naïve mouse cells. By genetic deletion of the Ryr1 gene we demonstrated contribution of RyR1 to $\mathrm{Ca}^{2+}$ signaling and TCR dependent $\mathrm{T}$ cell proliferation. This presumably caused the observed EAE attenuation in $R y r 1^{-/-}$fetal liver chimeras.

Amelioration of EAE was observed in mice with a whole-body knockout for Ryr3. However, in contrast to RyR1, we excluded a major role of Ryr3 in $\mathrm{T}$ cells using chimeric mice and T cell transfer experiments. However, we demonstrated a pivotal role for RyR3 in astrocytes. Ryr3 deficient astrocytes showed alterations in $\mathrm{Ca}^{2+}$ signaling and deficits in chemokine production upon inflammatory stimuli in vitro, but also during EAE in the inflamed CNS tissue, thus limiting the infiltration of immune cells and CNS histopathology. In addition we showed that pharmacological inhibition of RyRs attenuated EAE disease. In summary, our study provides evidence that RyRs play critical roles during EAE-RyR1 in T cells and RyR3 in astrocytes-and thus may be targets for therapeutic treatment of autoimmune CNS diseases. 


\section{Acknowledgment}

First of all, I would like to express my thanks to Prof. Alexander Flügel for giving me the opportunity to work in his lab on this exciting project, and for his support throughout this thesis. Furthermore, I gratefully thank Dr. Dmitri Lodygin for his superb supervision, advice and efficiency. Moreover, I would like to thank the additional members of the examination board, Prof. Hauke Werner, Prof. Mikael Simons and Prof. Jürgen Wienands for accepting the invitation to my thesis defence talk.

I would like to thank Fred Lühder and Francesca Odoardi for their advice and help of any kind.

Special thanks go to our collaboration partners from the lab of Prof. Andreas Guse in Hamburg, especially Insa Wolf and Björn-Philipp Diercks, for performing calcium imaging. I sincerely thank all the coworkers of Prof. Uwe-Karsten Hanisch $(† 2015)$ for teaching me the isolation of glia cells.

I am grateful to all our technicians. Without their help, this work would not be possible. Therefore I thank Adriane Stas, Simon Mole, Nancy Meyer, Simone Hamann, Martina Weig, Birgit Curdt and Brigitte Salzmann-Aue for their invaluable help throughout this thesis. I also like to thank our animal caretaker Michael Blessmann for his help and good taste in music. I thank Omar Diaz for help with any IT questions. Special thanks go to Cathy Ludwig, our secretary, for her help in any bureaucratic and administrative matters of any kind.

I also want to thank all of my fellow $\mathrm{PhDs}$ and anyone else working in the IMSF, present or past, for the nice atmosphere, their (moral) support and friendship. So I thank Alex, Anne, Christian, Corinna, Giuseppe, Iris, Judith, Henrike, Leon, Maike, Marit, Michael, Moritz, Nadine, Nicola, Stephen (thanks for proofreading!) and Tanja.

Last but not least I would like to thank my family and Julia for their endless patience and support. 


\section{Bibliography}

- Austrup, F.; Vestweber, D.; Borges, E.; Löhning, M.; Bräuer, R.; Herz, U.; Renz, H.; Hallmann, R.; Scheffold, A.; Radbruch, A. \& Hamann, A. (1997), 'P- and E-selectin mediate recruitment of T-helper-1 but not Thelper-2 cells into inflammed tissues.', Nature 385(6611), 81--83.

- Barcellos, L. F.; Oksenberg, J. R.; Begovich, A. B.; Martin, E. R.; Schmidt, S.; Vittinghoff, E.; Goodin, D. S.; Pelletier, D.; Lincoln, R. R.; Bucher, P.; Swerdlin, A.; Pericak-Vance, M. A.; Haines, J. L.; Hauser, S. L. \& Group, M. S. G. (2003), 'HLA-DR2 dose effect on susceptibility to multiple sclerosis and influence on disease course.', Am 7 Hum Genet 72(3), 710--716.

- Barnden, M. J.; Allison, J.; Heath, W. R. \& Carbone, F. R. (1998), 'Defective TCR expression in transgenic mice constructed using cDNA-based alpha- and beta-chain genes under the control of heterologous regulatory elements.', Immunol Cell Biol 76(1), 34--40.

- Bartholomäus, I.; Kawakami, N.; Odoardi, F.; Schläger, C.; Miljkovic, D.; Ellwart, J. W.; Klinkert, W. E. F.; Flügel-Koch, C.; Issekutz, T. B.; Wekerle, H. \& Flügel, A. (2009), 'Effector T cell interactions with meningeal vascular structures in nascent autoimmune CNS lesions.', Nature 462(7269), 94--98.

- Berg, I.; Potter, B. V.; Mayr, G. W. \& Guse, A. H. (2000), 'Nicotinic acid adenine dinucleotide phosphate $(\mathrm{NAADP}(+))$ is an essential regulator of T-lymphocyte $\mathrm{Ca}(2+)$-signaling.', 7 Cell Biol 150(3), 581--588.

- Berridge, M. J. (1997), 'Elementary and global aspects of calcium signalling.', f Physiol 499 ( Pt 2), 291--306.

- Berridge, M. J.; Lipp, P. \& Bootman, M. D. (2000), 'The versatility and universality of calcium signalling.', Nat Rev Mol Cell Biol 1(1), 11--21.

- Bettelli, E.; Baeten, D.; Jäger, A.; Sobel, R. A. \& Kuchroo, V. K. (2006), 'Myelin oligodendrocyte glycoprotein-specific $\mathrm{T}$ and B cells cooperate to induce a Devic-like disease in mice.', f Clin Invest 116(9), 23932402. 
- Bettelli, E.; Pagany, M.; Weiner, H. L.; Linington, C.; Sobel, R. A. \& Kuchroo, V. K. (2003), 'Myelin oligodendrocyte glycoprotein-specific T cell receptor transgenic mice develop spontaneous autoimmune optic neuritis.', f Exp Med 197(9), 1073--1081.

- Bootman, M. D.; Berridge, M. J. \& Roderick, H. L. (2002), 'Calcium signalling: more messengers, more channels, more complexity.', Curr Biol 12(16), R563--R565.

- Bootman, M. D.; Lipp, P. \& Berridge, M. J. (2001), 'The organisation and functions of local $\mathrm{Ca}(2+)$ signals.', $\mathcal{f}$ Cell Sci 114(Pt 12), 2213-2222 .

- Bosanac, I.; Yamazaki, H.; Matsu-Ura, T.; Michikawa, T.; Mikoshiba, K. \& Ikura, M. (2005), 'Crystal structure of the ligand binding suppressor domain of type 1 inositol 1,4,5-trisphosphate receptor.', Mol Cell 17(2), 193--203.

- Calabresi, P. A. (2004), 'Diagnosis and management of multiple sclerosis.', Am Fam Physician 70(10), 1935--1944.

- Calcraft, P. J.; Ruas, M.; Pan, Z.; Cheng, X.; Arredouani, A.; Hao, X.; Tang, J.; Rietdorf, K.; Teboul, L.; Chuang, K.-T.; Lin, P.; Xiao, R.; Wang, C.; Zhu, Y.; Lin, Y.; Wyatt, C. N.; Parrington, J.; Ma, J.; Evans, A. M.; Galione, A. \& Zhu, M. X. (2009), 'NAADP mobilizes calcium from acidic organelles through two-pore channels.', Nature 459(7246), 596-600.

- Cancela, J. M. (2001), 'Specific Ca2+ signaling evoked by cholecystokinin and acetylcholine: the roles of NAADP, cADPR, and IP3.', Annu Rev Physiol 63, 99--117.

- Carson, M. J.; Doose, J. M.; Melchior, B.; Schmid, C. D. \& Ploix, C. C. (2006), 'CNS immune privilege: hiding in plain sight.', Immunol Rev 213, 48--65.

- Chen, X.; Quinn, E. M.; Ni, H.; Wang, J.; Blankson, S.; Redmond, H. P.; Wang, J. H. \& Feng, X. (2012), 'B7-H3 participates in the development of experimental pneumococcal meningitis by augmentation of the inflammatory response via a TLR2-dependent mechanism.', f Immunol 189(1), 347--355.

- Choi, S. S.; Lee, H. J.; Lim, I.; ichi Satoh, J. \& Kim, S. U. (2014), 'Human astrocytes: secretome profiles of cytokines and chemokines.', PLoS 
One 9(4), e92325.

- Churchill, G. C. \& Galione, A. (2001), 'NAADP induces Ca2+ oscillations via a two-pool mechanism by priming IP3- and cADPRsensitive Ca2+ stores.', EMBO f 20(11), 2666--2671.

- Churchill, G. C.; Okada, Y.; Thomas, J. M.; Genazzani, A. A.; Patel, S. \& Galione, A. (2002), 'NAADP mobilizes $\mathrm{Ca}(2+)$ from reserve granules, lysosome-related organelles, in sea urchin eggs.', Cell 111(5), 703--708.

- Clapham, D. E. (2007), 'Calcium signaling.', Cell 131(6), 1047--1058.

- Compston, A. \& Coles, A. (2008), 'Multiple sclerosis.', Lancet 372(9648), 1502--1517.

- Cordiglieri, C.; Odoardi, F.; Zhang, B.; Nebel, M.; Kawakami, N.; Klinkert, W. E. F.; Lodygin, D.; Lühder, F.; Breunig, E.; Schild, D.; Ulaganathan, V. K.; Dornmair, K.; Dammermann, W.; Potter, B. V. L.; Guse, A. H. \& Flügel, A. (2010), 'Nicotinic acid adenine dinucleotide phosphate-mediated calcium signalling in effector $\mathrm{T}$ cells regulates autoimmunity of the central nervous system.', Brain 133(Pt 7), 1930-1943.

- Cree, B. A. C. (2014), '2014 multiple sclerosis therapeutic update.', Neurohospitalist 4(2), 63--65.

- Dammermann, W. \& Guse, A. H. (2005), 'Functional ryanodine receptor expression is required for NAADP-mediated local $\mathrm{Ca} 2+$ signaling in T-lymphocytes.', J Biol Chem 280(22), 21394--21399.

- Dammermann, W.; Zhang, B.; Nebel, M.; Cordiglieri, C.; Odoardi, F.; Kirchberger, T.; Kawakami, N.; Dowden, J.; Schmid, F.; Dornmair, K.; Hohenegger, M.; Flügel, A.; Guse, A. H. \& Potter, B. V. L. (2009), 'NAADP-mediated $\mathrm{Ca} 2+$ signaling via type 1 ryanodine receptor in $\mathrm{T}$ cells revealed by a synthetic NAADP antagonist.', Proc Natl Acad Sci U $S$ A 106(26), $10678--10683$.

- Dargie, P. J.; Agre, M. C. \& Lee, H. C. (1990), 'Comparison of Ca2+ mobilizing activities of cyclic ADP-ribose and inositol trisphosphate.', Cell Regul 1(3), 279--290.

- Dietrich, J.-B. (2002), 'The adhesion molecule ICAM-1 and its regulation in relation with the blood-brain barrier., $\mathcal{F}$ Neuroimmunol 128(1-2), 58--68. 
- DONATI \& JACOBSON (2002), 'Viruses and Multiple Sclerosis', Polymicrobial Diseases, Chapter 6, Washington DC, ASM Press.

- Endo, M. (2009), 'Calcium-induced calcium release in skeletal muscle.', Physiol Rev 89(4), 1153--1176.

- Endo, M. (1977), 'Calcium release from the sarcoplasmic reticulum.', Physiol Rev 57(1), 71--108.

- Eng, L. F.; Ghirnikar, R. S. \& Lee, Y. L. (1996), 'Inflammation in EAE: role of chemokine/cytokine expression by resident and infiltrating cells.', Neurochem Res 21(4), 511--525.

- Engelhardt, B. \& Ransohoff, R. M. (2012), 'Capture, crawl, cross: the T cell code to breach the blood-brain barriers.', Trends Immunol 33(12), 579--589.

- Ernst, I. M. A.; Fliegert, R. \& Guse, A. H. (2013), 'Adenine Dinucleotide Second Messengers and T-lymphocyte Calcium Signaling.', Front Immunol 4, 259.

- Feske, S.; Giltnane, J.; Dolmetsch, R.; Staudt, L. M. \& Rao, A. (2001), 'Gene regulation mediated by calcium signals in T lymphocytes.', Nat Immunol 2(4), 316--324.

- Feske, S.; Gwack, Y.; Prakriya, M.; Srikanth, S.; Puppel, S.-H.; Tanasa, B.; Hogan, P. G.; Lewis, R. S.; Daly, M. \& Rao, A. (2006), 'A mutation in Orai1 causes immune deficiency by abrogating CRAC channel function.', Nature 441(7090), 179--185.

- Feske, S.; Skolnik, E. Y. \& Prakriya, M. (2012), 'Ion channels and transporters in lymphocyte function and immunity.', Nat Rev Immunol 12(7), 532--547.

- Fischer, B. S.; Qin, D.; Kim, K. \& McDonald, T. V. (2001), 'Capsaicin inhibits Jurkat T-cell activation by blocking calcium entry current I(CRAC).', J Pharmacol Exp Ther 299(1), 238--246.

- Flügel, A.; Berkowicz, T.; Ritter, T.; Labeur, M.; Jenne, D. E.; Li, Z.; Ellwart, J. W.; Willem, M.; Lassmann, H. \& Wekerle, H. (2001), 'Migratory activity and functional changes of green fluorescent effector cells before and during experimental autoimmune encephalomyelitis.', Immunity 14(5), 547--560.

- Galione, A. (2011), 'NAADP receptors.', Cold Spring Harb Perspect Biol 
3(1), a004036.

- Galione, A. (1994), 'Cyclic ADP-ribose, the ADP-ribosyl cyclase pathway and calcium signalling.', Mol Cell Endocrinol 98(2), 125--131.

- Galione, A.; Lee, H. C. \& Busa, W. B. (1991), 'Ca(2+)-induced Ca2+ release in sea urchin egg homogenates: modulation by cyclic ADPribose.', Science 253(5024), 1143--1146.

- Galione, A.; White, A.; Willmott, N.; Turner, M.; Potter, B. V. \& Watson, S. P. (1993), 'cGMP mobilizes intracellular Ca2+ in sea urchin eggs by stimulating cyclic ADP-ribose synthesis.', Nature 365(6445), 456--459.

- Gasser, A.; Bruhn, S. \& Guse, A. H. (2006), 'Second messenger function of nicotinic acid adenine dinucleotide phosphate revealed by an improved enzymatic cycling assay.,, f Biol Chem 281(25), 16 906-16913.

- Gillard, E. F.; Otsu, K.; Fujii, J.; Duff, C.; de Leon, S.; Khanna, V. K.; Britt, B. A.; Worton, R. G. \& MacLennan, D. H. (1992), 'Polymorphisms and deduced amino acid substitutions in the coding sequence of the ryanodine receptor (RYR1) gene in individuals with malignant hyperthermia., Genomics 13(4), 1247--1254.

- Gimenez, M. A. T.; Sim, J. E. \& Russell, J. H. (2004), 'TNFR1-dependent VCAM-1 expression by astrocytes exposes the CNS to destructive inflammation.', f Neuroimmunol 151(1-2), 116--125.

- Goldenberg, M. M. (2012), 'Multiple sclerosis review.', P T 37(3), 175-184.

- Goverman, J. (2009), 'Autoimmune T cell responses in the central nervous system.', Nat Rev Immunol 9(6), 393--407.

- Grafton, G. \& Thwaite, L. (2001), 'Calcium channels in lymphocytes.', Immunology 104(2), 119--126.

- Guse, A. H. (1999), 'Cyclic ADP-ribose: a novel Ca2+-mobilising second messenger., Cell Signal 11(5), 309--316.

- Guse, A. H.; Berg, I.; da Silva, C. P.; Potter, B. V. \& Mayr, G. W. (1997), 'Ca2+ entry induced by cyclic ADP-ribose in intact T-lymphocytes.', $\mathcal{F}$ Biol Chem 272(13), 8546--8550. 
- Guse, A. H.; da Silva, C. P.; Berg, I.; Skapenko, A. L.; Weber, K.; Heyer, P.; Hohenegger, M.; Ashamu, G. A.; Schulze-Koops, H.; Potter, B. V. \& Mayr, G. W. (1999), 'Regulation of calcium signalling in $\mathrm{T}$ lymphocytes by the second messenger cyclic ADP-ribose.', Nature 398(6722), 70--73.

- Guse, A. H.; da Silva, C. P.; Emmrich, F.; Ashamu, G. A.; Potter, B. V. \& Mayr, G. W. (1995), 'Characterization of cyclic adenosine diphosphateribose-induced $\mathrm{Ca} 2+$ release in $\mathrm{T}$ lymphocyte cell lines.', $\mathcal{f}$ Immunol 155(7), 3353--3359.

- Györke, S.; Lukyanenko, V. \& Györke, I. (1997), 'Dual effects of tetracaine on spontaneous calcium release in rat ventricular myocytes.', f Physiol 500 ( Pt 2), 297--309.

- Hakamata, Y.; Nishimura, S.; Nakai, J.; Nakashima, Y.; Kita, T. \& Imoto, K. (1994), 'Involvement of the brain type of ryanodine receptor in T-cell proliferation.', FEBS Lett 352(2), 206--210.

- Handel, A. E.; Giovannoni, G.; Ebers, G. C. \& Ramagopalan, S. V. (2010), 'Environmental factors and their timing in adult-onset multiple sclerosis.', Nat Rev Neurol 6(3), 156--166.

- Harris, M. G.; Hulseberg, P.; Ling, C.; Karman, J.; Clarkson, B. D.; Harding, J. S.; Zhang, M.; Sandor, A.; Christensen, K.; Nagy, A.; Sandor, M. \& Fabry, Z. (2014), 'Immune privilege of the CNS is not the consequence of limited antigen sampling.', Sci Rep 4, 4422.

- Hauser \& Goodwin (2008), 'Multiple sclerosis and other demyelinating diseases', Harrison's Principles of Internal Medicine. 17th ed. II.: McGraw-Hill Medical, pp. 2611-2621.

- Hirota, J.; Baba, M.; Matsumoto, M.; Furuichi, T.; Takatsu, K. \& Mikoshiba, K. (1998), 'T-cell-receptor signalling in inositol 1,4,5trisphosphate receptor (IP3R) type-1-deficient mice: is IP3R type 1 essential for T-cell-receptor signalling?', Biochem 7333 ( Pt 3), 615-619.

- Hogan, P. G.; Chen, L.; Nardone, J. \& Rao, A. (2003), 'Transcriptional regulation by calcium, calcineurin, and NFAT.', Genes Dev 17(18), 2205--2232.

- Hohenegger, M.; Suko, J.; Gscheidlinger, R.; Drobny, H. \& Zidar, A. (2002), 'Nicotinic acid-adenine dinucleotide phosphate activates the 
skeletal muscle ryanodine receptor.', Biochem $\mathcal{f} 367(\mathrm{Pt} 2), 423--431$.

- Hosoi, E.; Nishizaki, C.; Gallagher, K. L.; Wyre, H. W.; Matsuo, Y. \& Sei, Y. (2001), 'Expression of the ryanodine receptor isoforms in immune cells.', f Immunol 167(9), 4887--4894.

- Hua, X.; Malarkey, E. B.; Sunjara, V.; Rosenwald, S. E.; Li, W.-H. \& Parpura, V. (2004), 'C(a2+)-dependent glutamate release involves two classes of endoplasmic reticulum $\mathrm{Ca}(2+)$ stores in astrocytes.', $\mathcal{f}$ Neurosci Res 76(1), 86--97.

- Iliff, J. J. \& Nedergaard, M. (2013), 'Is there a cerebral lymphatic system?', Stroke 44(6 Suppl 1), S93--S95.

- Imagawa, T.; Smith, J. S.; Coronado, R. \& Campbell, K. P. (1987), 'Purified ryanodine receptor from skeletal muscle sarcoplasmic reticulum is the $\mathrm{Ca} 2+-$ permeable pore of the calcium release channel.', f Biol Chem 262(34), 16636--16643.

- Ishibashi, K.; Suzuki, M. \& Imai, M. (2000), 'Molecular cloning of a novel form (two-repeat) protein related to voltage-gated sodium and calcium channels.', Biochem Biophys Res Commun 270(2), 370--376.

- Jenkins, M. K.; Khoruts, A.; Ingulli, E.; Mueller, D. L.; McSorley, S. J.; Reinhardt, R. L.; Itano, A. \& Pape, K. A. (2001), 'In vivo activation of antigen-specific CD4 T cells.', Annu Rev Immunol 19, 23--45.

- Jeremic, A.; Jeftinija, K.; Stevanovic, J.; Glavaski, A. \& Jeftinija, S. (2001), 'ATP stimulates calcium-dependent glutamate release from cultured astrocytes.', f Neurochem 77(2), 664--675.

- Jäger, A.; Dardalhon, V.; Sobel, R. A.; Bettelli, E. \& Kuchroo, V. K. (2009), 'Th1, Th17, and Th9 effector cells induce experimental autoimmune encephalomyelitis with different pathological phenotypes.', f Immunol 183(11), 7169--7177.

- Kanno, T. \& Siebenlist, U. (1996), 'Activation of nuclear factor-kappaB via $\mathrm{T}$ cell receptor requires a Raf kinase and $\mathrm{Ca} 2+$ influx. Functional synergy between Raf and calcineurin.', J Immunol 157(12), 5277--5283.

- Kawakami, N.; Lassmann, S.; Li, Z.; Odoardi, F.; Ritter, T.; Ziemssen, T.; Klinkert, W. E. F.; Ellwart, J. W.; Bradl, M.; Krivacic, K.; Lassmann, H.; Ransohoff, R. M.; Volk, H.-D.; Wekerle, H.; Linington, C. \& Flügel, A. (2004), 'The activation status of neuroantigen-specific T cells in the target organ determines the clinical outcome of autoimmune 
encephalomyelitis., J Exp Med 199(2), 185--197.

- Kinnear, N. P.; Boittin, F.-X.; Thomas, J. M.; Galione, A. \& Evans, A. M. (2004), 'Lysosome-sarcoplasmic reticulum junctions. A trigger zone for calcium signaling by nicotinic acid adenine dinucleotide phosphate and endothelin-1., f Biol Chem 279(52), 54319--54326.

- Kinnear, N. P.; Wyatt, C. N.; Clark, J. H.; Calcraft, P. J.; Fleischer, S.; Jeyakumar, L. H.; Nixon, G. F. \& Evans, A. M. (2008), 'Lysosomes colocalize with ryanodine receptor subtype 3 to form a trigger zone for calcium signalling by NAADP in rat pulmonary arterial smooth muscle.', Cell Calcium 44(2), 190--201.

- Kobayashi, S.; Yano, M.; Suetomi, T.; Ono, M.; Tateishi, H.; Mochizuki, M.; Xu, X.; Uchinoumi, H.; Okuda, S.; Yamamoto, T.; Koseki, N.; Kyushiki, H.; Ikemoto, N. \& Matsuzaki, M. (2009), 'Dantrolene, a therapeutic agent for malignant hyperthermia, markedly improves the function of failing cardiomyocytes by stabilizing interdomain interactions within the ryanodine receptor.', $\mathcal{F}$ Am Coll Cardiol 53(21), 1993--2005.

- Krishnamoorthy, G.; Lassmann, H.; Wekerle, H. \& Holz, A. (2006), 'Spontaneous opticospinal encephalomyelitis in a double-transgenic mouse model of autoimmune T cell/B cell cooperation.', 7 Clin Invest 116(9), 2385--2392.

- Kroenke, M. A.; Carlson, T. J.; Andjelkovic, A. V. \& Segal, B. M. (2008), 'IL-12- and IL-23-modulated $\mathrm{T}$ cells induce distinct types of EAE based on histology, CNS chemokine profile, and response to cytokine inhibition.', f Exp Med 205(7), 1535--1541.

- Kunerth, S.; Mayr, G. W.; Koch-Nolte, F. \& Guse, A. H. (2003), 'Analysis of subcellular calcium signals in T-lymphocytes.', Cell Signal 15(8), 783--792.

- Kunkel, E. J. \& Butcher, E. C. (2002), 'Chemokines and the tissuespecific migration of lymphocytes.', Immunity 16(1), 1--4.

- Lai, F. A.; Erickson, H. P.; Rousseau, E.; Liu, Q. Y. \& Meissner, G. (1988), 'Purification and reconstitution of the calcium release channel from skeletal muscle.', Nature 331(6154), 315--319.

- Langhorst, M. F.; Schwarzmann, N. \& Guse, A. H. (2004), 'Ca2+ release via ryanodine receptors and $\mathrm{Ca} 2+$ entry: major mechanisms in 
NAADP-mediated Ca2+ signaling in T-lymphocytes.', Cell Signal 16(11), 1283--1289.

- Lawrence, M. B.; McIntire, L. V. \& Eskin, S. G. (1987), 'Effect of flow on polymorphonuclear leukocyte/endothelial cell adhesion.', Blood 70(5), 1284--1290.

- Lee, H. C. (2001), 'Physiological functions of cyclic ADP-ribose and NAADP as calcium messengers.', Annu Rev Pharmacol Toxicol 41, 317--345.

- Lee, H. C. (1993), 'Potentiation of calcium- and caffeine-induced calcium release by cyclic ADP-ribose.', J Biol Chem 268(1), 293--299.

- Lee, H. C. \& Aarhus, R. (1995), 'A derivative of NADP mobilizes calcium stores insensitive to inositol trisphosphate and cyclic ADPribose.', f Biol Chem 270(5), 2152--2157.

- Lee, H. C.; Aarhus, R.; Graeff, R.; Gurnack, M. E. \& Walseth, T. F. (1994), 'Cyclic ADP ribose activation of the ryanodine receptor is mediated by calmodulin.', Nature 370(6487), 307--309.

- Lee, H. C.; Walseth, T. F.; Bratt, G. T.; Hayes, R. N. \& Clapper, D. L. (1989), 'Structural determination of a cyclic metabolite of NAD+ with intracellular Ca2+-mobilizing activity.', f Biol Chem 264(3), 1608-1615.

- Ley, K.; Laudanna, C.; Cybulsky, M. I. \& Nourshargh, S. (2007), 'Getting to the site of inflammation: the leukocyte adhesion cascade updated.', Nat Rev Immunol 7(9), 678--689.

- Lieberman, A. P.; Pitha, P. M.; Shin, H. S. \& Shin, M. L. (1989), 'Production of tumor necrosis factor and other cytokines by astrocytes stimulated with lipopolysaccharide or a neurotropic virus.', Proc Natl Acad Sci U S A 86(16), 6348--6352.

- Lindsay, A. R.; Tinker, A. \& Williams, A. J. (1994), 'How does ryanodine modify ion handling in the sheep cardiac sarcoplasmic reticulum $\mathrm{Ca}(2+)$-release channel?', 7 Gen Physiol 104(3), 425--447.

- $\quad$ Litzenburger, T.; Fässler, R.; Bauer, J.; Lassmann, H.; Linington, C.; Wekerle, H. \& Iglesias, A. (1998), 'B lymphocytes producing demyelinating autoantibodies: development and function in genetargeted transgenic mice.', J Exp Med 188(1), 169--180. 
- $\quad$ Lodygin, D.; Odoardi, F.; Schläger, C.; Körner, H.; Kitz, A.; Nosov, M.; van den Brandt, J.; Reichardt, H. M.; Haberl, M. \& Flügel, A. (2013), 'A combination of fluorescent NFAT and H2B sensors uncovers dynamics of T cell activation in real time during CNS autoimmunity.', Nat Med 19(6), 784--790.

- Loma, I. \& Heyman, R. (2011), 'Multiple sclerosis: pathogenesis and treatment.', Curr Neuropharmacol 9(3), 409--416.

- Luche, H.; Weber, O.; Rao, T. N.; Blum, C. \& Fehling, H. J. (2007), 'Faithful activation of an extra-bright red fluorescent protein in "knock-in" Cre-reporter mice ideally suited for lineage tracing studies.', Eur F Immunol 37(1), 43--53.

- Macian, F. (2005), 'NFAT proteins: key regulators of T-cell development and function.', Nat Rev Immunol 5(6), 472--484.

- Malarkey, E. B. \& Parpura, V. (2008), 'Mechanisms of glutamate release from astrocytes.', Neurochem Int 52(1-2), 142--154.

- Maragakis, N. J. \& Rothstein, J. D. (2006), 'Mechanisms of Disease: astrocytes in neurodegenerative disease., Nat Clin Pract Neurol 2(12), 679--689.

- Matsumoto, M. \& Nagata, E. (1999), 'Type 1 inositol 1,4,5trisphosphate receptor knock-out mice: their phenotypes and their meaning in neuroscience and clinical practice.', $7 \mathrm{Mol} \mathrm{Med} \mathrm{(Berl)} \mathrm{77(5),}$ 406--411.

- McGeer, P. L.; Kawamata, T.; Walker, D. G.; Akiyama, H.; Tooyama, I. \& McGeer, E. G. (1993), 'Microglia in degenerative neurological disease., Glia 7(1), 84--92.

- McRae, B. L.; Kennedy, M. K.; Tan, L. J.; Canto, M. C. D.; Picha, K. S. \& Miller, S. D. (1992), 'Induction of active and adoptive relapsing experimental autoimmune encephalomyelitis (EAE) using an encephalitogenic epitope of proteolipid protein.', $\mathcal{f}$ Neuroimmunol 38(3), 229--240.

- MEDAWAR, P. B. (1948), 'Immunity to homologous grafted skin; the fate of skin homografts transplanted to the brain, to subcutaneous tissue, and to the anterior chamber of the eye.', Br f Exp Pathol 29(1), $58--69$. 
- Meissner, G. (1986), 'Ryanodine activation and inhibition of the Ca2+ release channel of sarcoplasmic reticulum.', 7 Biol Chem 261(14), 6300--6306.

- Mendel, I.; de Rosbo, N. K. \& Ben-Nun, A. (1995), 'A myelin oligodendrocyte glycoprotein peptide induces typical chronic experimental autoimmune encephalomyelitis in $\mathrm{H}-2 \mathrm{~b}$ mice: fine specificity and $\mathrm{T}$ cell receptor $\mathrm{V}$ beta expression of encephalitogenic $\mathrm{T}$ cells.', Eur F Immunol 25(7), 1951--1959.

- Mickelson, J. R.; Gallant, E. M.; Litterer, L. A.; Johnson, K. M.; Rempel, W. E. \& Louis, C. F. (1988), 'Abnormal sarcoplasmic reticulum ryanodine receptor in malignant hyperthermia.', f Biol Chem 263(19), 9310--9315

- Middleton, J.; Patterson, A. M.; Gardner, L.; Schmutz, C. \& Ashton, B. A. (2002), 'Leukocyte extravasation: chemokine transport and presentation by the endothelium.', Blood 100(12), 3853--3860.

- Miller, S. D. \& Karpus, W. J. (2007), 'Experimental autoimmune encephalomyelitis in the mouse.', Curr Protoc Immunol Chapter 15, Unit 15.1 .

- Murayama, T. \& Ogawa, Y. (1996), 'Properties of Ryr3 ryanodine receptor isoform in mammalian brain.', f Biol Chem 271(9), 5079-5084.

- Murthy, K. S.; Kuemmerle, J. F. \& Makhlouf, G. M. (1995), 'Agonistmediated activation of PLA2 initiates $\mathrm{Ca} 2+$ mobilization in intestinal longitudinal smooth muscle.', Am f Physiol 269(1 Pt 1), G93--102

- Nair, A.; Frederick, T. J. \& Miller, S. D. (2008), 'Astrocytes in multiple sclerosis: a product of their environment., Cell Mol Life Sci 65(17), 2702--2720.

- Neumann, H.; Boucraut, J.; Hahnel, C.; Misgeld, T. \& Wekerle, H. (1996), 'Neuronal control of MHC class II inducibility in rat astrocytes and microglia.', Eur 7 Neurosci 8(12), 2582--2590.

- O'Connell, P. J.; Klyachko, V. A. \& Ahern, G. P. (2002), 'Identification of functional type 1 ryanodine receptors in mouse dendritic cells.', FEBS Lett 512(1-3), 67--70.

- O'Connor, R. A.; Prendergast, C. T.; Sabatos, C. A.; Lau, C. W. Z.; 
Leech, M. D.; Wraith, D. C. \& Anderton, S. M. (2008), 'Cutting edge: Th1 cells facilitate the entry of Th17 cells to the central nervous system during experimental autoimmune encephalomyelitis.', $\mathcal{f}$ Immunol 181(6), 3750--3754.

- Ogunbayo, O. A.; Zhu, Y.; Rossi, D.; Sorrentino, V.; Ma, J.; Zhu, M. X. \& Evans, A. M. (2011), 'Cyclic adenosine diphosphate ribose activates ryanodine receptors, whereas NAADP activates two-pore domain channels.', f Biol Chem 286(11), 9136--9140.

- Oh-Hora, M. O. \& Rao, A. (2008), 'Calcium signaling in lymphocytes.', Curr Opin Immunol 20(3), 250--258.

- Overend, C. L.; O'Neill, S. C. \& Eisner, D. A. (1998), 'The effect of tetracaine on stimulated contractions, sarcoplasmic reticulum $\mathrm{Ca} 2+$ content and membrane current in isolated rat ventricular myocytes.', J Physiol 507 ( Pt 3), 759--769.

- Parpura, V.; Basarsky, T. A.; Liu, F.; Jeftinija, K.; Jeftinija, S. \& Haydon, P. G. (1994), 'Glutamate-mediated astrocyte-neuron signalling.', Nature 369(6483), 744--747.

- Petersen, O. H. \& Cancela, J. M. (1999), 'New Ca2+-releasing messengers: are they important in the nervous system?', Trends Neurosci 22(11), 488--495.

- Pierson, E.; Simmons, S. B.; Castelli, L. \& Goverman, J. M. (2012), 'Mechanisms regulating regional localization of inflammation during CNS autoimmunity.', Immunol Rev 248(1), 205--215.

- Porta, M.; Zima, A. V.; Nani, A.; Diaz-Sylvester, P. L.; Copello, J. A.; Ramos-Franco, J.; Blatter, L. A. \& Fill, M. (2011), 'Single ryanodine receptor channel basis of caffeine's action on $\mathrm{Ca} 2+$ sparks.', Biophys $\mathcal{F}$ 100(4), 931--938.

- Prakash, Y. S.; Kannan, M. S.; Walseth, T. F. \& Sieck, G. C. (1998), 'Role of cyclic ADP-ribose in the regulation of $[\mathrm{Ca} 2+] \mathrm{i}$ in porcine tracheal smooth muscle.', Am J Physiol 274(6 Pt 1), C1653--C1660.

- Raivich, G. (2005), 'Like cops on the beat: the active role of resting microglia.', Trends Neurosci 28(11), 571--573.

- Ransohoff, R. M. \& Estes, M. L. (1991), 'Astrocyte expression of major histocompatibility complex gene products in multiple sclerosis brain tissue obtained by stereotactic biopsy.', Arch Neurol 48(12), 1244--1246. 
- $\quad$ Ransohoff, R. M.; Kivisäkk, P. \& Kidd, G. (2003), 'Three or more routes for leukocyte migration into the central nervous system.', Nat Rev Immunol 3(7), 569--581.

- Rivest, S. (2009), 'Regulation of innate immune responses in the brain.', Nat Rev Immunol 9(6), 429--439.

- Robinson, A. P.; Harp, C. T.; Noronha, A. \& Miller, S. D. (2014), 'The experimental autoimmune encephalomyelitis (EAE) model of MS: utility for understanding disease pathophysiology and treatment.', Handb Clin Neurol 122, 173--189.

- de Rosbo, N. K.; Mendel, I. \& Ben-Nun, A. (1995), 'Chronic relapsing experimental autoimmune encephalomyelitis with a delayed onset and an atypical clinical course, induced in $\mathrm{PL} / \mathrm{J}$ mice by myelin oligodendrocyte glycoprotein (MOG)-derived peptide: preliminary analysis of MOG T cell epitopes.', Eur F Immunol 25(4), 985--993.

- $\quad$ Rosenberg, H.; Davis, M.; James, D.; Pollock, N. \& Stowell, K. (2007), 'Malignant hyperthermia.', Orphanet f Rare Dis 2, 21.

- Rousseau, E.; Ladine, J.; Liu, Q. Y. \& Meissner, G. (1988), 'Activation of the $\mathrm{Ca} 2+$ release channel of skeletal muscle sarcoplasmic reticulum by caffeine and related compounds.', Arch Biochem Biophys 267(1), $75--86$.

- Santonastasi, M. \& Wehrens, X. H. T. (2007), 'Ryanodine receptors as pharmacological targets for heart disease.', Acta Pharmacol Sin 28(7), 937--944.

- Schmidt, M.; Evellin, S.; Weernink, P. A.; von Dorp, F.; Rehmann, H.; Lomasney, J. W. \& Jakobs, K. H. (2001), 'A new phospholipase-Ccalcium signalling pathway mediated by cyclic AMP and a Rap GTPase.', Nat Cell Biol 3(11), 1020--1024.

- Schwarzmann, N.; Kunerth, S.; Weber, K.; Mayr, G. W. \& Guse, A. H. (2002), 'Knock-down of the type 3 ryanodine receptor impairs sustained $\mathrm{Ca} 2+$ signaling via the $\mathrm{T}$ cell receptor/CD3 complex.', $\mathrm{f}$ Biol Chem 277(52), 50636--50642.

- Seder, R. A. \& Ahmed, R. (2003), 'Similarities and differences in CD4+ and CD8+ effector and memory T cell generation.', Nat Immunol 4(9), 835--842. 
- Sei, Y.; Gallagher, K. L. \& Daly, J. W. (2001), 'Multiple effects of caffeine on Ca2+ release and influx in human B lymphocytes.', Cell Calcium 29(3), 149--160.

- Snyder, H. R.; Davis, C. S.; Bickerton, R. K. \& Halliday, R. P. (1967), '1[(5-arylfurfurylidene)amino]hydantoins. A new class of muscle relaxants.', f Med Chem 10(5), 807--810.

- $\quad$ Srinivasan, R.; Huang, B. S.; Venugopal, S.; Johnston, A. D.; Chai, H.; Zeng, H.; Golshani, P. \& Khakh, B. S. (2015), 'Ca(2+) signaling in astrocytes from Ip3r2(-/-) mice in brain slices and during startle responses in vivo.', Nat Neurosci 18(5), 708--717.

- Supattapone, S.; Worley, P. F.; Baraban, J. M. \& Snyder, S. H. (1988), 'Solubilization, purification, and characterization of an inositol trisphosphate receptor., f Biol Chem 263(3), 1530--1534.

- Takeshima, H.; Iino, M.; Takekura, H.; Nishi, M.; Kuno, J.; Minowa, O.; Takano, H. \& Noda, T. (1994), 'Excitation-contraction uncoupling and muscular degeneration in mice lacking functional skeletal muscle ryanodine-receptor gene., Nature 369(6481), 556--559.

- Takeshima, H.; Ikemoto, T.; Nishi, M.; Nishiyama, N.; Shimuta, M.; Sugitani, Y.; Kuno, J.; Saito, I.; Saito, H.; Endo, M.; Iino, M. \& Noda, T. (1996), 'Generation and characterization of mutant mice lacking ryanodine receptor type 3., J Biol Chem 271(33), 19649--19652.

- $\quad$ Takeshima, H.; Nishimura, S.; Matsumoto, T.; Ishida, H.; Kangawa, K.; Minamino, N.; Matsuo, H.; Ueda, M.; Hanaoka, M. \& Hirose, T. (1989), 'Primary structure and expression from complementary DNA of skeletal muscle ryanodine receptor.', Nature 339(6224), 439--445.

- Tanaka, Y. \& Tashjian, A. H. (1995), 'Calmodulin is a selective mediator of $\mathrm{Ca}(2+)$-induced $\mathrm{Ca} 2+$ release via the ryanodine receptorlike Ca2+ channel triggered by cyclic ADP-ribose.,, Proc Natl Acad Sci U S A 92(8), 3244--3248.

- Thakur, P.; Dadsetan, S. \& Fomina, A. F. (2012), 'Bidirectional coupling between ryanodine receptors and $\mathrm{Ca} 2+$ release-activated $\mathrm{Ca} 2+$ (CRAC) channel machinery sustains store-operated Ca2+ entry in human T lymphocytes.', J Biol Chem 287(44), 37 233--37 244.

- Thomas, A. P.; Bird, G. S.; Hajnóczky, G.; Robb-Gaspers, L. D. \& Putney, J. W. (1996), 'Spatial and temporal aspects of cellular calcium 
signaling.', FASEB $\mathcal{f}$ 10(13), 1505--1517.

- Tinker, A. \& Williams, A. J. (1993), 'Probing the structure of the conduction pathway of the sheep cardiac sarcoplasmic reticulum calcium-release channel with permeant and impermeant organic cations.', f Gen Physiol 102(6), 1107--1129.

- Torkildsen, O.; Brunborg, L. A.; Myhr, K.-M. \& Bø, L. (2008), 'The cuprizone model for demyelination.', Acta Neurol Scand Suppl 188, $72--76$.

- Tran, E. H.; Prince, E. N. \& Owens, T. (2000), 'IFN-gamma shapes immune invasion of the central nervous system via regulation of chemokines.', f Immunol 164(5), 2759--2768.

- Welch, W.; Williams, A. J.; Tinker, A.; Mitchell, K. E.; Deslongchamps, P.; Lamothe, J.; Gerzon, K.; Bidasee, K. R.; Besch, H. R.; Airey, J. A.; Sutko, J. L. \& Ruest, L. (1997), 'Structural components of ryanodine responsible for modulation of sarcoplasmic reticulum calcium channel function.', Biochemistry 36(10), 2939--2950.

- Willer, C. J.; Dyment, D. A.; Risch, N. J.; Sadovnick, A. D.; Ebers, G. C. \& Group, C. C. S. (2003), 'Twin concordance and sibling recurrence rates in multiple sclerosis.', Proc Natl Acad Sci U S A 100(22), 12877-12882 .

- Wülfing, C.; Sjaastad, M. D. \& Davis, M. M. (1998), 'Visualizing the dynamics of $\mathrm{T}$ cell activation: intracellular adhesion molecule 1 migrates rapidly to the $\mathrm{T}$ cell/B cell interface and acts to sustain calcium levels.', Proc Natl Acad Sci U S A 95(11), 6302--6307.

- Xiong, L.; Zhang, J.-Z.; He, R. \& Hamilton, S. L. (2006), 'A Ca2+binding domain in RyR1 that interacts with the calmodulin binding site and modulates channel activity.', Biophys f 90(1), 173--182.

- Yule, D. I. (2001), 'Subtype-specific regulation of inositol 1,4,5trisphosphate receptors: controlling calcium signals in time and space.', J Gen Physiol 117(5), 431--434.

- Zalk, R.; Clarke, O. B.; des Georges, A.; Grassucci, R. A.; Reiken, S.; Mancia, F.; Hendrickson, W. A.; Frank, J. \& Marks, A. R. (2015), 'Structure of a mammalian ryanodine receptor.', Nature 517(7532), 44-49.

- Zhao, F.; Li, P.; Chen, S. R.; Louis, C. F. \& Fruen, B. R. (2001), 
'Dantrolene inhibition of ryanodine receptor Ca2+ release channels. Molecular mechanism and isoform selectivity., f Biol Chem 276(17), $13810--13816$.

- Zucchi, R. \& Ronca-Testoni, S. (1997), 'The sarcoplasmic reticulum $\mathrm{Ca} 2+$ channel/ryanodine receptor: modulation by endogenous effectors, drugs and disease states.', Pharmacol Rev 49(1), 1--51. 


\section{CURRICULUM VITAE}

Full name:

Address:

Email:

\section{Education}

$2012-$

$2011-2012$

$2010-2011$

$2004-2009$
Manuel von Osten

Institute for Multiple Sclerosis Research

Waldweg 33

37073 Göttingen

+495513913344

manuel.von-osten(at)med.uni-goettingen.de

$\mathrm{PhD}$ student in the Department of Neuroimmunology, Institute for Multiple Sclerosis Research, University Medical Center Göttingen \& Max-Planck Institute for Experimental Medicine under supervision of Prof. Dr. Alexander Flügel

Scientific coworker, University Medical Center Göttingen

Scientific coworker, Institute for Pharmacology and Toxicology, Biomedical Center, Bonn \& Bonn International Graduate School of Drug Sciences

Biology course, University of Cologne; Diploma degree Diploma thesis in genetics under supervision of Prof. Jonathan Howard, PhD, FRS 